\title{
ЭЛЕКТРОННАЯ ТЕХНИКА
}

\author{
СЕРИЯ 2 \\ ПОЛУПРОВОДНИКОВЫЕ ПРИБОРЫ
}

Научно-технический журнал

Выпуск 2 (257) 2020

\section{ELECTRONIC ENGINEERING}

\author{
SERIES 2 \\ SEMICONDUCTOR DEVICES \\ Scientific \& technical journal
}

Issue 2 (257) 2020

Москва, 2020 
Журнал издаётся с 1958 года Учредитель:

АО «Научно-производственное предприятие

«Пульсар»

Наблюдательньій совет

Председатель совета:

В.В. Груздов, д.т.н., профессор, генеральный

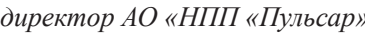

Заместитель председателя совета:

Ф.И. Шамхалов, д.э.н., профессор, учёный

секретарь АО «НПП «Пульсар»

Члены совета:

А.С.Сигов, академик РАН, д.ф.-м.н., профессор, президент РТУ (МИРЭА)

В.Л.Панков, профессор, первый проректор РТУ (МИРЭА)

Г.А. Егорочкин, к.х.н., генеральный директор $A O$ «ФНПЦ «ННИИРТ »

С.Н. Игнатьков, генеральнылй директор $A O$ «КБ «Куниево»

В.А. Телеи, д.т.н., профессор, директор ИЭПЭ НИЯУ «МИФИ»

Редакиионная коллегия

Главный редактор:

Ю.В.Колковский, д.т.н., профессор

Заместители главного редактора:

В.Ф. Синкевич,д.т.н., профессор

М.М. Крымко, к.т.н.,

Члены редколлегии:

А.Н. Алёшин, д.ф.-м.н.

А.А. Глыбин, к.т.н.

А.С. Евстигнеев, к.т.н.

И.П. Жиган, д.т.н., профессор

Е.В. Каевицер, к.ф.-м.н.

Ю.А. Концевой, д.т.н., профессор

С.В. Корнеев, к.т.н.

Е.И. Минаков, д.т.н., доиент

B.М. Миннебаев, к.т.н., доиент

А.В. Перевезениев, к.т.н.

К.О. Петросяни, д.т.н., профессор

В.П. Чальій, к.ф.-м.н.

А.А. Шаповалов, к.э.н.

Н.И. Шарапежникова, ответственный

секретарь редколлегии

Редакторы:

В.М. Миннебаев, к.т.н., дочент

Н.И. Шарапежникова

Дизайн и вёрстка:

Е.В. Силонова

Перевод:

Д.И. Леканов

Свидетельство о регистрации средств массовои информации ПИ № ФС77-63844 от 27.11.2015 2.

Журнал включён в Перечень ведущих

реиензируемых научных журналов и изданий

ВАК в России и в Российский индекс научного иитирования

Журнал отражсается в РЖ и БД ВИНИТИ

Адрес издательства и редакции:

105187, Москва, Окружной проезд, 27

Тел.:8-499-745-05-44 доб.1104

E-mail: journal@pulsarnpp.ru

Подписка по каталогам агентства

"Роспечать": «Издания органов научно-

технической информации» - индекс 59890

Подиисано в печать: 15.05.2020 2.

Печать офсетная цветная

Уч.-изд.л. 18,7

Тиражс 500 экз.

Заказ № 76 оm 18.06.2020 2

(C) $А О$ «НПП «Пульсар», Москва 2020

\section{Содержание}

1. Евдокимова Н.Л., Долгов В.В., Моторин В.С.,

Синкевич В.Ф.

Примеры использования аналитических структурных функиий для теплового анализа полупроводниковых приборов.

2. Чупрунов А.Г., Сидоров В.А., Биларус И.А., Пронин А.А.

Анализ теплового состояния металлостеклянных и металлокерамических корпусов типа ТО при различных режимах эксплуатации.

3. Сидоров В.А., Чупрунов А.Г., Катаев С.В., Сидоров К.В.

Конструктивно-технологические особенности металлокерамических корпусов типа

TO 247 и TO 254

4. Коптев Н.С., Пугачёв А.А.

Методика определения параметров микролинз для элементов фоточувствительной ПЗС ИС с помощью TCAD-моделирования.

\section{5. Попов А.А., Билевич Д.В., Сальников А.С.,}

Калентьев А.А.

Исследование влияния электрофизическими характеристик на параметры компактных моделей компонентов сверх высокочастотных монолитных интегральных схем..

6. Ваничкин Д.О., Гантман И.Я., Левко А.В.

Анализ большого массива результатов испьтаний изделий электронной техники на импульсную

электрическую прочность

\section{7. Кирьянов А.Ю.}

Разработка методики и конструкичии испытательного стенда для отбраковочных испытаний твердотельных СВЧ модулей 


\section{Contents}

1. Evdokimova N.L., Dolgov V.V., Motorin A. Yu., SinkevichV.F.

Examples of using the analytical structural functions for the thermal analysis of semiconductor devices

2. Chuprunov A.G., Sidorov V.A., Bilarus I.A.,

Grishaeva A.S.

Analysis of the thermal ststes of glass-metal and ceramic-metal TO-packages under different operation modes.

3. Sidorov V. A., Chuprunov A.G., Kataev S.V.,

Sidorov K.V.

Design and technological features

of ceramic-metal TO-247 and TO-220

semiconductor packages

4. Koptev N.S., Pugachev A.A.

TCAD-assisted technique determining

the perameters of microlenses used

in photosensitive CCD VLSI

5. Popov A.A., Bilevich D.V., Salnikov A.S.,

Kalentyev A.A.

Study on the influence of electrophysical

characteristics on the parameters of compact models

of the components used in radio frequency monolithic

integrated circuits

6. Vanichkin D.O., Gantman I.Ya., Levko A.V.

Analysis of large array of results obtained during

the pulsed mode dielectric breakdown testing

of electronic devices.

\section{Kiryanov A.Yu.}

Development of the methodology and design of the test facility for screening test of solid-state microwave modules. 70
In publication since 1958

Founder:

Joint Stock Company «Scientific and Production

Enterprise "Pulsar»)

Supervisory Board

Chairman of the Board:

V. V. Gruzdov, Sc.D., Professor, General Director

of SPE «PULSAR» JSC

Deputy Chairman:

F.I. Shamkhalov, Sc.D., Professor, Scientific Secretary

of SPE «Pulsar» JSC

Members of the Board:

A. S. Sigov, Sc.D., Professor, President of RTU MIREA,

Academician of the Russian Academy of Sciences

V. L. Pankov, First Pro-rector of RTU MIREA

G. A. Egorochkin, Ph.D., General Director

of «FRPC «NNIIRT» JSC

S. N. Ignatkov, General Director

of «CB «KUNTSEVO» JSC

V. A. Telets, Sc.D., Professor, Director

of NRNU MEPhI

Editorial Board

Chief Editor:

Yu. V. Kolkovskiy, Sc.D., Professor

Deputy Chief Editor:

V. F. Sinkevich, Sc.D., Professor

M. M. Krymko, Ph.D.

Members of the Board:

A. N. Alyoshin, Sc.D.

A.A. Glybin, Sc.D.

A. S. Evstigneev, Ph.D.

I. P. Zhigan, Sc.D., Professor

E. V. Kaevitser, Ph.D.

Y. A. Kontsevoi, Sc.D., Professor

S.V. Korneev Ph.D.

E. I. Minakov, Sc.D., Associate Professor

V. M. Minnebaev, Ph.D., Associate Professor

A.V. Perevezentsev, Ph.D

K. O. Petrosyants, Sc.D., Professor

V. P. Chalyi, Ph.D.

A.A. Shapovalov, Ph.D.

N.I. Sharapezhnikova, Editorial Board Executive

Secretary

Editors:

V. M. Minnebaev

N.I. Sharapezhnikova

Design and layout:

E.V. Silonova

Translation:

D. I. Lekanov

Mass Media Registration Certificate PI

No. FS77-63844 of 27 Nov. 2015

The Journal is included in the list of the leading peer-reviewed scientific journals and publications of the Russian Higher Attestation Commission and the Russian Index of Scientific Citation.

Journal recognized at VINITI database and Abstract Journal

Publisher and Editorial Office:

105187, Moscow, Okruzhnoy proezd, 27

Tel.: 8-499-745-05-44, ext. 1104

E-mail:journal@pulsarnpp.ru

Subscription via the catalogs of «Rospechat»:

"Publications of scientific and technical information

agencies》 - index 59890

Signed to print: 15.05 .2020

Offset color printing

Publisher's sheets 18.7

Print run 500 copies.

Order No. 76 at 18.06.2020

(C) $S \& P E$ «Pulsar», JSC, Moscow 2020 


\title{
ПРИМЕРЫ ИСПОЛЬЗОВАНИЯ АНАЛИТИЧЕСКИХ СТРУКТУРНЫХ ФУНКЦИЙ ДЛЯ ТЕПЛОВОГО АНАЛИЗА ПОЛУПРОВОДНИКОВЫХ ПРИБОРОВ
}

\author{
Н.Л. Евдокимова, В.В. Долгов, А.Ю. Моторин, В.Ф.Синкевич \\ АО «НПП «Пульсар», 105187, Москва, Окружной пр., 27
}

\begin{abstract}
Тепловой анализ полупроводниковых приборов включает в себя определение тепловых сопротивлений кристалла, корпуса и теплоотвода раздельно. Сегодня тепловой анализ проводится с использованием тепловых структурных функиий, полученных методом численной деконволюиии. В этой работе на примерах диодов и транзисторов показана методика теплового анализа и определения теплового сопротивления кристалл-корпус с помощью аналитических структурных функиий. Предложенная методика может быть использована для улучшения тепловых параметров приборов и для диагностики брака, где важно знать тепловые сопротивления отдельных элементов конструкиии.
\end{abstract}

Ключевые слова: тепловое сопротивление кристалл-корпус, структурная функция, теплоёмкость

Сведения об авторах: Наталья Львовна Евдокимова, к.т.н., evdokimova@pulsarnpр.ru; Владимир Викторович Долгов, dolgov_vv@pulsarnpp.ru; Андрей Юрьевич Моторин motorin_aj@pulsarnpp. ru; Владимир Фёдорович Синкевич, д.т.н., профессор, sinkevich@pulsarnpp.ru

\section{EXAMPLES OF USING THE ANALYTICAL STRUCTURAL FUNCTIONS FOR THE THERMAL ANALYSIS OF SEMICONDUCTOR DEVICES}

\author{
N.L. Evdokimova, V.V. Dolgov, A.Yu. Motorin, V.F. Sinkevich \\ S\&PE Pulsar JSC, 105187, Moscow, Okruzhnoy Pr., 27
}

Thermal analysis of semiconductor devices includes determination of thermal resistance of the chip, the case and the heatsink separately. Nowadays, the thermal analysis is carried out with the thermal structural functions obtained by the numerical deconvolution method. In this paper we experimentally show a possibility of performing the thermal analysis and determining the junction-to-case thermal resistance with the analytical thermal structure functions applied to certain diodes and transistors. The proposed technique can be used to improve the quality of thermal design and also in the screening tests of semiconductor devices, when it is necessary to know separate thermal resistances of the components.

Keywords: junction-to-case thermal resistance, structure function, thermal capacitance

Data on author: Natalya Lvovna Evdokimova,Ph.D., evdokimova@pulsarnpp.ru; Vladimir Viktorovich Dolgov,dolgov_vv@pulsarnpp.ru; Andrey Yurievich Motorin, motorin_aj@pulsarnpp.ru; Vladimir Fedorovich Sinkevich, Sc.D., Professor, sinkevich@pulsarnpp.ru 


\section{1. Введение}

Для надёжной работы полупроводниковых приборов важно обеспечить рабочую температуру, которая не превышала бы максимально допустимое для данного кристалла значение. Тепловое сопротивление между кристаллом прибора и корпусом

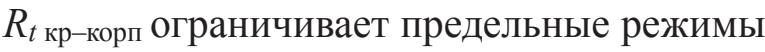
работы прибора при тепловой нагрузке.

Тепловое сопротивление кристалл-кор-

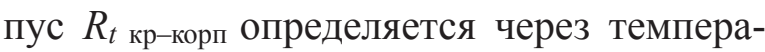
туру кристалла $T_{\text {кр}}$, температуру корпуса

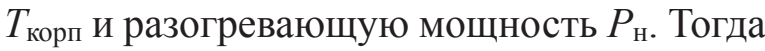
тепловое сопротивление кристалл-корпус рассчитывается следующим образом:

$$
R_{t \text { кр-корп }}=\frac{T_{\mathrm{\kappa p}}-T_{\text {корп }}}{P_{H}} .
$$

Вклад в тепловое сопротивление $R_{t \text { кр- }}$ корп Вносят все конструктивные элементы, находящиеся на пути теплового потока от кристалла к теплоотводу. Основными элементами являются тепловые сопротивления кристалла, корпуса и тепловые контактные сопротивления между ними.

Для улучшения тепловых свойств конструкции, а также при анализе брака по тепловому сопротивлению уже готового прибора необходимо выделить и проанализировать вклад отдельных элементов его конструкции. Для этого проводится тепловой анализ прибора, позволяющий найти тепловые сопротивления его отдельных элементов.

В настоящее время используется метод теплового анализа полупроводниковых структур, основанный на применении тепловых структурных функций [1-9]: интегральной (кумулятивной) теплоёмкости $C$ и дифференциальной теплоёмкости $K=d C / d R_{t}$. В этих работах элементы тепловых $R C$ цепей находятся с помощью метода NID (Network Identification by Deconvolution) [7].

NID метод описан в стандарте по тепловым испытаниям JESD51-14 [8]. Он даёт возможность анализировать путь теплового потока и определять тепловые сопротивления отдельных элементов конструкции, а также свойства материалов, по которым идёт тепловой поток. Кумулятивная теплоёмкость $C$ была использована в JESD51-14 [8] для определения тепловых сопротивле-

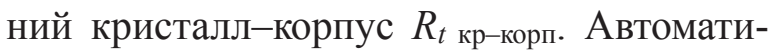
ческое определение тепловых структурных функций реализовано в приборе T3Ster компании Mentor Graphics [9].

В основу данного метода положена обработка экспериментальной зависимости теплового сопротивления полупроводникового прибора от времени $R_{t}=f(t)$, получаемая при нагреве либо при охлаждении прибора.

При этом в случае нагрева стандарт JEDEC № 51-14 рекомендует использовать для нагрева и измерения термочувствительного параметра (ТЧП) разные элементы структуры для исключения влияния нагревающего режима на ТЧП.

Недостатком NID метода является необходимость применения настраиваемых сглаживающих фильтров для погашения осцилляций, возникающих в результате численной деконволюции. А также то, что сам алгоритм деконволюции чувствителен к шумам во входных данных, и следовательно, из кривой охлаждения структурная функция не может быть реконструирована достаточно точно [10].

В работе [11], в отличие от [1-10], была введена аналитическая интегральная теплоёмкость $C^{*}$, которая определялась из уравнения теплового баланса. Полученное телом за время $t$ количество теплоты (без 
учёта потерь тепла за счёт конвекции и теплового излучения) $Q=P_{\text {н }} \cdot t$ равно накопленному телом теплу $Q=C \cdot \Delta T$. Из этого равенства можно найти полную (или интегральную) к моменту времени $t$ теплоёмкость $C^{*}=P_{\mathrm{H}} \cdot t / \Delta T$. Данное соотношение не учитывает конвекцию, тепловое излучение и потери тепла в теплоотводе (которые необходимо учитывать при длительном нагреве). Обозначив приращение температуры кристалла $\Delta \mathrm{T}_{\text {кр }}$ и переходное тепловое сопротивление $R_{t}(t)$, получим полную аналитическую теплоёмкость $C^{*}$ в виде:

$$
C^{*}=\frac{Q}{\Delta T_{\mathrm{\kappa р}}}=\frac{P_{\mathrm{H}} t}{\Delta T_{\mathrm{\kappa p}}}=\frac{t}{R_{t}(t)} .
$$

Предложенная аналитическая теплоёмкость $C^{*}$ позволяет анализировать проходящие в структуре тепловые процессы без применения сложного математического анализа и лишена проблем, связанных с процедурой численной деконволюции [10]. В дальнейшем для указания того, что используется аналитическая теплоёмкость, найденная по формуле (2), будем обозначать её со звездочкой $C^{*}$. Рассчитанные через неё другие тепловые функции также названы «аналитическими» и отмечены звездочкой (*):

- аналитическая дифференциальная теплоёмкость:

$$
K^{*}=\frac{d C^{*}}{d R_{t}}
$$

- аналитическая функция теплового потока (heat flow) $F^{*} h f$, меняющая свой характер (убывание, возрастание) в зависимости от формы теплового фронта [14]:

$$
F_{h f}^{*}=\frac{1}{\mathrm{C}^{*}} \frac{d \mathrm{C}^{*}}{d R_{t}} .
$$

Аналитические структурные функции так же, как структурные функции, полученные методом деконволюции, позволяют анализировать путь теплового потока.
В [12] методом численного моделирования рассмотрено поведение аналитических функций для разных конструкций при наличии и при отсутствии радиального растекания. В работе [13] по аналогии с работой [3] аналитические структурные функции в случае радиального растекания теплового потока были использованы для определения теплопроводности пластин. В [14] они были использованы для определения теплового сопротивления кристалл-корпус $R_{t \text { кр-корп. }}$

Следует отметить также, что в некоторых конструкциях кривая охлаждения может отличаться от кривой нагрева [15]. Это может повлиять на значения тепловых сопротивлений, найденных из кривой остывания. Во всех экспериментах, описываемых в данной работе, аномального поведения кривой остывания [15] не наблюдалось.

В ходе обсуждения работы [14] нам пришли письма с пожеланиями более подробно описать поведение введённых нами аналитических тепловых структурных функций.

Цель данной работы - показать возможность использования аналитических тепловых структурных функций на простых примерах. В разделе 2 для лучшего восприятия данной работы мы повторили основные моменты измерения кривой остывания и расчёта аналитических структурных функций, подробно описанные в $[14,15]$. В разделе III приведены примеры использования аналитических тепловых функций для теплового анализа диодов и транзисторов. В разделе IV в качестве примера рассмотрены определения теплового сопротивления кристалл-корпус с использованием функции теплового потока $F^{*} h f$. Выводы даны в разделе V. 


\section{2. Методика эксперимента}

Аналитические тепловые функции определялись из теплового переходного сопротивления. В соответствии со стандартом JESD51-14 для определения переходного теплового сопротивления $R_{t}(t)$ [8] на исследуемый прибор подавался разогревающий импульс (мощностью $\left.P_{\mathrm{H}}=U_{\mathrm{H}} \cdot I_{\mathrm{H}}\right)$. По его окончании на измерительном токе снималась кривая остывания - зависимость термочувствительного параметра (ТЧП) от времени. При этом мощность, подаваемая на прибор в режиме измерения, была равна $P_{\text {изм }}=U_{\text {изм }} \cdot I_{\text {изм. }}$.

В качестве ТЧП было использовано прямое падение напряжения на $p$ - $n$ пере-

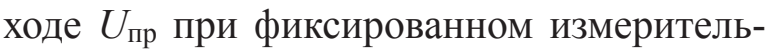
ном токе. У исследуемых приборов заранее был определён температурный коэффициент термочувствительного параметра (напряжения $U_{\text {пр) }}$ ТКН. Обработка результатов проводилась в программе Origin 9. Процесс проведения измерений $R_{t}(t)$ более подробно описан в $[14,15]$. Повторим основные моменты:

В результате измерения создаются два массива: массив времен $t_{i}$ и массив $U_{\text {пр } i}$. По изменению $U_{\text {пр } i}$ рассчитывается массив изменения температуры $\Delta T_{i}$ на участке остывания (для кривой остывания $\Delta \mathrm{T}_{i}<0$ ):

$$
\Delta T_{i}=\frac{U_{\text {пр } i}-U_{\text {пр } 0}}{T K U},
$$

где $U_{\text {пр } 0}-$ это напряжение в начале кривой остывания при $t=0$. Оно рассчитывается линейной экстраполяцией функции $U_{\text {пр }} i$ $\left(\sqrt{ } t_{i}\right)$ к моменту времени $t=0$.

Затем рассчитывается массив тепловых сопротивлений кристалл-среда:

$$
R_{t i}=\frac{\Delta T_{i}}{\Delta P}
$$

где $\Delta P=U_{\text {изм }} \cdot I_{\text {изм }}-U_{\text {н }} \cdot I_{\text {н }}$ (для кривой остывания $\Delta P<0$ ).

Далее проводится экспоненциальный фитинг, в результате которого вместо дискретной функции $R_{t}{ }_{i}\left(t_{i}\right)$ получаем аналитическую функцию $R_{t}(t)$. Проведение фитинга связано с необходимостью сглаживания экспериментальной кривой для последующего дифференцирования функции $C^{*}$ и получения $d C^{*} / d R_{t}$.

Затем рассчитываются аналитические тепловые функции: кумулятивная теплоёмкость $C^{*}(2)$, дифференциальная теплоёмкость $d C^{*} / d R_{t}$ (3) и функция теплового потока $F^{*} h f(4)$.

Таким образом, алгоритм обработки экспериментальных данных является следующим:

$$
\begin{gathered}
\text { ТЧП } \rightarrow \Delta T_{i}(5) \rightarrow R_{t i}(6) \rightarrow \text { фитинг } \rightarrow \\
\rightarrow R_{t}(t) \rightarrow C^{*}(2) \rightarrow d C^{*} / d R_{t}(3) \rightarrow F^{*}{ }_{h f}(4) .
\end{gathered}
$$

\section{3. Пример использования аналитических тепловых функций для теплового анализа полупроводниковых приборов}

Аналитические структурные функции могут быть использованы для определения вклада в общее тепловое сопротивление отдельных элементов конструкции полупроводниковых приборов: кристалла, корпуса и теплоотвода. На рис. 1 представлены зависимость аналитической кумулятивной $C^{*}$ и аналитической дифференциальной теплоёмкости $d C^{*} / d R_{t}$ от теплового сопротивления для двух разных диодов. Были выбраны мощный диод 2Д2931 (прямой ток до 30 А) и диод средней мощности 2 Д237 (прямой ток до 1 А), имеющие размер кристалла соответственно 56 мм $^{2}$ и $1,8 \mathrm{Mm}^{2}$.

По точкам перегиба графика $d C^{*} / d R_{t}$ (рис. 1a, в) на обоих диодах можно вы- 
делить 3 участка, соответствующих тепловым сопротивлениям кристалла (участок I), корпуса (участок II) и теплоотвода (участок III). Для диода 2Д237: тепловое сопротивление, падающее на кристалле, $R_{t \text { кр }}=2,7^{\circ} \mathrm{C} / \mathrm{BT}$, на корпусе $-R_{t \text { корп }}=6,5^{\circ} \mathrm{C} /$ $\mathrm{Bт}$, на теплоотводе $-R_{t \text { тепл }}=2,0^{\circ} \mathrm{C} / \mathrm{B}$. Для диода 2Д2931: тепловое сопротивление, падающее на кристалле, $-R_{t \text { кр }}=0,11^{\circ} \mathrm{C} / \mathrm{B}$, на корпусе $-R_{t \text { корп }}=0,19^{\circ} \mathrm{C} / \mathrm{BT}$, на теплоотводе $-R_{t \text { тепл }}=0,3^{\circ} \mathrm{C} / \mathrm{BT}$.

Следует отметить, что каждый из участков начинается с контактного сопротивления между ним и предыдущим слоем.

Таким образом, метод определения тепловых сопротивлений кристалла, корпуса и теплоотвода по аналитической дифференциальной структурной функции применим к диодам малой и большой площади. Тепловые сопротивления диода 2Д237 на каждом из участков существенно больше соответствующих тепловых сопротивлений диода 2Д2931, что соответствует разнице их площадей. Кумулятивная теплоёмкость $C^{*}$ (рис. 16, г) и дифференциальная теплоёмкость $d C^{*} / d R_{t}$ (рис. $1 \mathrm{a}$, в) мощного диода 2Д2931 на каждом из участков в десятки раз больше, чем у диода средней мощности 2Д237. Это соответствует резкому отличию их площадей и масс.

Рассмотрим аналитическую дифференциальную теплоёмкость $d C^{*} / d R_{t}$ транзи-

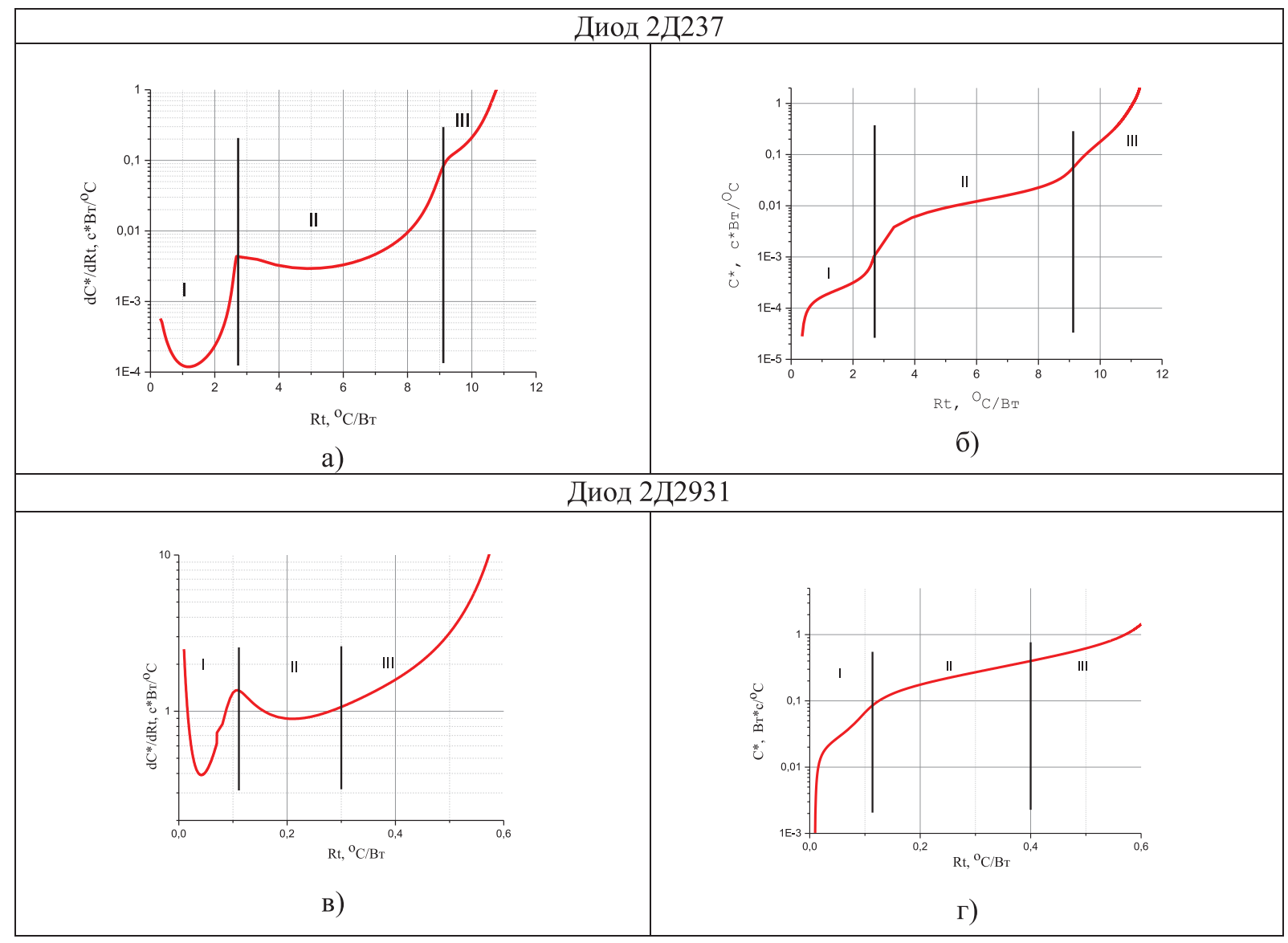

Puc. 1

Аналитическая дифференциальная теплоёмкость $d C^{*} / d R_{t}$ и кумулятивная теплоёмкость $C^{*}$ диодов 
сторов. На рис. 2 приведены аналитические дифференциальные теплоёмкости двух разных транзисторов. В качестве 1-го примера была использована кривая остывания транзистора MOSFET, прилагаемая к программе TDIM-Master [17] (файл MOSFET_tim.txt). Мы обработали её согласно алгоритму (7). В качестве 2-го примера был использован транзистор 2ПЕ301. Полученная после обработки аналитическая дифференциальная теплоёмкость MOSFET и 2ПЕ301 приведена на рис. 2а и 26 соответственно.

Из рис. 2 видно, что в транзисторах (так же, как и в рассмотренных выше диодах) на функции $d C^{*} / d R_{t}$ можно выделить участки I, II и III, соответствующие нагреву кристалла, корпуса и теплоотвода. Идентичность тепловых функций диодов и транзисторов подтверждает идентичность их тепловых моделей, включающих источник тепла на поверхности кристалла, сам кристалл, корпус прибора и теплоотвод.

Таким образом, и в диодах и в транзисторах с помощью функции $d C / d R_{t}$ можно выделить и определить тепловые сопротивления кристалла, корпуса и теплоотвода. Это может быть использовано для ана- лиза брака по тепловому сопротивлению и для улучшения тепловых параметров конструкции.

Наличие или отсутствие пологого участка $\left(d C * / d R_{t}=\right.$ const $)$ на графике $d C / d R_{t}$ (рис. 1,2 ) зависит от формы фронта теплового потока. Пологий участок соответствует плоскому фронту, то есть постоянной площади теплового потока. При этом для пологого участка выполняется соотношение [11]:

$$
K^{*}=\frac{d C^{*}}{d R_{t}}=\frac{\pi}{4} S^{2} \lambda c \rho,
$$

где $\lambda$ - теплопроводность, $\rho-$ плотность, $c$ - удельная теплоёмкость.

По определённому из графиков 1 или 2 значению $d C^{*} / d R_{t}$ на пологом участке, используя параметры материалов $\lambda, c$ и $\rho$ (например, [16]), можно определять площадь сечения теплового потока $S$. Сравнение площади теплового потока с конструктивной площадью контакта позволяет анализировать качество теплового контакта между слоями.

Форма фронта теплового потока определяется геометрией кристалла и корпуса, а также теплопроводностью используемых в конструкции материалов.

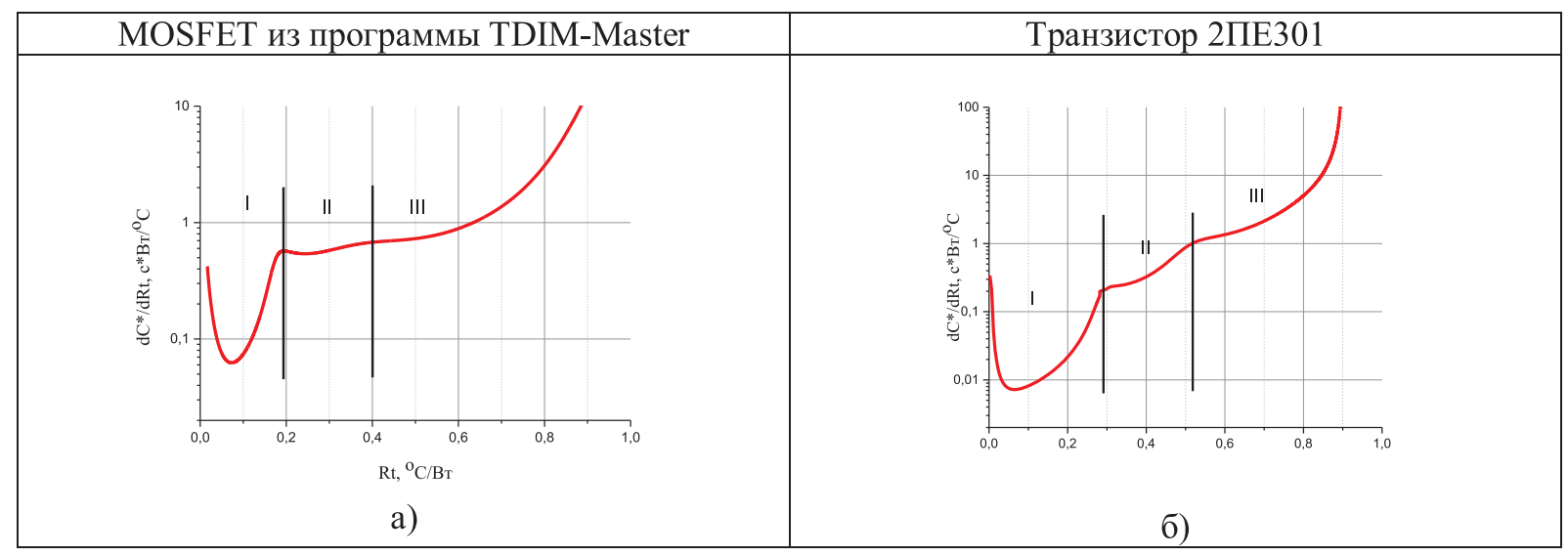

Puc. 2

Аналитическая дифференщиальная теплоёмкость $d C^{*} / d R_{t}$ транзисторов 


\section{4. Пример определения теплового сопротивления кристалл-корпус с использованием функции теплового потока $F^{*}$ hf}

Для определения теплового сопротивления кристалл-корпус $R_{t \text { кр-корп согласно }}$ (1) необходимо измерить температуру кристалла $T_{\text {кр}}$, температуру корпуса $T_{\text {корп }}$ и разогревающую мощность $P_{\text {н. }}$ При этом температура корпуса, как правило, измеряется термопарой. Использование термопары на практике приводит к увеличению погрешности измерения, которую трудно оценить. Применение тепловых функций позволяет исключить использование термопары при определении температуры корпуса [8].

Для определения теплового сопротивления кристалл-корпус с помощью аналитических структурных функций нужно сложить тепловые сопротивления кристалла и корпуса: $R_{t h-j c}=R_{t h}$ chip $+R_{\text {th }}$ case (области I и II на рис. 1 и 2).

Однако в некоторых приборах выделить границу корпус-теплоотвод по зависимости $d C^{*} / d R_{t h}$ сложно (рис. 1в). В работе [14] показано, что для этой цели лучше использовать аналитическую функцию потока $F^{*}{ }_{h f}$. При достижении тепловым потоком теплоотвода начинается резкое растекание теплового потока по корпусу. Это соответствует изменению фронта теплового потока (от плоского либо цилиндрического к сферическому). Визуализацию результатов моделирования происходящих тепловых процессов во времени можно посмотреть в видеоролике [18]. При этом максимум функции теплового потока (в интервале 10-1000 мс) соответствует достижению тепловым потоком теплоотвода. Растеканию тепла по корпусу соответствует либо убывание функции потока (в случае плоского фронта растекания), либо постоянное зна- чение функции потока (когда фронт растекания близок к цилиндрическому). Уходу тепла в теплоотвод соответствует возрастание функции потока. Поскольку при переходе от процесса растекания тепла по корпусу к уходу тепла в теплоотвод меняется функция теплового потока, критерием теплового сопротивления может быть точка перегиба функции потока. Более подробно функция потока рассмотрена в [14].

На рис. 3 приведены примеры функции $d C * / d R_{t}$ и функции потока $F^{*}{ }_{h f}$ для разных приборов. Тепловое сопротивление кристалл-корпус $R_{t \text { кр-корп }}$ (рис. 3 ) было определено по точке перегиба функции $F^{*} h f$. Для сравнения на этих же приборах мы определили тепловые сопротивления кристаллкорпус по стандарту JESD51-14 [8]. Coгласно данному стандарту, на одном и том же полупроводниковом приборе снимают две кривые остывания, монтируя прибор с пастой (W) и без пасты (WO) между корпусом и теплоотводом. Затем обе кривые остывания загружают в программу TDIMMaster [17]. При этом тепловое сопротивление кристалл-корпус определяется в программе [17] по точке расслоения переходных тепловых сопротивлений, снятых с пастой и без пасты между корпусом и теплоотводом. Полученные значения тепловых сопротивлений, определённые по стандарту JESD51-14 [8] в программе TDIM-Master [17], указаны на рис. 3 под графиком функции $F^{*}{ }_{h f}\left(R_{t}\right)$.

Из рис. 3 видно, что функция $F^{*} h f$ имеет экстремумы, а функция $d C^{*} / d R_{t h}$ их не имеет. Поэтому разделять на участки и определять тепловое сопротивление кристалл-корпус лучше по функции $F^{*} h$, чем по функции $d C^{*} / d R_{t h}$. Полученные значения тепловых сопротивлений кристалл-корпус, найденные с применением 


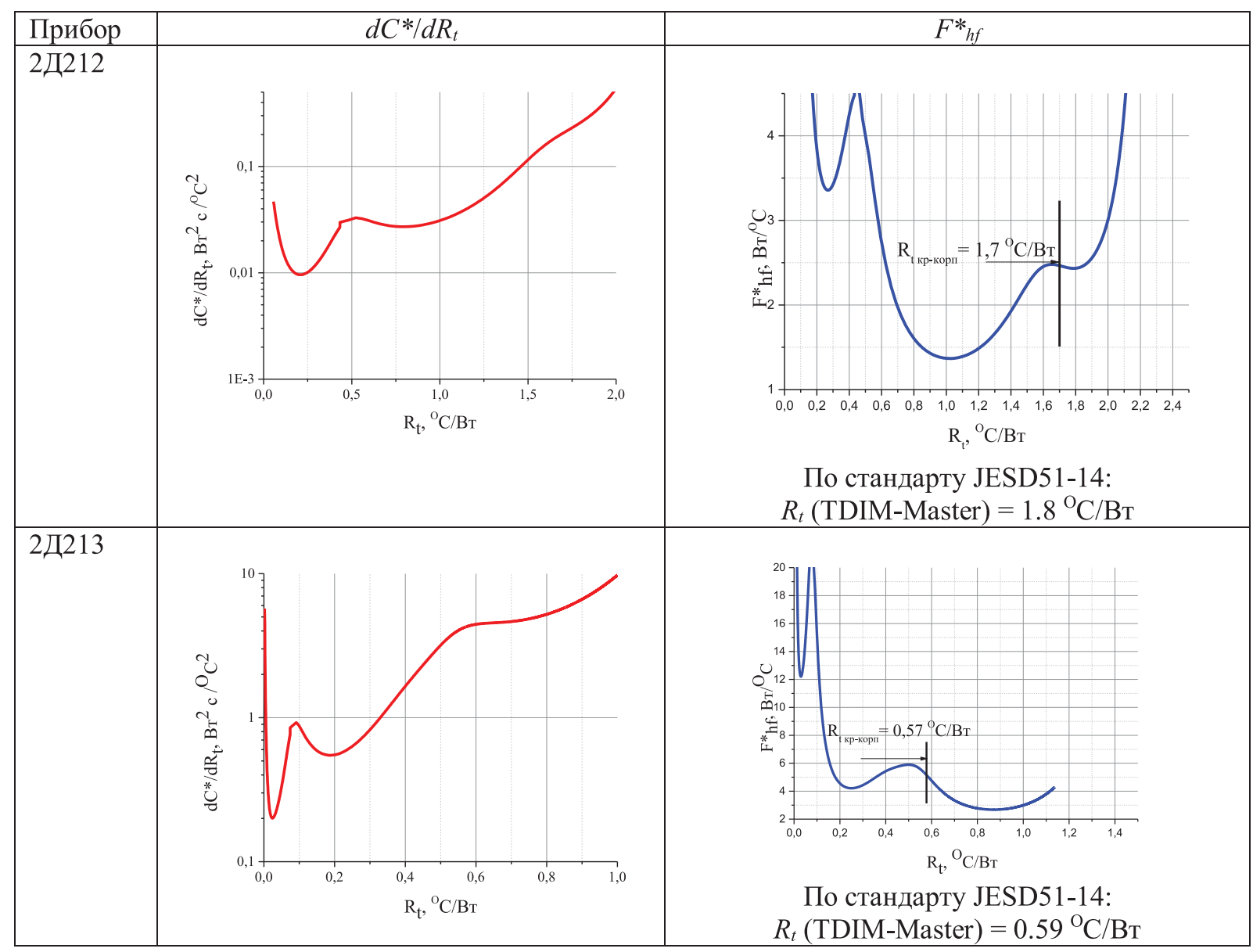

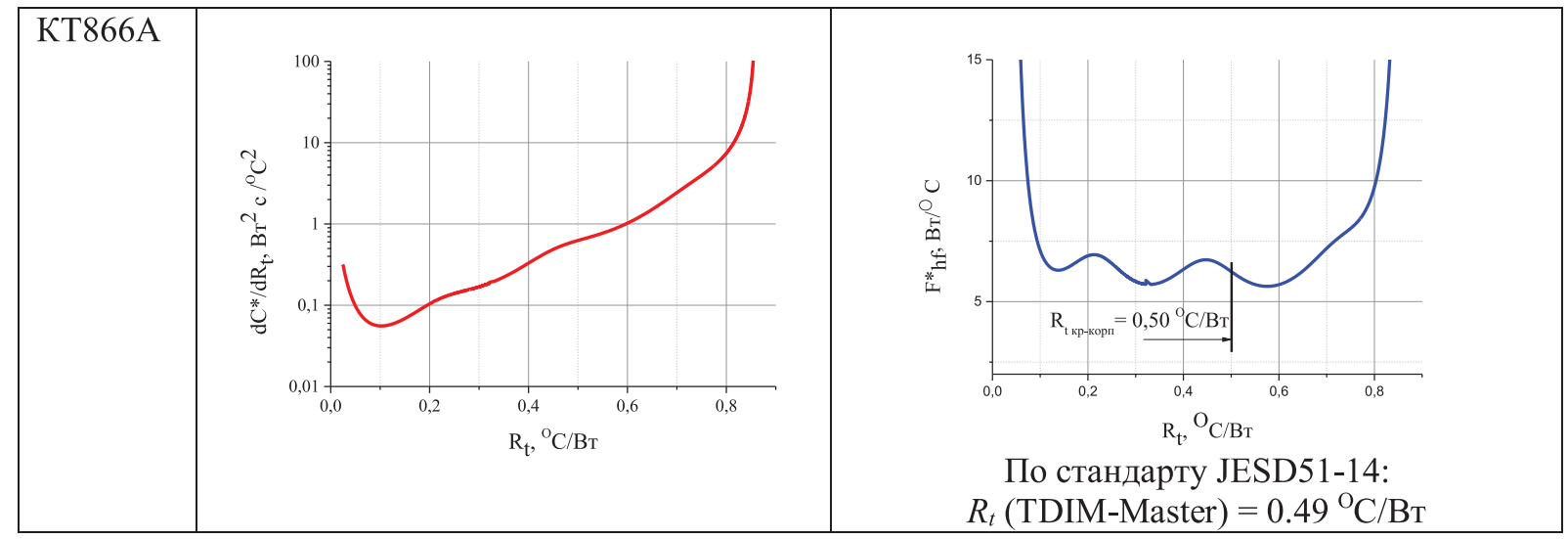

Puc. 3

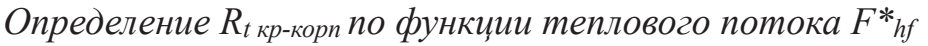

аналитической функции потока, близки к значениям тепловых сопротивлений, найденных по стандарту JESD51-14 [8]. При этом данная методика по сравнению с [8] сокращает время измерения (так как нужно снять только одну кривую остывания, а не две W и WO) и менее чувствительна к качеству теплоотвода [14]. Поэтому тепловое сопротивление кристалл-корпус удобно определять с помощью функции теплового потока $F^{*} h$. 


\section{5. Выводы}

Использование аналитических структурных функций позволяет определить отдельно тепловое сопротивление кристалла, корпуса и теплоотвода.

По аналитическим функциям $d C * / d R_{t}$ и $F^{*}{ }_{h f}$ можно определить тепловое сопротивление кристалл-корпус диодов, транзисторов и микросхем без использования термопары для измерения температуры корпуса.

Функция $F^{*}{ }_{h f}$ более наглядно позволяет находить границу кристалл-корпус приборов, чем функция $d C^{*} / d R_{t}$.

\section{Лumepamypa}

1. V. Székely, Tran van Bien. Fine structure of heat flow path in semiconductor devices: measurement and identification method. Solid-State Electronics, 1988, v. 31, N 9, pp. 1363-1368.

2. A. Poppe, V. Székely. Dynamic Temperature measurements: Tools providing a look into package and mount structures. Electronics Cooling, 2002. https://www.electronics-cooling.com/2002/05/ dynamic-temperature-measurements-tools-providing-a-look-into-package-and-mount-structures/

3. V. Szekely, M. Rencz, S. Torok, S. Ress. Calculating effective board parameters from transient measurements. - IEEE Transactions on Component and Packing Technologies, 2002, v. 24(4), 2002, pp. 605-610.

4. M. Rencz, V. Székely. Structure function evaluation of stacked dies. Annual IEEE Semiconductor Thermal Measurement and Management Symposium, April 2004.

5. A. Poppe, G.Farkas,V. Székely et al. Multidomain simulation and measurement of power LED-s and power LED assemblies. Annual IEEE Semiconductor Thermal Measurement and Management Symposium, April 2006, pp.191-198.

6. J. Dai, J. Li, P. Agyakwa, M. Corfield, C. Johnson. Comparative thermal and structural characterization of sintered nano-silver and high-lead solder die attachment during power cycling. - IEEE Transactions on Device and Materials Reliability, June 2018, vol.18, NO.2, pp. 256-264.

7. V. Szekely. Identification of RC networks by deconvolution: chances and limits. IEEE Transaction on Circuits and Systems-I: Fundamental Theory and Applications, Mar 1998, v.45, Issue 3, pp. 244-258.

8. Transient dual interface test method for the measurement of the thermal resistance junctionto-case of semiconductor devices with heat flow through a single path. JESD51-14 . Nov 2010.

9. T3Ster®: сайт. - URL: http://www.mentor.com/ products/mechanical/products/t3ster/

10. D. Schweitzer, H. Pape, L. Chen. Transient Measurement of the junction-to-case thermal resistance using structure functions: chances and limits. Twenty-fourth Annual IEEE Semiconductor Thermal Measurement and Management Symposium. 2008.

11. Евдокимова, Н.Л. Тепловой анализ полупроводниковых структур / Н.Л. Евдокимова, В.С Ежов, В.Ф Минин // Электронная техника. Серия 2. Полупроводниковые приборы. 2013. - Вып. 1 (230). - С. 69-75.

12. Евдокимова, Н.Л. Аналитическая тепловая структурная функция. Численное моделирование / Н.Л. Евдокимова, В.С. Ежов, К.А. Иванов // Электронная техника. Серия 2. Полупроводниковые приборы. - 2015. - Вып. 1 (235). - C. 27-35.

13. Евдокимова, Н.Л. Определение теплопроводности материалов, используемых в производстве полупроводниковых приборов / Н.Л. Евдокимова, В.В. Долгов, А.Ю. Моторин // Электронная техника. Серия 2. Полупроводниковые приборы. - 2017. - Вып. 1 (244). - С. 45-52.

14. Евдокимова, Н.Л. Определение теплового сопротивления кристалл-корпус из его кривой охлаждения / Н.Л. Евдокимова, В.В. Долгов, К.А. Иванов // Известия высших учебных заведений. Электроника. - 2019. - Т. 24. - № 1. - С. 30-41. 
15. Евдокимова, Н.Л. Сравнение переходных тепловых сопротивлений полупроводниковых приборов, полученных методами нагрева и остывания / Н.Л. Евдокимова, В.В. Долгов, К.А. Иванов, А.Ю. Моторин, В.С. Ежов // Электронная техника. Серия 2. Полупроводниковые приборы. - 2018. - Вып. 4 (251). - С. 37-45.

16. Kaye, G.W.C. and Laby, T.H. (1995) Tables of Physical \& Chemical Constants. 16th Edition, NPL (National Physical Laboratory). URL: https://www. npl.co.uk/resources

17. D. Schweitzer, Software TDIM-MASTER: Program for the evaluation of transient dual interface measurements of Rth-JC. This software serves as reference and example implementation of the algorithms described in standard and can be downloaded from the JEDEC homepage: http:// www.jedec.org.

18. Сайт. -URL: https://yadi.sk/i/uqduILVHb1Mnsg.

\section{References}

1. Székely V., Van Bien T. Fine structure of heat flow path in semiconductor devices: measurement and identification method. Solid-State Electronics, 1988, vol. 31, no. 9, pp. 1363-1368.

2. Poppe A., Székely V. Dynamic Temperature measurements: Tools providing a look into package and mount structures. Electronics Cooling, 2002, available at: https://www.electronicscooling.com/2002/05/dynamic-temperaturemeasurements-tools-providing-a-look-intopackage-and-mount-structures/

3. Szekely V., Rencz M., Torok S., Ress S. Calculating effective board parameters from transient measurements. IEEE Transactions on Component and Packing Technologies, 2002, vol. 24(4), pp. 605-610.

4. Rencz M., Székely V. Structure function evaluation of stacked dies. Annual IEEE Semiconductor Thermal Measurement and Management Symposium, April, 2004.
5. Poppe A., Farkas G., Székely V., et al. Multidomain simulation and measurement of power LED-s and power LED assemblies. Annual IEEE Semiconductor Thermal Measurement and Management Symposium, April, 2006, pp.191-198.

6. Dai J., Li J., Agyakwa P., Corfield M., Johnson C. Comparative thermal and structural characterization of sintered nano-silver and high-lead solder die attachment during power cycling. - IEEE Transactions on Device and Materials Reliability, June, 2018, vol. 18, no. 2, pp. 256-264.

7. Szekely V. Identification of RC networks by deconvolution: chances and limits. IEEE Transaction on Circuits and Systems-I: Fundamental Theory and Applications, March, 1998, vol. 45, iss. 3, pp. 244-258.

8. Transient dual interface test method for the measurement of the thermal resistance junctionto-case of semiconductor devices with heat flow through a single path. JEDEC Committee, JESD51-14, 2010, available at: https://www.jedec. org/standards-documents/docs/jesd51-14-0

9. Website T3Ster®. Available at: http://www.mentor. com/products/mechanical/products/t3ster/

10. Schweitzer D., Pape H., Chen L. Transient Measurement of the junction-to-case thermal resistance using structure functions: chances and limits. 24th Annual IEEE Semiconductor Thermal Measurement and Management Symposium, 2008.

11. Evdokimova N. L., Ezhov V. S., Minin V. F. Teplovoy analiz poluprovodnikovykh struktur [Thermal analysis of semiconductor structures]. Electronic Engineering. Series 2. Semiconductor Devices, 2013, iss. 1 (230), pp. 69-75.

12. Evdokimova N. L., Ezhov V. S., Ivanov K. A. Analiticheskaya teplovaya strukturnaya funktsiya. Chislennoye modelirovaniye [Analytical thermal structural function. Numerical simulation]. Electronic Engineering. Series 2. Semiconductor Devices, 2015, iss. 1 (235), pp. 27-35.

13. Evdokimova N. L., Dolgov V. V., Motorin A. Yu. Opredeleniye teploprovodnosti materialov, 
ispol'zuyemykh v proizvodstve poluprovodnikovykh priborov [Determination of thermal conductivity of the materials used in manufacturing of semiconductor devices]. Electronic Engineering. Series 2. Semiconductor Devices, 2017, iss. 1 (244), pp. 45-52.

14. Evdokimova N. L., Dolgov V. V., Ivanov K. A. Opredeleniye teplovogo soprotivleniya kristall-korpus iz yego krivoy okhlazhdeniya [Determination of the thermal resistance of a junction-case by its cooling curve]. Izvestiya vysshikh uchebnykh zavedeniy. Elektronika, 2019, vol. 24, no. 1, pp. 30-41.

15. Evdokimova N. L., Dolgov V. V., Ivanov K. A., Motorin A. Yu., Ezhov V. S. Sravneniye perekhodnykh teplovykh soprotivleniy poluprovodnikovykh priborov, poluchennykh metodami nagreva i ostyvaniya [Transient thermal resistances of semiconductor devices, obtained by the heating and cooling methods]. Electronic Engineering. Series 2. Semiconductor Devices, 2018, iss. 4 (251), pp. 37-45.

16. Kaye, G.W.C., Laby, T.H. Tables of Physical \& Chemical Constants. 16th Edition. National Physical Laboratory, 1995, available at: https:// www.npl.co.uk/resources

17. Schweitzer D., Software TDIM-MASTER: Program for the evaluation of transient dual interface measurements of Rth-JC. JEDEC Committee, available at: http://www.jedec.org

18. Website, available at: https://yadi.sk/i/ uqduILVHb1Mnsg 


\title{
АНАЛИЗ ТЕПЛОВОГО СОСТОЯНИЯ МЕТАЛЛОСТЕКЛЯННЫХ И МЕТАЛЛОКЕРАМИЧЕСКИХ КОРПУСОВ ТИПА ТО ПРИ РАЗЛИЧНЫХ РЕЖИМАХ ЭКСПЛУАТАЦИИ
}

\author{
А.Г. Чупрунов, В.А. Сидоров, И.А. Биларус, А.С. Гришаева \\ АО «НПП «Пульсар», 105187, г. Москва, Окружной проезд, д. 27
}

Представлены результаты измерений и установлены зависимости температуры ввода и монтажной площадки на флание корпуса от времени при пропускании через ввод тока на металлостеклянном корпусе КТ-97В и металлокерамическом корпусе ТО-254. В корпусе КТ-97В фланеи выполнен из меди, а вводы длиной 15 мм и диаметром 1 мм из проволоки МК (ковар с медной жилой). В корпусе ТО-254 фланеи выполнен из псевдосплава молибден-медь, а вводы длиной 15 мм и диаметром 1 мм из медной проволоки. Измерения проводили при температуре окружающей среды $\approx 24^{\circ} \mathrm{C}$.

Ключевые слова: корпус, фланеи, ввод, температура, металлостеклянный, металлокерамический, теплопроводность

Сведения об авторах: Чупрунов Алексей Геннадиевич, chuprunov@pulsar.ru; Сидоров Владимир Алексеевич, к.m.н., vlsidorov@pulsar.ru; Биларус Илья Александрович, bilarus_ia@pulsar.ru; Гришаева Александра Александровна, grishaeva_as@pulsar.ru

\section{ANALYSIS OF THE THERMAL STATES OF GLASS-METAL AND CERAMIC- METAL TO-PACKAGES UNDER DIFFERENT OPERATION MODES}

\author{
A.G. Chuprunov, V.A. Sidorov, I.A. Bilarus, A.S. Grishaeva \\ S\&PE Pulsar JSC, 105187, Moscow, Okruzhnoy pr., 27
}

In this paper we present the results of measurements that reveal the dependences between the temperature of pins and pad on the flange of the package and the time factor when pins are subjected to electric current. Measurements were conducted for the KT-97V glass-metal package and the TO-254 ceramicmetal package. Flange of the KT-97V consists of copper, its pins (15 mm long and $1 \mathrm{~mm}$ in diameter) are made of MK wire (covar with copper core). Flange of the TO-254 consists of pseudo-alloy of molybdenum and copper, its pins (15 mm long and $1 \mathrm{~mm}$ in diameter) are made of copper wire. Measurements were conducted at $\approx 24^{\circ} \mathrm{C}$ ambient temperature.

Keywords: package, flange, pin, temperature, glass-metal, ceramic-metal, thermal conductivity

Data on authors: Chuprunov Aleksey Gennadievich, chuprunov@pulsar.ru; Sidorov Vladimir Alekseevich,Ph.D.,vlsidorov@pulsar.ru; BilarusIlyaAleksandrovich,bilarus_ia@pulsar.ru; Grishaeva AleksandraAleksandrovna,grishaeva_as@pulsar.ru 
Необходимым условием надёжной работы полупроводникового прибора является обеспечение его нормального теплового режима. Увеличение температуры полупроводникового прибора вызывает ухудшение изоляционных свойств материалов, изменение плотности и подвижности носителей тока в полупроводниках, существенное снижение теплопроводности полупроводниковых и теплоотводящих материалов и т.д. Все эти факторы могут привести к снижению параметров полупроводникового прибора или даже к выходу его из строя. Отвод тепловой энергии от полупроводникового прибора, от его активной структуры в пространство осуществляется тремя способами: теплопроводностью (кондукцией), конвекцией и теплоизлучением. Обычно все три способа переноса тепловой энергии существуют одновременно и определяют тепловой режим полупроводникового прибора. Основную роль в обеспечении нормального теплового режима полупроводникового прибора выполняет его корпус.

Обычно герметичные силовые мощные полупроводниковые приборы собирают в металлостеклянных и металлокерамических корпусах. Корпуса металлостеклянные предлагают и производят как предприятия РФ, так и зарубежные. Массовым производителем металлостеклянных корпусов в Российской Федерации является АО «Марс», г. Торжок. В каталоге этого завода представлена большая номенклатура металлостеклянных корпусов типа КТ-97В, выпускаемых в массовом производстве, с медным фланцем, стальным ободком, вводами из проволоки МК и корпусов типа КТ 107А с медным фланцем, стальным ободком, вводами из сплава 38НКД.
$\mathrm{AO}$ «СКТБ РТ» (Специальное конструкторское технологическое бюро по релейной технике, г. Великий Новгород) занимается изготовлением металлостеклянных корпусов типа КТ-97 ИДЯУ.432254.014 ТУ для силовых полупроводниковых приборов.

ОАО «Воронежский завод полупроводниковых приборов» в своём каталоге выпускаемых изделий представляет производимые заводом металлостеклянные корпуса КТ-97А (ТО-257АA), КТ-97В (ТО-254AА) и большую номенклатуру собранных в них диодных сборок и полевых транзисторов по АЕЯР 432140.273-01 ТУГК.

$\mathrm{AO}$ «НПП «Завод Искра» (г. Ульяновск) выпускает транзистор 2П7152А в металлостеклянном корпусе КТ-97 В (рис. 1) [1].

В аналогичном корпусе унитарное предприятие «Завод Транзистор» (г. Минск) выпускает мощный МОП транзистор 2П7172А
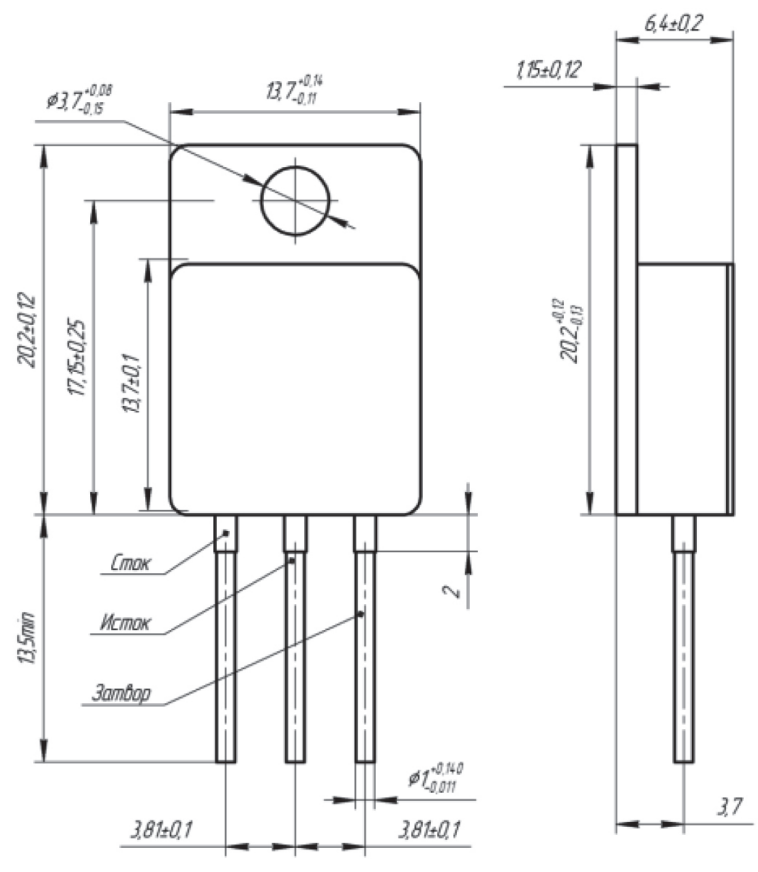

Puc. 1

Металлостеклянный корпус КТ-97В ( $А О$ «НПП «Завод Искра») 


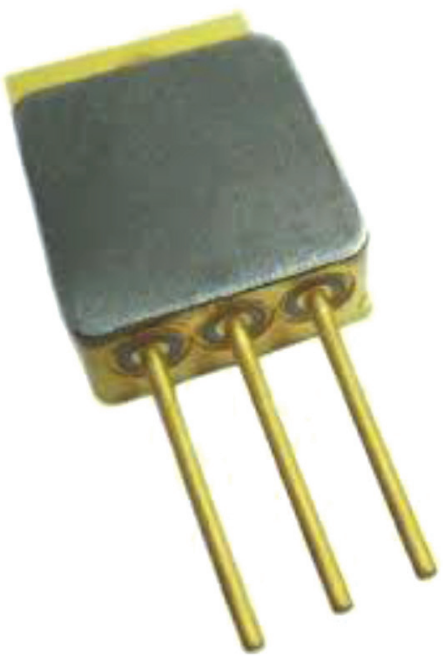

Puc. 2

Транзистор 2П7172A

(«Завод Транзистор»)

АЕЯР.432140.398ТУ (рис. 2) с максимально допустимым импульсным током сток-исток 130 А при $t_{\text {и }} \leq 80$ мкс, $Q \geq 20$ [2].

В настоящее время АО «Фрязинский завод мощных транзисторов» выпускает биполярные и полевые транзисторы в металлостеклянных корпусах КТ-97А, В, С (рис. 3)

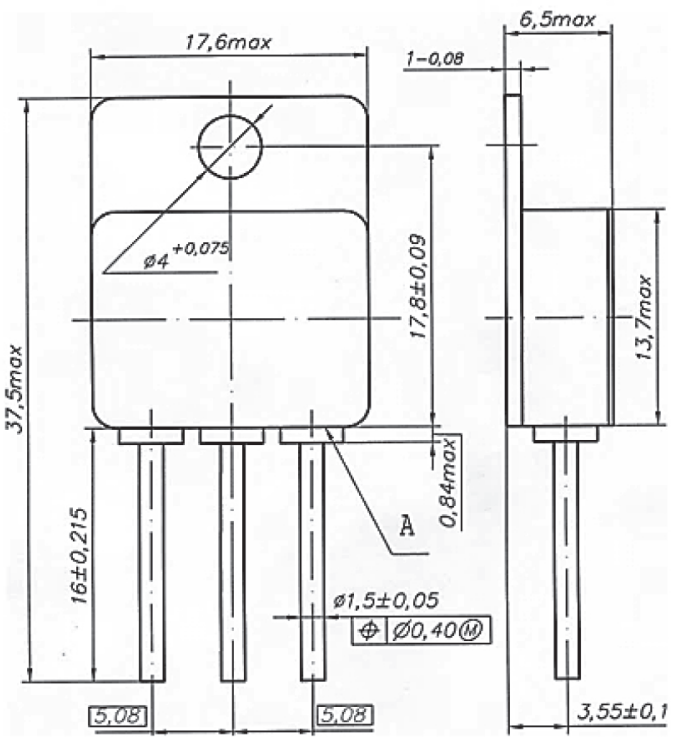

Puc. 3

Корпус металлостеклянный КТ-97С $A O \ll \Phi 3 M T »$
Одним из основных недостатков металлостеклянных корпусов является существенное ограничение вводов по пропускаемому току, т. к. в таких конструкциях вводы из-за необходимости согласования по тепловому расширению материалов со стеклом во многих случаях делают из специальных сплавов (29HК, 38НКД) [4], имеющих высокое электрическое сопротивление, превышающее сопротивление меди более чем в 30 раз. При прохождении тока через ввод на нём выделяется мощность, равная $I^{2} \cdot R$, где $I-$ ток, проходящий через ввод, а $R$ - его электрическое сопротивление. Электрическое сопротивление ввода длиной 15 мм и диаметром 1 мм из сплава $29 \mathrm{HК}$ ориентировочно составляет 0,01 Ом. При прохождении через ввод тока 10 А на вводе выделяется мощность 1 Вт, которая может нагреть ввод при непрерывном токе до температуры, превышающей температуру плавления припоя ПОС 61. При прохождении через ввод тока 20 А на вводе выделяется мощность 4 Вт. Металлостеклянный корпус КТ-97В-1.05 (чертёж КУШ Р432 264.001), серийно выпускаемый АО «Завод «МАРС», содержит теплоотводящий фланец из меди, стальной ободок с вводами из проволоки МК, впаянными стеклом в отверстиях ободка. Данную конструкцию металлостеклянного корпуса можно считать наиболее удачной. Через вводы такого корпуса можно пропускать несколько больший ток, чем у предыдущих аналогов, поскольку у проволоки МК электрическое сопротивление в 6-8 раз ниже, чем у проволоки из сплавов 29 НК и 38 НКД. Ободок выполнен из стали, теплопроводность которой существенно больше, чем у сплавов 29 НК и 38 НКД, а фланец выполнен из высокотеплопроводной меди. Электрическое сопротивление ввода длиной 15 мм и диаметром 1 мм из 
проволоки МК равно примерно 0,0012 Ом. При прохождении через ввод тока 10 А на вводе выделяется мощность 0,12 Вт, которая может нагреть ввод при непрерывном токе до температуры, превышающей $100^{\circ} \mathrm{C}$. При прохождении тока 20 А на вводе выделяется мощность 0,5 Вт, которая может нагреть ввод при непрерывном токе до температуры, превышающей температуру плавления припоя ПОС-61. От ввода тепло на корпус плохо отводится из-за низкой теплопроводности стекла. При измерении температур на внутреннем конце ввода и на фланце внутри корпуса в качестве теплоотвода использовали алюминиевый брусок с размерами $80 \times 30 \times 10$ мм. Ток задавали инверторным источником тока UNIV-50A/12B $\mathrm{P}$, а температуру измеряли температурным пробником модели ТР-01. Измерения проводили на металлостеклянных корпусах с фланцем из меди с вводами длиной 15 мм и диаметром 1 мм из проволоки МК при температуре окружающей среды $\approx 24^{\circ} \mathrm{C}$. Ток пропускали через последовательно соединённые ввода (рис. 4). Были установлены

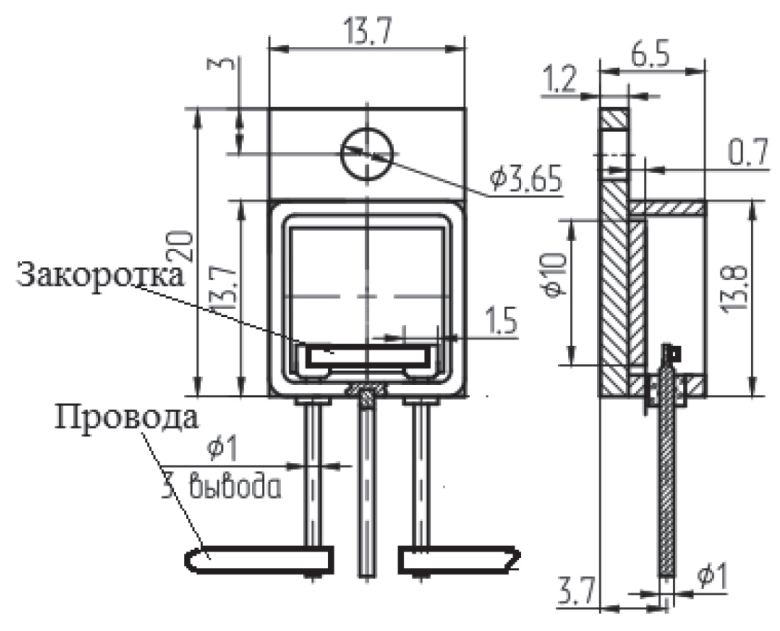

Puc. 4

Корпус КТ-97В с проводами, подводящими ток к выводам

зависимости (рис. 5) температуры ввода и монтажной площадки на фланце от времени пропускания тока через ввод.

По результатам измерений был построен график (рис. 5), представляющий зависимость роста температур на вводе и фланце от времени при пропускании тока $10 \mathrm{~A}$ и 20 А через ввод металлостеклянного корпуса ТО-97В с медной жилой без теплоотвода и с теплоотводом.
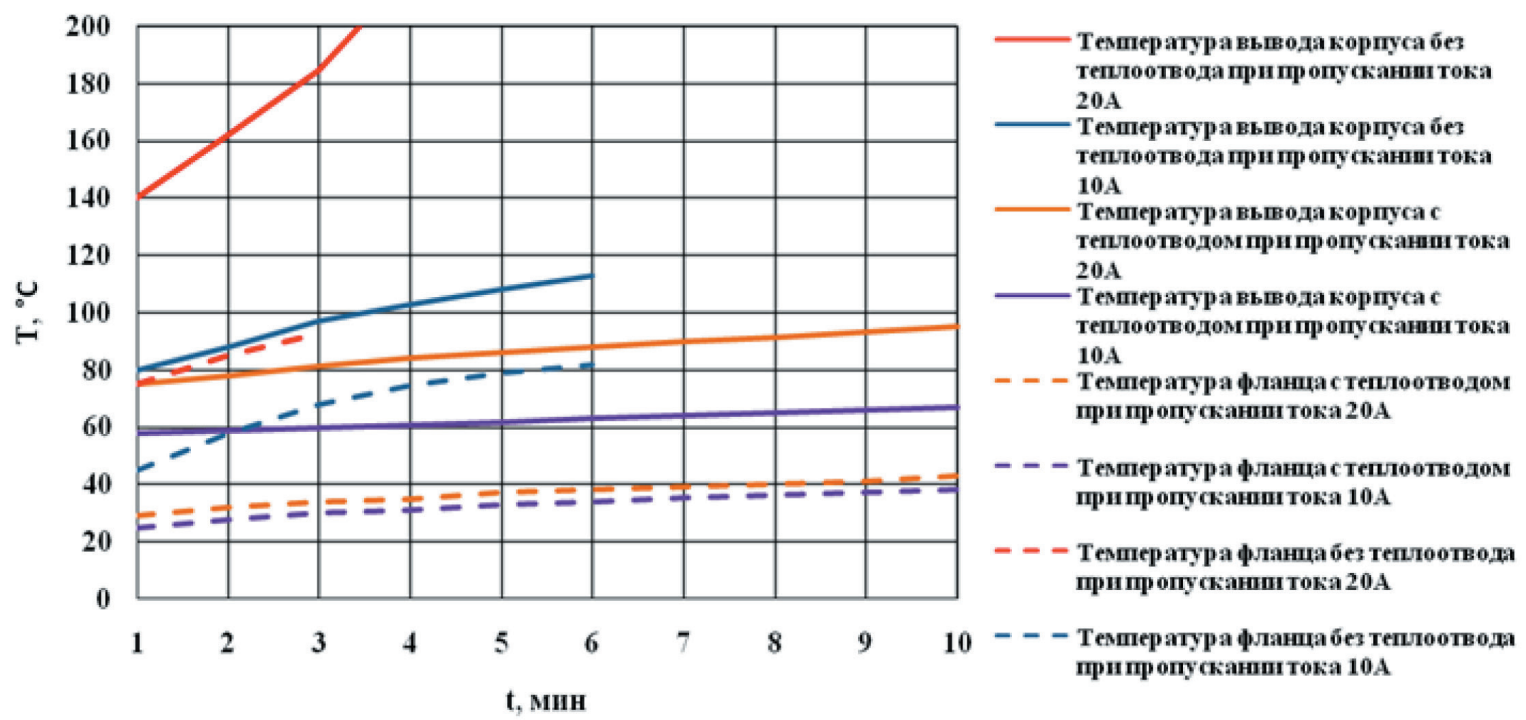

Puc. 5

Зависимость роста температур на вводе и фланце от времени при пропускании тока через ввод металлостеклянного корпуса ТО-97 


\section{Металлокерамические корпуса}

Металлокерамические корпуса, в которых на теплоотводящий фланец припаян изолятор из алюмонитридной керамики, в отверстиях которого размещены медные вводы, отличаются от металлостеклянных более высокими значениями тока, пропускаемого через вводы. Это объясняется низким электрическим сопротивлением меди и большей теплопроводностью алюмооксидной керамики. Удельное сопротивление меди 1.67 Ом.см [5], а у алюмооксидной керамики $22 \mathrm{XC}$, из которой сделаны изоляторы, $\lambda=11,5-13$ ккал/м'час·град, в то время как у стекла $\lambda \leq 0,9$ ккал/м'час'град [6], а у проволоки МК удельное сопротивление примерно 7 Омссм.

На металлокерамическом корпусе типа TO-254 (рис. 6) с медными вводами так же, как и в случае металлостеклянного корпуса, были проведены измерения температур

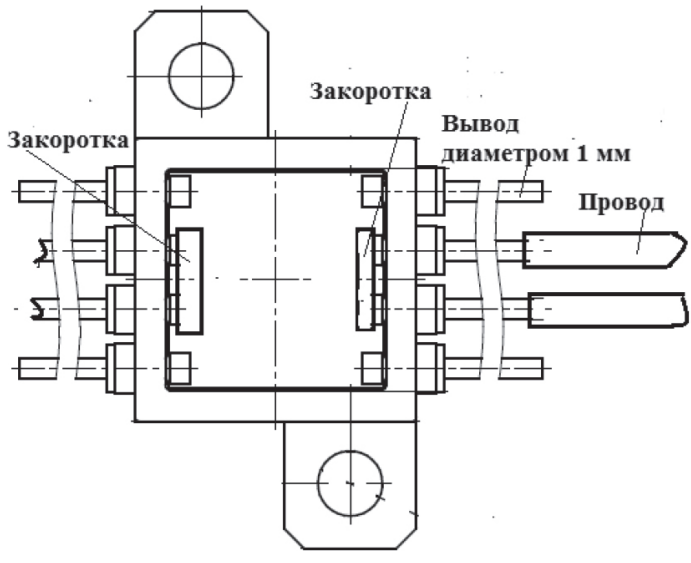

Puc. 6

Металлокерамический корпус ТО-254 с проводами, подводящими ток к выводам

на внутреннем конце ввода и на фланце внутри корпуса. Корпус ТО-254 и ТО 97В по геометрическим размерам вводов идентичны. Были установлены зависимости (рис. 7) температуры ввода и монтажной площадки на фланце от времени пропускания через ввод тока. Измерения проводились при температуре окружающей среды $\approx 24^{\circ} \mathrm{C}$.

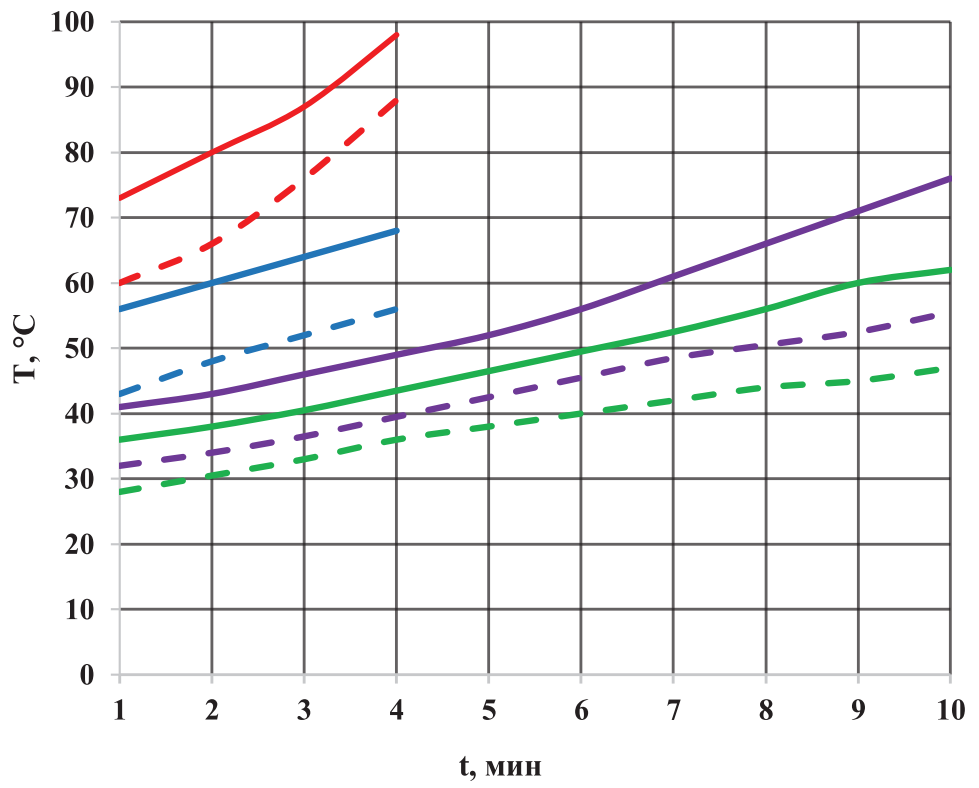

\footnotetext{
Температура вывода корпуса без теплоотвода при пропускании тока 40A

- Температура фланца без теплоотвода при пропускании тока 40A

- - Температура фланца без теплоотвода при пропускании тока 30А

- Температура вывода корпуса с теплоотводом при пропускании тока 40A

- Температура фланца при пропускании тока 40A

- Температура фланца без теплоотвода при пропускании тока 30A

Температура вывода корпуса при пропускании тока 30A

Температура вывода корпуса при пропускании тока 30A
}

Puc. 7

Зависимость роста температур на вводе и флание от времени при пропускании тока через ввод корпуса TO-254 


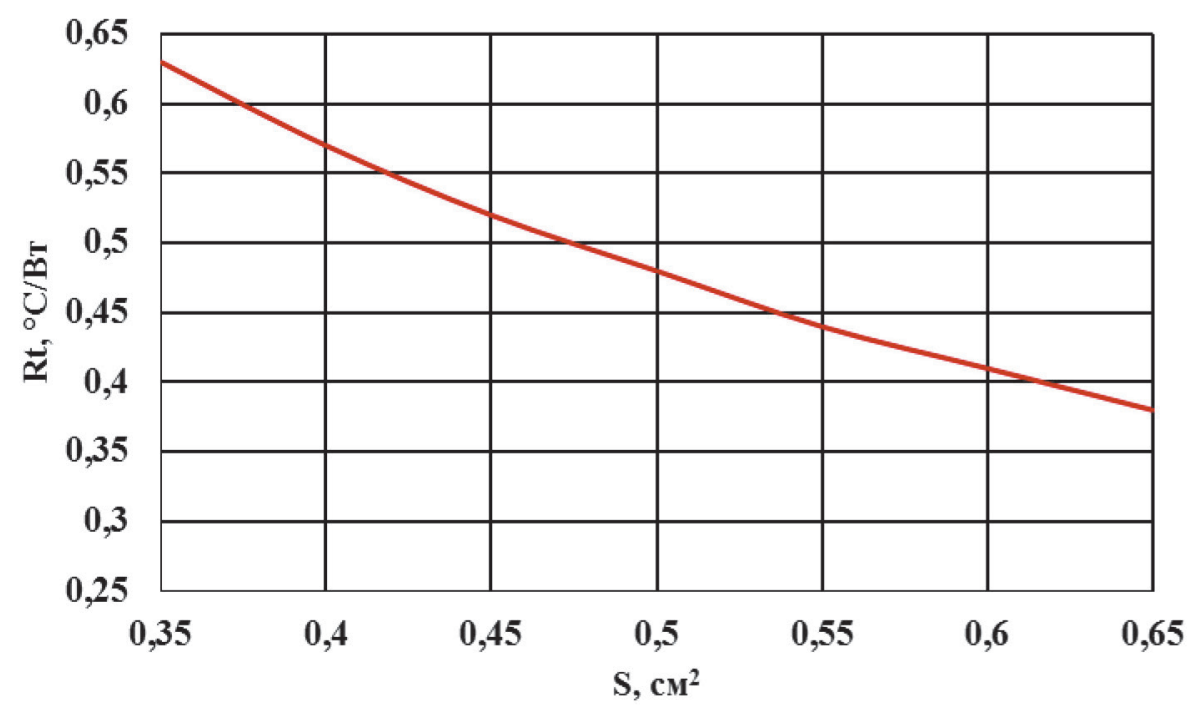

Puc. 8

График зависимости среднеарифметических значений внутреннего теплового сопротивления от площуади источника тепла для металлокерамического корпуса ТО-254

Проверка внутреннего теплового сопротивления основания металлокерамического корпуса проводилась на установке измерения теплового сопротивления ИВТС-1 в соответствии с руководством по эксплуатации ЛРПА 25207.00002 (АО НПП «НИИТАЛ») и ГОСТ 57967-2017. Сущность методики заключается в пропускании теплового потока от нагревателя через последовательно установленные на нём исследуемый образец и образцовое тепловое сопротивление с замером падения температур на концах образцов.

Результаты измерений температур на стыках теплового тракта и расчёта внутреннего теплового сопротивления основания корпуса представлены на рис. 8 .

Среднеарифметические значения величины внутреннего теплового сопротивления основания корпуса от различных источников тепла:

$$
\begin{aligned}
& S=0,64 \mathrm{~cm}^{2}-0,375^{\circ} \mathrm{C} / \mathrm{BT} ; \\
& S=0,49 \mathrm{~cm}^{2}-0,489^{\circ} \mathrm{C} / \mathrm{BT} ; \\
& S=0,64 \mathrm{~cm}^{2}-0,64^{\circ} \mathrm{C} / \mathrm{BT} .
\end{aligned}
$$

\section{Заключение}

Металлокерамические корпуса типа ТО с медными вводами способны работать при значениях тока, в 3-5 раз превышающих значения тока, допустимого для металлостеклянных корпусов. При этом электрическое сопротивление вводов в металлокерамических корпусах в 5-30 раз меньше, чем в металлостеклянных корпусах с вводами из проволоки МК примерно в 5 раз, а с вводами из сплава 29 НК примерно в 30 раз.

\section{Литература}

1. Каталог завода АО «Марс», г. Торжок. - 2019. C. $40-41$.

2. Каталог АО «НПП «Завод Искра», г. Ульяновск. - 2016. - С. 28.

3. ОАО «ИНТЕГРАЛ» - управЛяющая компания холдинга «ИНТЕГРАЛ. Электронная компонентная база». - Каталог 2018.

4. Максимов, А. Корпуса для полупроводниковых приборов металлостеклянные и металлокерамические / А. Максимов // ЭЛЕКТРОНИКА: Наука, Технология, Бизнес. - 2010. - № 6. - С.112-114. 
5. Таблицы физических величин / Справочник. Под ред. акад. И.К. Киконина. - М.: Атомиздат, 1976. $-328 \mathrm{c}$.

6. Рот, А. Вакуумные уплотнения / Пер. с англ. М.: Энергия, 1971. - 112 с.

\section{References}

1. Product catalogue of Mars LLC, Torzhok, 2019, pp. 40-41.

2. Product catalogue of "NPP Zavod Iskra" LLC, Ulyanovsk, 2016, p. 28.
3. Product catalogue of Integral LLC, 2018.

4. Maksimov A. Korpusa dlya poluprovodnikovykh priborov metallosteklyannyye i metallokeramicheskiye [Metal-glass and metal-ceramic packages for semiconductor devices]. ELEKTRONIKA: Nauka, Tekhnologiya, biznes, 2010, iss. 6.

5. Reference book of tables of physical quantities. Ed. by Kikonin I.K., Moscow, Atomizdat, 1976, p. 328 .

6. Roth A. Vakuumnyye uplotneniya [Vacuum Sealing Techniques], Moscow, Energiya, 1971, p. 112. 


\title{
КОНСТРУКТИВНО-ТЕХНОЛОГИЧЕСКИЕ ОСОБЕННОСТИ МЕТАЛЛОКЕРАМИЧЕСКИХ КОРПУСОВ ТИПА ТО-247 И ТО-220
}

\author{
В.А. Сидоров, А.Г. Чупрунов, С.В. Катаев, К.В. Сидоров \\ АО «НПП «Пульсар», 105187, г. Москва, Окружной проезд, д. 27
}

Представлена конструкиия герметичных металлокерамических корпусов типа ТО-247 и ТО-220, являющихся аналогами металлопластмассовых и металлостеклянных корпусов. Корпуса могут быть использованы для многокристальных сборок на основе эпитаксиальных структур кремния и карбида кремния, для интеллектуальных силовых ключей на нитриде галлия и т.п. с максимальным рабочим напряжением до 2500 В и импульсным током до $350 \mathrm{~A}$.

Ключевые слова: металлопластмассовый корпус, металлокерамический корпус, металлостеклянный корпус, медный ввод, керамический изолятор

Сведения об авторах: Сидоров Владимир Алексеевич, к.m.н., vlsidorov@pulsarnpp.ru; Чупрунов Алексей Геннадиевич, chuprunov_ag@pulsarnpp.ru; Катаев Сергей Владимирович, s_kataev@pulsarnpp.ru; Сидоров Кирилл Владимирович, sidorov_kv@pulsarnpp.ru

\section{DESIGN AND TECHNOLOGICAL FEATURES OF CERAMIC-METAL TO-247 AND TO-220 SEMICONDUCTOR PACKAGES}

\author{
V.A. Sidorov, A.G. Chuprunov, S.V. Kataev, K.V. Sidorov \\ S\&PE Pulsar JSC, 105187, Moscow, Okruzhnoy pr., 27
}

In this paper we introduce the design of sealed ceramic-metal TO-247 and TO-220 packages, which are intended for the same applications as plactic-metal and glass-metal alternatives. Packages could be used for epitaxial Si and SiC multi-die assemblies, for GaN smart power switches, etc., with operating voltage up to $2500 \mathrm{~V}$ and pulsed current up to $350 \mathrm{~A}$.

Keywords: plastic-metal package, ceramic-metal package, glass-metal package, copper pin, ceramic insulator

Data on authors: Sidorov Vladimir Alekseevich, Ph.D., vlsidorov@pulsarnpp.ru; Chuprunov Aleksey Gennadievich, chuprunov_ag@pulsarnpp.ru; Kataev Sergey Vladimirovich, s_kataev@pulsarnpp.ru; Sidorov Kirill Vladimirovich, sidorov_kv@pulsarnpp.ru 
Корпуса типа ТО-247, ТО-220 и им подобные, выполненные в металлокерамическом варианте, имеют хорошую электрическую изоляцию между вводами, низкое значение электрического сопротивления вводов, высокое значение рабочего тока за счёт выполнения выводов из меди и обеспечивают возможность надёжной герметизации приборов шовно-роликовой сваркой. Корпуса различаются габаритными размерами и количеством вводов, а также электрическими характеристиками.

На рис. 1 представлен корпус ТО-247 в металлокерамическом исполнении. Особенностью данной конструкции в отличие от металлостеклянного исполнения является наличие керамического изолятора (1), в проходных отверстиях которого размещены медные вводы (2), герметично при- паянные к металлизированным выступам изолятора припоем ПСр-72 с помощью шайбы. Керамический изолятор с вводами припаян к фланцу (3). Материалами теплоотводящего фланца могут быть псевдосплавы молибден-медь или вольфрам-медь, имеющие близкие значения коэффициента теплового линейного расширения (КТЛР) с КТЛР керамики. На верхней поверхности изолятора припаян ободок из сплава $29 \mathrm{HК}$ для герметизации корпуса шовно-роликовой сваркой.

На рис. 2 представлен корпус ТО-220 с двумя медными вводами. Конструктивные и технологические особенности корпуса такие же, как и у металлокерамического корпуса ТО-247. Материалы фланца, шайбы и герметизирующей рамки использованы максимально согласо-
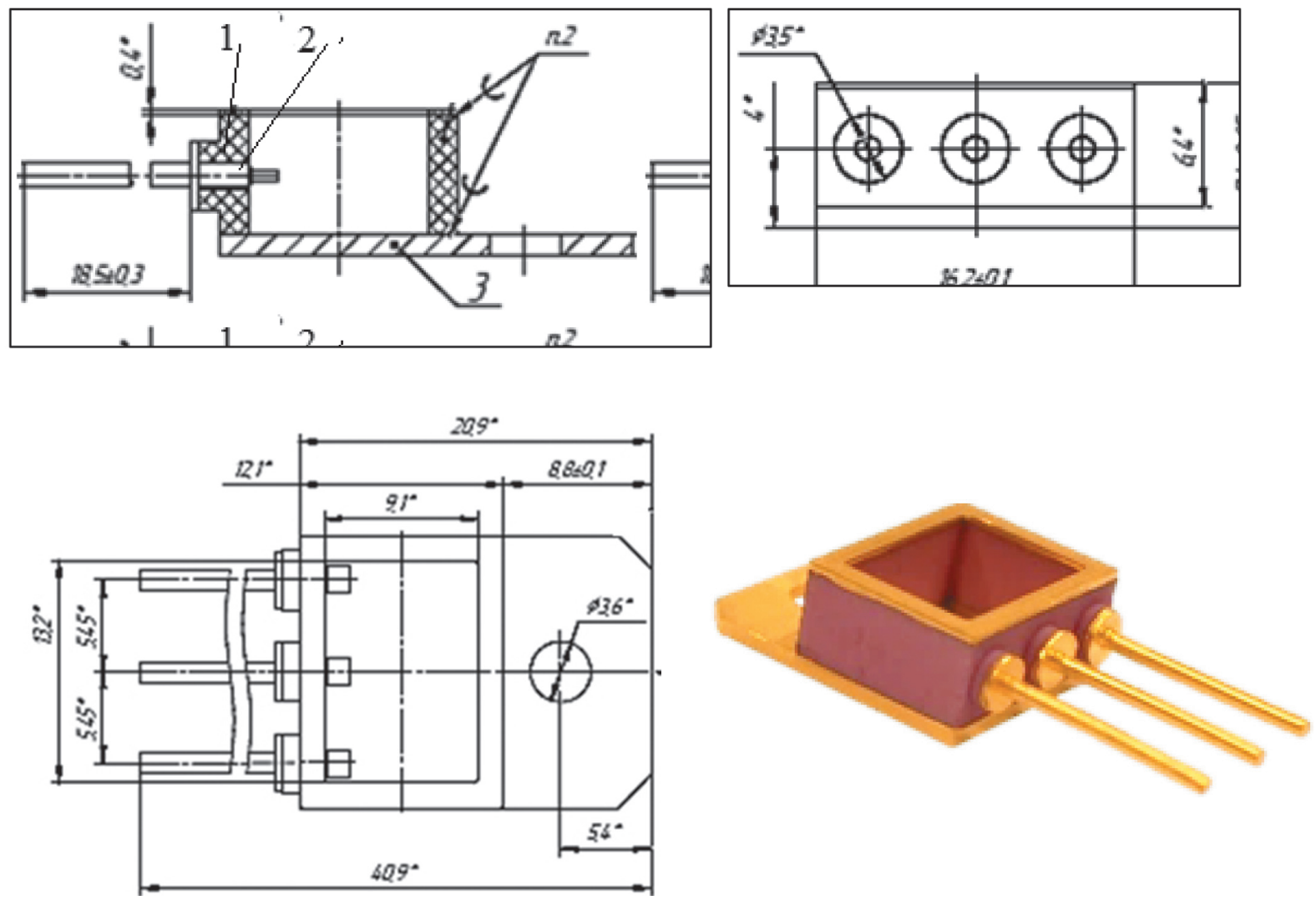

Puc. 1

Металлокерамический корпус ТО-247 

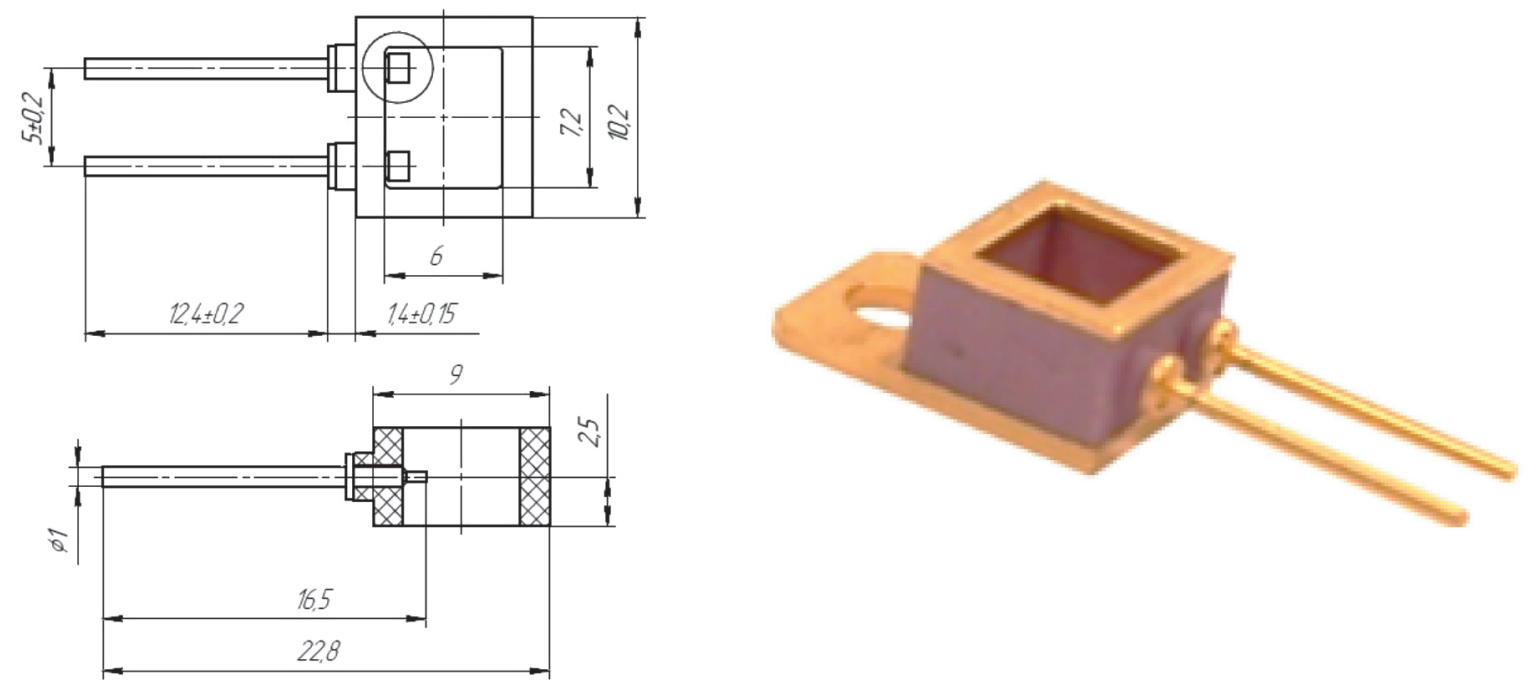

Puc. 2

Металлокерамический корпус ТО-220

ванные по тепловому расширению с керамикой, как и в металлокерамическом корпусе ТО-247 [1].

Основными параметрами корпусов, подтверждающими их работоспособность, являются напряжение между вводами и электрическое сопротивление вводов.

Электрическое сопротивление $R$ силовых вводов корпусов определяется по фор- муле $R=\rho \cdot l / S$, где $\rho$ - удельное электрическое сопротивление материала (Ом·см); $l$ - длина проводника (см); $S$ - поперечное сечение проводника (см).

При проведении расчётов использованы справочные данные [2,3].

Результаты расчёта допустимых значений пробивного напряжения приведены в табл. 1.

\section{Таблица 1}

\begin{tabular}{|c|c|c|c|c|}
\hline \multicolumn{5}{|c|}{ Расчётные значения пробивного напряжения } \\
\hline \multirow{2}{*}{ Корпус } & \multicolumn{2}{|c|}{ Расстояние, мм } & \multirow{2}{*}{$\begin{array}{c}\text { Расчётное } \\
\text { напряжение } \\
\text { между вводами, В }\end{array}$} & \multirow{2}{*}{$\begin{array}{c}\text { Напряжение, В } \\
\text { Вывод-фланец } \\
\text { Вывод-рамка }\end{array}$} \\
\hline & Вводы & $\begin{array}{c}\text { Вывод-фланец } \\
\text { Вывод-рамка }\end{array}$ & & \\
\hline TO-247 & 2,9 & 1,5 & 8990 & 4650 \\
\hline TO-220 & 2,5 & 1,6 & 7750 & 4960 \\
\hline
\end{tabular}

Измеренные значения пробивного напряжения несколько выше расчётных. Разницу в значении пробивного напряжения расчётного и измеренного можно объяснить тем, что справочное напряжение пробоя воздуха при давлении 760 мм рт.ст., равное 32 кВ/см, измерялось между двумя шарами диаметром 1 см, а детали корпуса имеют другие размеры и форму.
На рис. 3 представлена электрическая модель корпуса типа ТО-247.

В табл. 2 представлены расчётные значения $L, C, R$ для корпуса типа ТО-247.

$L_{1}$ - индуктивность внешнего участка вывода, $L_{2}-$ индуктивность участка в изоляторе, $L_{3}-$ индуктивность участка внутри корпуса. 


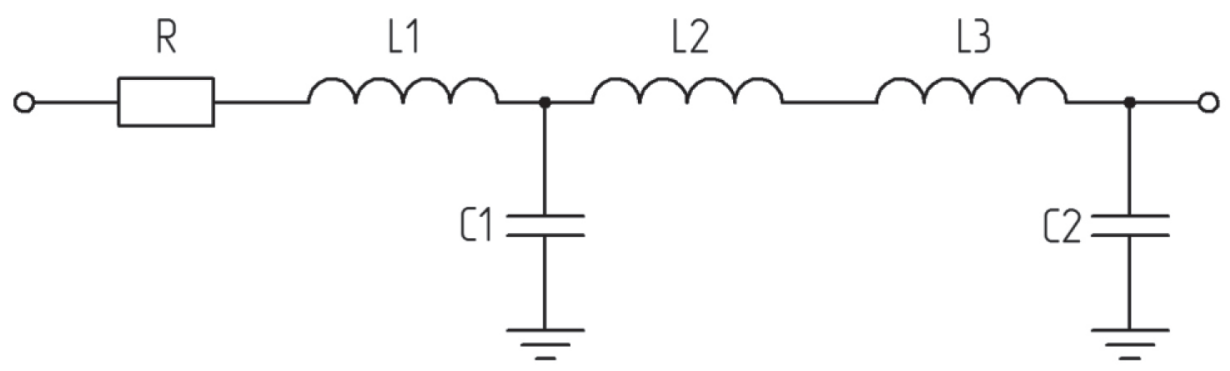

Puc. 3

Электрическая модель корпуса типа ТО-247

Индуктивность вывода рассчитана по формуле [6]:

$$
L=\frac{\mu_{0} \cdot l}{2 \pi} \cdot\left(\ln \frac{2 l}{\mathrm{r}}-\frac{3}{4}\right)
$$

где $l$ - длина участка ввода, $r$ - радиус вывода; $\mu_{0}=1,257 \cdot 10^{-6}$ Гн/м - магнитная постоянная.

Металлокерамический корпус в отличие от металлостеклянного имеет не только существенно меньшее электрическое сопротивление выводов, но и потенциально более стоек к циклическому изменению температур.

В табл. 3 приведены сравнительные характеристики металлокерамических и металлостеклянных корпусов ТО-247 и TO-220.
При производстве металлокерамических корпусов типа ТО используются традиционные технологические процессы изготовления керамических изоляторов посредством литья заготовок из шликера с последующим удалением связующего вещества высокотемпературным обжигом и металлизацией пастами на основе тугоплавких металлов.

При изготовлении металлических деталей корпуса также применимы традиционные процессы штамповки и химических покрытий. Сборка корпуса проводится пайкой высокотемпературным припоем на основе серебра в среде водорода.

Одним из основных узлов герметичных металлокерамических корпусов типа

Таблица 2

Расчётные значения $L, C, R$ для металлокерамического корпуса типа ТO-247

\begin{tabular}{|c|c|c|c|c|c|}
\hline$L_{1}, \mathrm{нГ}$ & $L_{2}, \mathrm{н} Г \mathrm{H}$ & $L_{3}, \mathrm{нГ}$ & $C_{1}$, пФ & $\mathrm{C}_{2}, \Pi \Phi$ & $R$, Ом \\
\hline 13,4 & 0,69 & 0,1 & 0,19 & 0,017 & $2,4 \cdot 10^{-4}$ \\
\hline
\end{tabular}

\section{Таблица 3}

Сравнительные характеристики металлокерамических

и металлостеклянных корпусов по функциональным параметрам

\begin{tabular}{|l|c|c|}
\hline $\begin{array}{c}\text { Конструкция корпуса } \\
\text { ТО-247 }\end{array}$ & $\begin{array}{c}\text { Сопротивление вводов на } \\
\text { длине 5 мм, мОм }\end{array}$ & $\begin{array}{c}I_{\text {макс }} \\
\text { непрерывный, А }\end{array}$ \\
\hline ТО-247 металлокерамический & 0,053 & 90 \\
\hline тО-247 металлостеклянный & 0,3 & 15 \\
\hline TO-220 металлокерамический & 0,1 & 40 \\
\hline TО-220 металлостеклянный & 0,6 & 8 \\
\hline
\end{tabular}



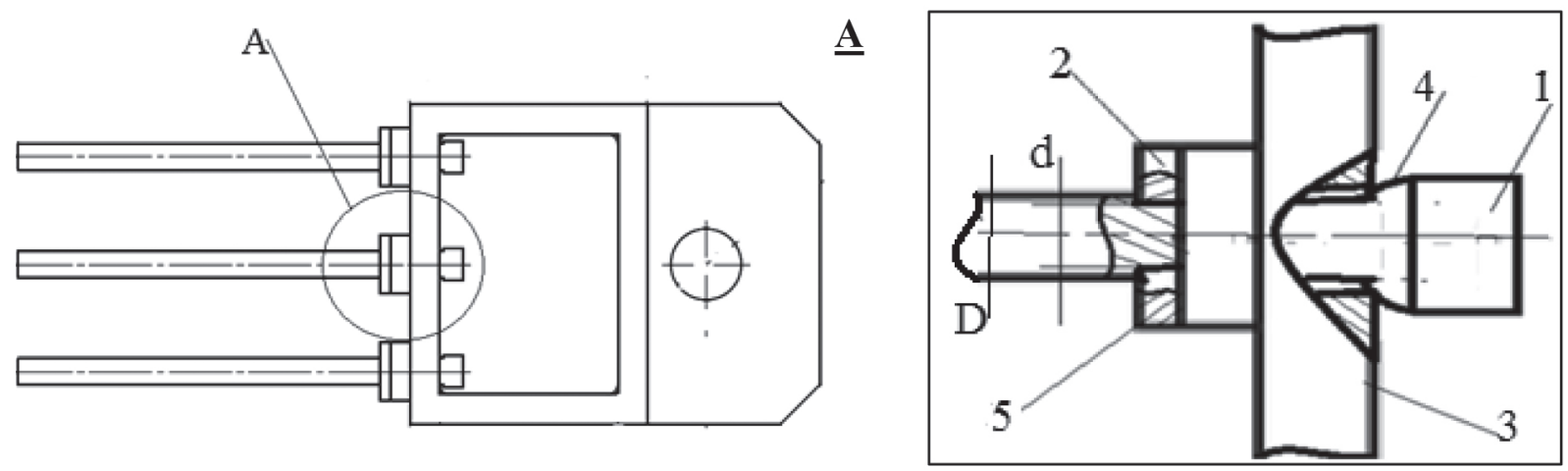

Puc. 4

Сборка ввода в корпусе ТO-247

ТО-247 и ТО-220 является герметичный ввод. Герметичность медного ввода можно обеспечить посредством пайки припоем ПСр-72 при условии запрессовки ввода в отверстии шайбы из сплава 29НК (ковар). Сборку ввода (рис. 4) в корпусе предпочтительно проводить в следующей последовательности: металлические шайбы (2) после размещения в них вводов (1) осаживают до образования плотного неразъёмного соединения шайб с вводами, плоские площадки на вводах для сборки полупроводникового прибора термокомпрессионной или ультразвуковой сваркой внутри корпуса формируют посредством расплющивания до получения плотного и неподвижного контакта шайб с металлизацией на изоляторе. При осаживании шайбы диаметр $d$ отверстия в шайбе (2) уменьшается, становится несколько меньше диаметра $D$ ввода (1). Шайба (2) как бы пережимает ввод, внедряясь в него. Соединение ввода с шайбой становится неразъёмным. Ввод предварительно перед расплющиванием отжигают, повышая его пластичность. При расплющивании концов вводов (1) внутри изолятора не только получаются плоскими монтажные площадки, но медный наплыв (4) течёт также в сторону внутренней стенки изолятора (3) и, достигая её, плотно прижимает шайбы к металлизации (5). Вводы при этом неподвижно фиксируются в изоляторе и далее может проводиться одностадийная пайка вводов и изолятора с фланцем с использованием кассеты, ориентирующей только изолятор относительно фланца и рамку для герметизации на изоляторе, вместо двухстадийной пайки, включающей пайку изолятора с вводами серебром и затем пайку корпуса с фланцем и рамкой припоем ПСр-72.

Такая сборка, помимо сокращения трудоёмкого технологического процесса, также повышает процент выхода годных корпусов за счёт гарантированного плотного соединения поверхности шайбы (2) с вводом (1) к металлизации (5) на изоляторе.

\section{Заключение}

Металлокерамические корпуса типа ТО-247 и ТО-220 способны работать при значениях тока, в 3-5 раз превышающих значения тока в металлостеклянных корпуcax, при обеспечении существенно меньшего падения напряжения на вводах.

Расчётная и экспериментальная оценка предложенных конструктивных и технологических решений подтверждает воз- 
можность использования металлокерамических корпусов типа ТО-247 и ТО-220, аналогичных по основным габаритным размерам металлостеклянным и металлопластмассовым корпусам, в изделиях силовой электроники.

\section{Лumepamypa}

1. Пат. 183394 Российская Федерация, МПК ${ }^{51} \mathrm{H}$ 05 K 7/02. Мощная гибридная интегральная СВЧ интегральная схема / Груздов В.В., Крымко М.М., Савченко Е.М., Сидоров В.А., Пронин А.А., Першин А.Д., Попов М.С., Чупрунов А.Г.; заявитель АО «НПП «Пульсар». - № 2017131322; заявл. 06.09.17; опубл. 21.09.18 4 от 14.06.2017.

2. Таблицы физических величин / Справочник под ред. акад. И.К. Киконина. - М.: Атомиздат, 1976. - 328 c.

3. Рот, А. Вакуумные уплотнения / А. Рот; пер. с англ. - М.: Энергия, 1971. - 456 с.
4. Калантаров П.Л., Цейтлин Л.А. Расчёт индуктивностей: Справочная книга. - 3-е изд., перераб. и доп. - Л.: Энергоатомиздат, 1986. 92 c.

\section{References}

1. Gruzdov V. V., Krymko M. M., Savchenko E. M., Sidorov V. A., Pronin A. A., Pershin A. D., Popov M. S. Korpus moshchnoy gibridnoy SVCH integral'noy skhemy [Power hybrid microwave integrated circuit package]. Russian Federation patent no. RUS 2659304 (2017).

2. Reference book of tables of physical quantities. Ed. by Kikonin I.K., Moscow, Atomizdat, 1976, 328 p.

3. Roth A. Vakuumnyye uplotneniya [Vacuum Sealing Techniques], Moscow, Energiya, 1971, p. 112.

4. Kalantarov P. L., Tseytlin L. A., Reference book of inductance calculation, 3rd ed. Saint Petersburg, Energoatomizdat, 1986, 92 p. 


\title{
МЕТОДИКА ОПРЕДЕЛЕНИЯ ПАРАМЕТРОВ МИКРОЛИНЗ ДЛЯ ЭЛЕМЕНТОВ ФОТОЧУВСТВИТЕЛЬНОЙ ПЗС ИС С ПОМОЩЬЮ ТСАD-МОДЕЛИРОВАНИЯ
}

\author{
H.C. Коптев, А.А. Пугачёв \\ АО «НПП «Пульсар», 105187, Москва, Окружной проезд, д. 27
}

\begin{abstract}
Разработана методика моделирования фоточувствительной ячейки с микролинзой ПЗС СБИС с межстрочным переносом. Микролинза повышает фоточувствительность ячейки и снижает смаз изображения. Методика основана на расчёте и сравнении интегралов скорости объёмной фотогенерачии по площядям различных областей фотоячейки, являюшихся областями сбора и переноса фотогенерированных носителей заряда. Данный метод не требует моделирования полного ичикла накопления кадра ячейки, что значительно сокращает время моделирования и позволяет оценивать множество вариантов конструкиий микролинз. Метод реализован в среде программного комплекса Sentaurus TCAD (Synopsys). Приведены результаты моделирования ячеек с различными микролинзами. Методика также подходит для оптимизачии микролинз фотоячеек КМОП-фотодиодных СБИС.
\end{abstract}

Ключевые слова: фотоприёмная матричная СБИС; прибор с зарядовой связью, микролинза; метод моделирования; приборно-топологическое моделирование; TCAD

Сведения об авторах: Никита Сергеевич Коптев; Андрей Алексеевич Пугачёв, pиgachev@, pulsarnpp.ru

\section{TCAD-ASSISTED TECHNIQUE FOR DETERMINING THE PARAMETERS OF MICROLENSES USED IN PHOTOSENSITIVE CCD VLSI}

\author{
N.S. Koptev, A.A. Pugachev \\ S\&PE Pulsar JSC, 105187, Moscow, Okruzhnoy pr., 27
}

In this paper we introduce the simulation technique for photosensitive cell with CCD VLSI microlens with interline transfer. A microlens enhances the photosensitivity of the cell and reduces image blur. The technique is based on the calculation and comparison of the volumetric photogeneration rate integrals of different areas of the photocell, where generated charge carriers are collected and transferred. This technique does not require simulation of the full frame accumulation cycle of the cell, significantly reducing the time of simulation and enabling the evaluation of many design options for microlenses. The technique is implemented in the Sentaurus TCAD (by Synopsys). In the paper we present the results of simulation made for cells with various microlenses. The proposed technique can also be used for the optimization of microlenses of CMOS photodiode VLSI photocells.

Keywords: photo-integrated matrix VLSI, charge-coupled device, microlens, simulation technique, design simulation, TCAD

Data on authors: Nikita Sergeevich Koptev; Andrey Alekseevich Pugachev, pugachev@pulsarnpp.ru 


\section{Введение}

Для повышения фоточувствительности и уменьшения перекрёстных световых и диффузионных помех в матричных СБИС на приборах с зарядовой связью (ФЧ ПЗС) и в СБИС на фотодиодах и КМОП транзисторах (КМОП-ФД) используются микролинзы [1], рис. 1.

Микролинзы (МЛ) формируются над каждой фотоприёмной ячейкой (ФЯ) и собирают световой поток со всей поверхности ячейки в её фоточувствительную область. Это позволяет не только увеличить долю света, попадающего непосредственно в фоточувствительную часть (то есть увеличить фактор заполнения ячейки), но и избежать попадания света в периферийные области ячейки, где он может либо проникнуть в соседние ячейки за счёт межслойных переотражений, либо сгенерировать электронно-дырочные пары, которые за счёт диффузии также могут попасть в соседние ячейки. Таким обра- зом, применение микролинз повышает фоточувствительность матриц пропорционально соотношению активной площади (светочувствительный элемент) и пассивной площади фотоприёмной ячейки и улучшает их разрешающую способность за счёт увеличения пространственной модуляции сигнала вследствие уменьшения перекрестных помех.

Основные параметры микролинзы, влияющие на эффективность сбора светового потока, следующие:

- радиус микролинзы,

- высота постамента,

- апертура линзы.

В данной работе представлена методика быстрого моделирования фотоприёмной ячейки с микролинзой, позволяющая оценить степень увеличения фоточувствительности ФЯ. Вопросы технологии изготовления микролинз, и соответственно, вопросы моделирования такой технологии в данной работе не рассматриваются.

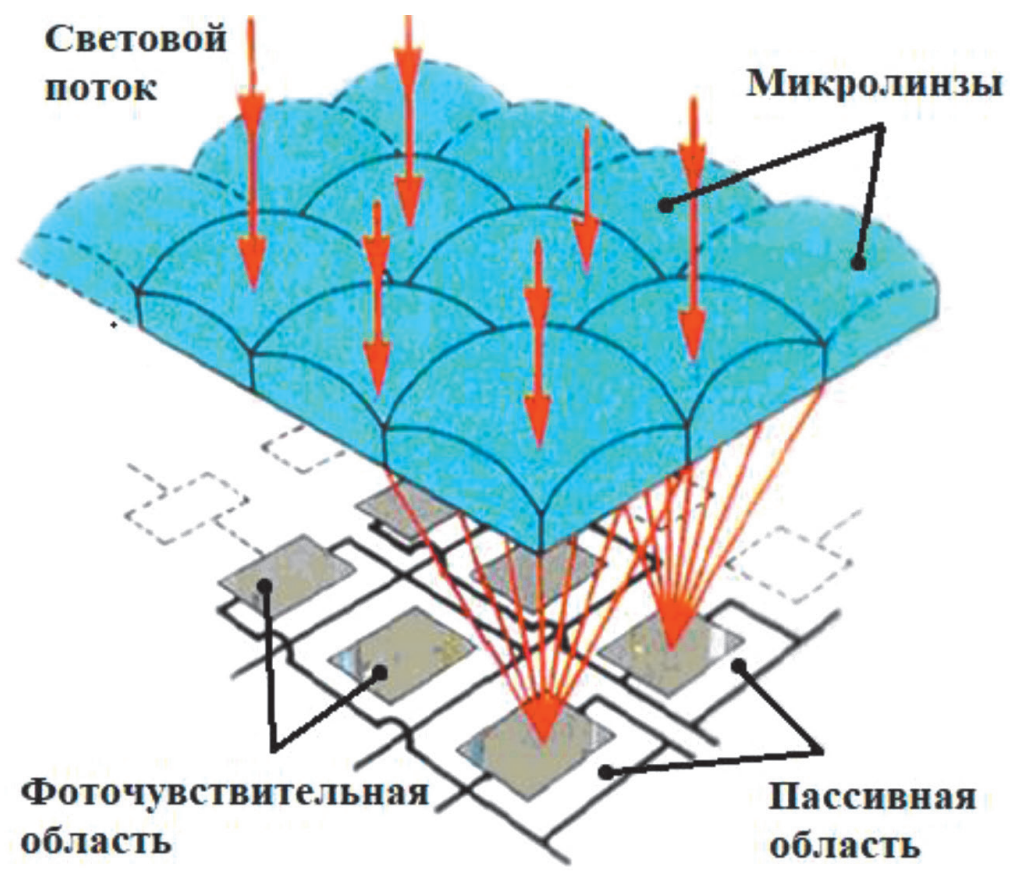

Puc. 1

Принщии действия микролинз 


\section{Обоснование методики определения эффективности микролинзы}

Для моделирования ФЯ с микролинзами и определения параметров микролинз разработаны как аналитические $[1,2]$, так и численные [3-5] модели. Аналитические модели позволяют оперативно оценить положение точки фокуса линзы по её основным геометрическим параметрам. Такие модели, однако, не могут оценить влияние объёмной структуры ячейки на эффективности системы линза+ячейка. Численные модели позволяют учесть все физические процессы, связанные с распространением света в системе линза+ячейка, последующим его поглощением в объёме полупроводника и дальнейшим перераспределением фотогенерированных носителей заряда. Данные модели реализованы в различных вариантах в системах компьютерного моделирования, в том числе в Sentaurus TCAD (Synopsys). Однако вычислительные затраты при анализе, например, фоточувствительных ПЗС с межстрочным переносом, очень велики: часы на один вариант системы линза+ячейка при моделировании полного цикла одного кадра, включающего стадии накопления, горизонтального переноса, вертикального переноса и электронного затвора. При этом значительное время дополнительно тратится на создание моделей структуры прибора для каждого нового варианта конструкции микролинзы.

Нами предлагается методика определения параметров микролинзы, основанная на расчёте величины объёмной фотогенерации в различных областях ФЯ без моделирования процессов переноса заряда, в отличие от метода, предлагаемого, например, в [2].

Определить эффективность микролинзы можно путём сравнения числа элек- тронов, которые были собраны в область накопления к моменту окончания времени интегрирования с общим числом электронов, которые были фотогенерированы за это время в объёме фотоприёмной ячейки. Для этого в общем случае необходимо сначала смоделировать её реальную структуру, а затем процессы перераспределения зарядов в ней в течение времени накопления. Такой подход требует значительных аппаратных ресурсов и времени моделирования, так как оптимальные параметры МЛ получаются путём многократного перебора различных сочетаний их значений. Анализ многочисленных результатов двумерного моделирования различных фотоприёмных ячеек без микролинз показал, что для определения эффективности их работы достаточно иметь информацию о скорости фотогенерации в том объёме кремния, из которого фотогенерированные электроны будут собираться в область хранения ФЯ. Предлагается подход, в котором числовой мерой эффективности микролинзы выбрано отношение интеграла скорости фотогенерации по площади области сбора фотогенерированных зарядов к сумме аналогичных интегралов, взятых по всему оставшемуся объёму фотоприёмного элемента. Данную характеристику будем называть «коэффициентом усиления микролинзы». При этом для TCAD-моделирования необходима информация только о конфигурации области сбора и не требуется модель объёмной структуры конкретной ФЯ и также не требуется проведение расчёта распределения фотогенерированных электронов к моменту окончания времени стадии накопления, как в [2-5]. Указанная числовая мера является одновременно мерой повышения фоточувствительности ячейки. 
Для реализации предложенного подхода предлагается замена реальной структуры ФЯ на некоторую «примитивную» структуру, разбитую на области для оценки величин интегралов фотогенерации. Примитивная структура требуется только для оценки распределения скорости фотогенерации в объёме кремния, поэтому она не содержит сложных $p$ - $n$-переходов, как в реальной ячейке. Область сбора носителей в потенциальную яму и остальные области выбираются из анализа двумерного распределения потенциала в объёме реальной фотоприёмной ячейки, которое показано на рис. 2.

«Примитивная» структура моделируемой фотоприёмной ячейки ПЗС имеет на своей поверхности систему диэлектриков и микролинзу, совпадающие с таковыми в реальной ячейке, в то время как объёмная структура профиля примеси «примитив- ной ячейки» представляет собой $p$ - $n$-переход с глубиной залегания порядка 1,0 мкм, работающий при нулевом смещении.

Моделирование выполняется с помощью модуля Ray Tracer (RT) ПО Sentaurus TCAD (Synopsys). RT использует рекурсивный алгоритм трассировки, который начинает трассировку с исходного луча и затем отслеживает пропускание и отражение луча от всех поверхностей, встречающихся на его пути [3]. Визуализация трасс лучей позволяет определить область их максимальной концентрации в объёме ФЯ и наглядно получить информацию о том, каким образом скорректировать геометрию линзы.

На рис. 3 показана структура «примитивной» ячейки с микролинзой. Для максимального совпадения со структурой реальной ПЗС-ячейки в модель структуры

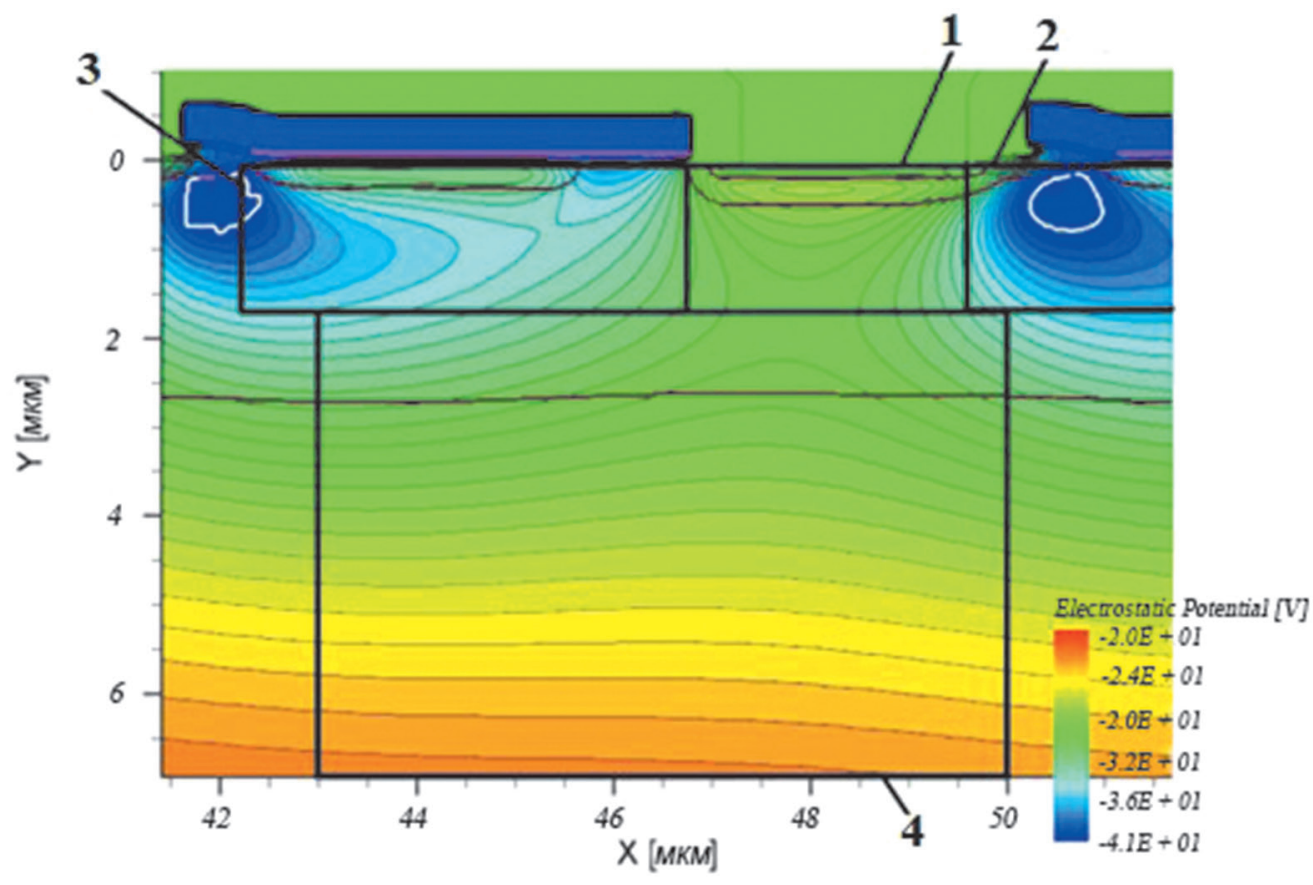

Puc. 2

Двумерное распределение потенциала в фотоприёмной ячейке с указанными областями интегрирования:

1 - область интегрирования фотодиода; 2 - область интегрирования правой, 3 - область интегрирования левой; 4 - область интегрирования подложки фотодиода 


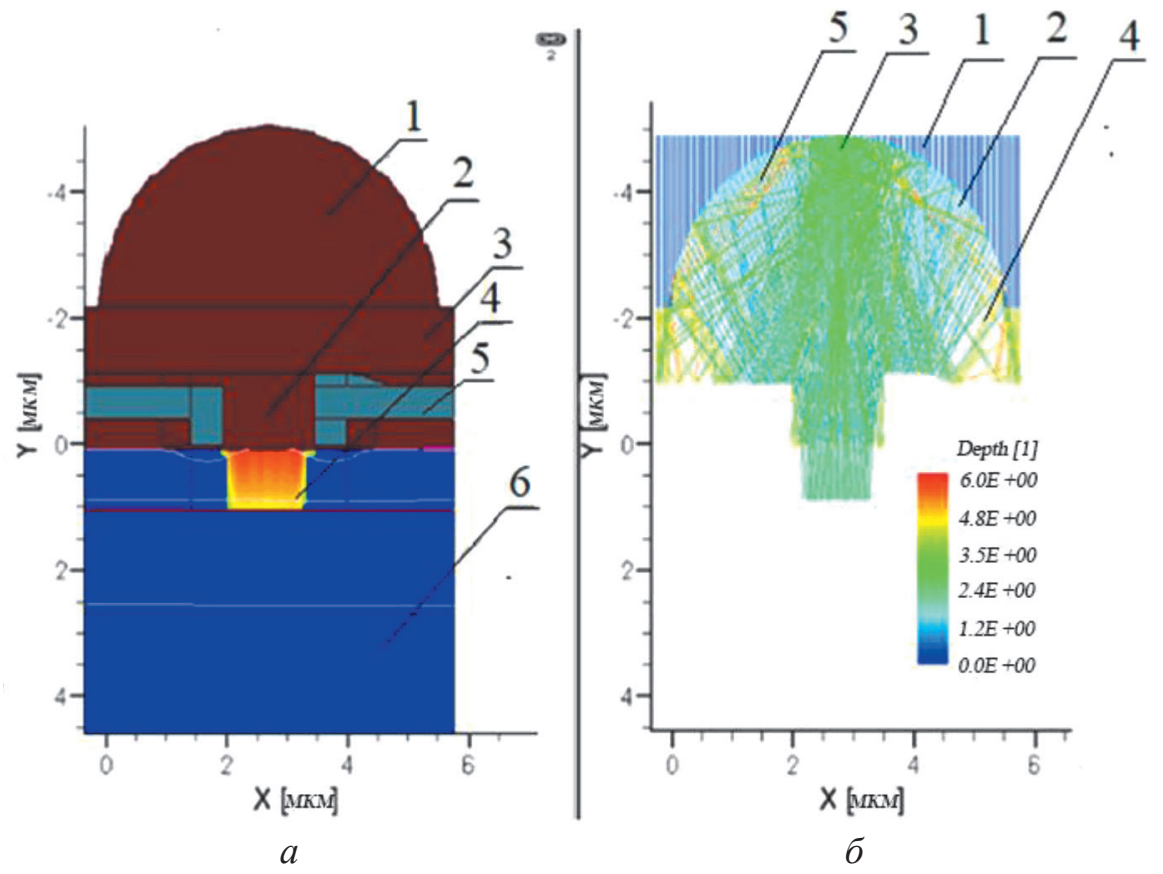

Puc. 3

$a$ - «примитивная» структура ячейки с микролинзой: 1 -микролинза, 2 - планаризующий слой, 3 - постамент, 4 - графическое изображение распределения скорости фотогенерачии,

5 - экраны вертикальных регистров, 6 - подложка; б-ход лучей в ячейке: 1 - исходные лучи,

2, 3, 4, 5-лучи с одним, двумя, тремя и четырьмя переотражениями соответственно

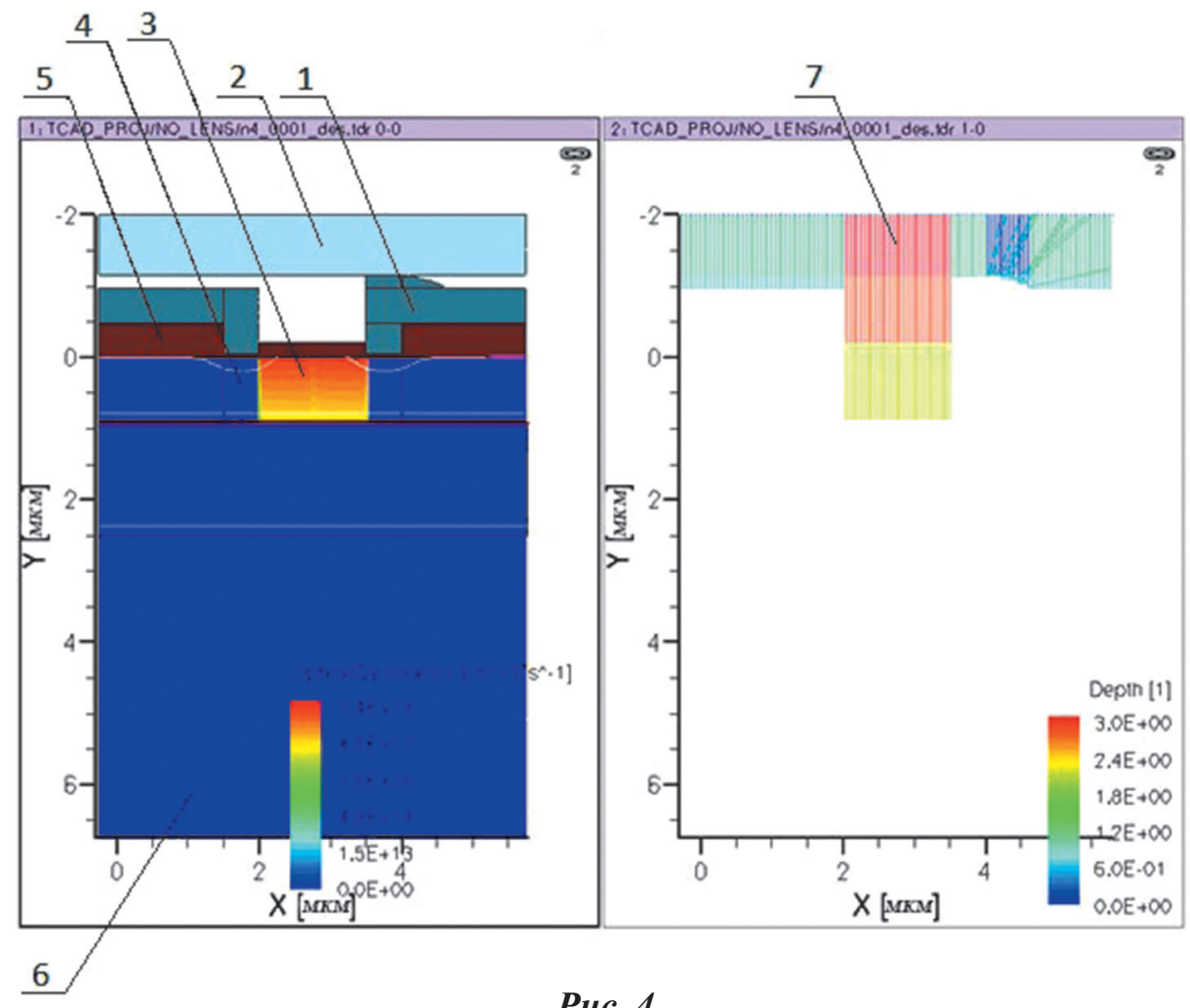

Puc. 4

«Примитивная» структура без микролинзы: 1 - замитный экран; 2 - планаризатор;

3 - графическое изображение распределения скорости фотогенерации; 4 - область сбора фотогенерированных носителей в фотодиод; 5 - разрешающий затвор; 6 - подложкка р-типа; 7 - лучи в структуре 
«примитивной» ячейки были внесены металлические экраны, которые защищают регистр ячейки от попадания отражённого в диэлектрических слоях света.

Для расчёта эффективности микролинзы дополнительно рассчитываются интегралы скорости фотогенерации в «примитивной» ячейке без микролинзы, рис. 4.

Таким образом, подход основан на сравнении интегралов скоростей фотогенерации в областях, полностью определяющих соотношение числа фотогенерированных носителей заряда, собранных в фотодиод и «утерянных» в соседних областях. Данный подход оценки эффективности линзы по величине фотогенерации в заданном объёме физически корректен и его точность зависит от точности задания границ области сбора фотогенерированных носителей заряда.

Проведённые расчёты показали, что количество итераций подбора пары «радиус микролинзы - высота постамента», дающих максимальную эффективность микролинзы, может превышать 100. Аналогичную процедуру было бы невозможно провести с помощью двумерного моделирования реальной структуры ПЗС ячейки при её работе в режиме накопления фотогенерированного заряда, так как время моделирования одного варианта «линза+постамент» такой ячейки составляет порядка 10-40 минут, причём без учёта времени коррекции самой структуры.

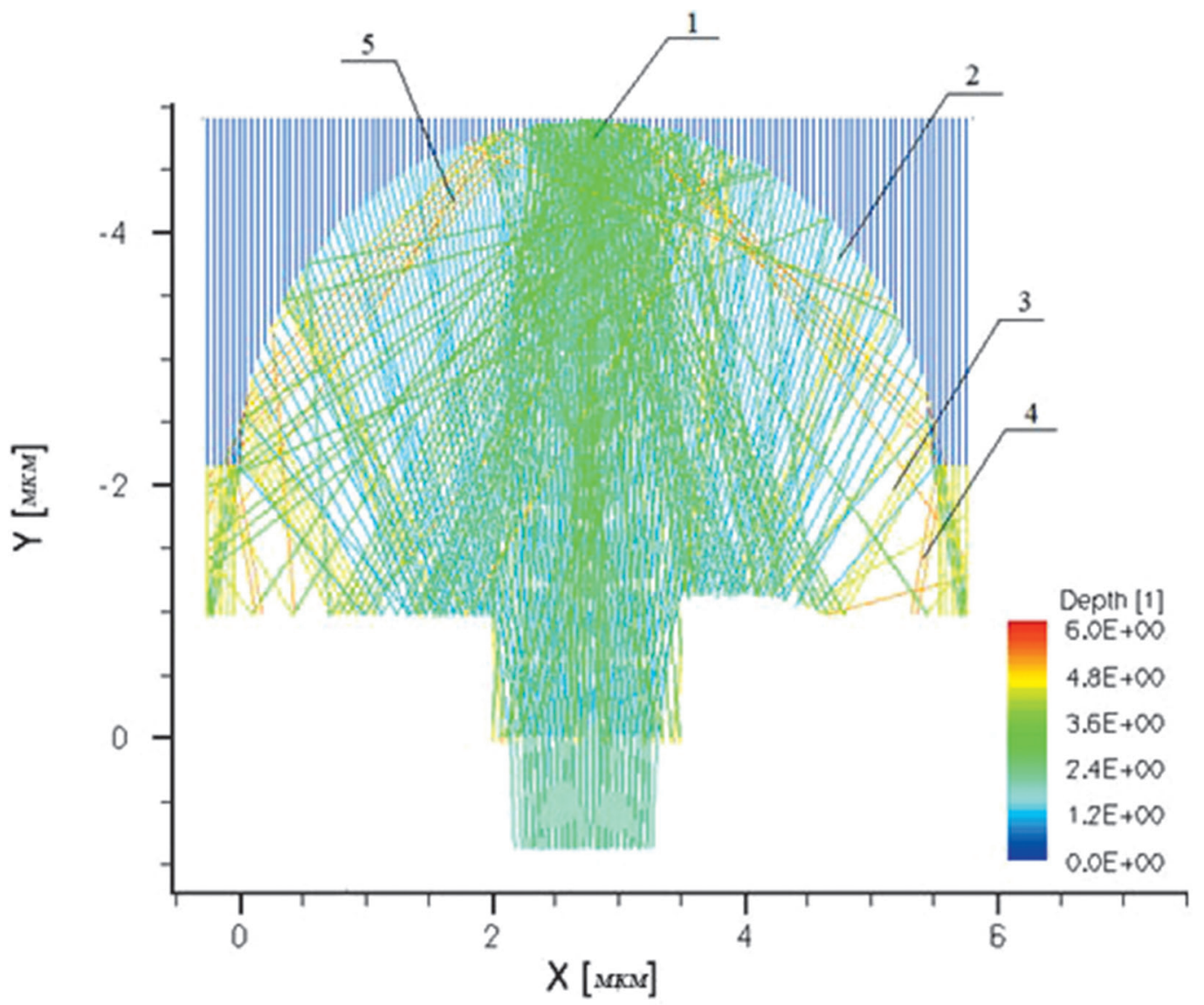

Puc. 5

Распределение лучей светового потока: 1 - начальная траектория светового потока (исходный луч); 2 - одно отражение луча; 3 - два отражения луча; 4 - три отражения луча; 5 - четыре отражения луча 
Рис. 5 демонстрирует направления лучей света в микролинзе. На рисунке можно увидеть, как преломляются и отражаются лучи светового потока (до заданного минимального значения интенсивности). Если значительная часть лучей отражается множество раз, прежде чем попасть в фотодиод, то такая линза имеет неподходящие параметры и, следовательно, недостаточную эффективность.

\section{Примеры результатов моделирования}

На рис. 6-9 приведены примеры полученных оценок конструкций ячеек с микролинзами, демонстрирующие возможности метода.

На рис. 6 даны распределения скорости фотогенерации для линзы радиусом 2,75 мкм и постаментом толщиной 1 мкм. Данная линза показала наилучший коэффициент усиления среди всех рассмотренных вариантов, равный 1,7.

На рис. 7 дана зависимость отношения интеграла скорости фотогенерации в

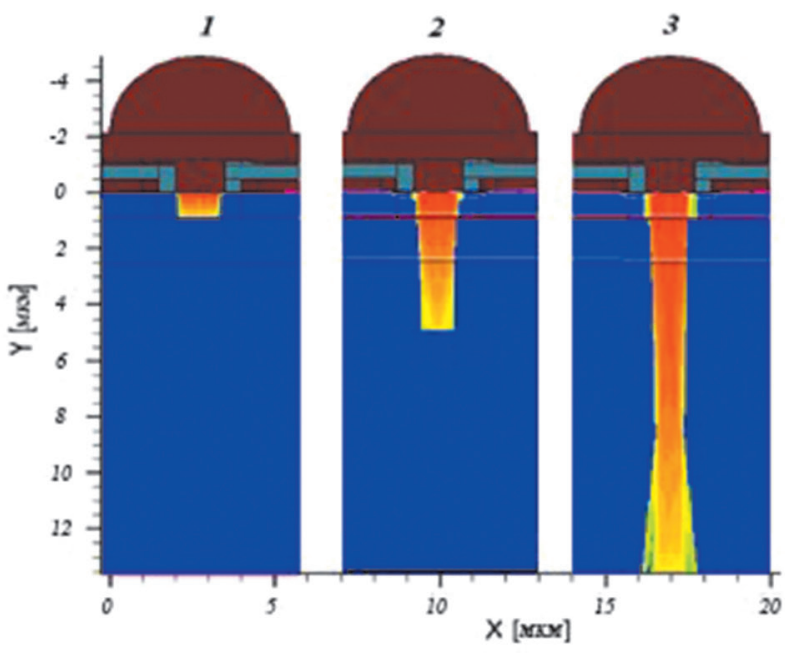

Puc. 6

Распределение скорости фотогенерачии для линзы с максимальным коэффичиентом усиления: 1 - длина волны 450 нм, 2 - длина волны 555 нм, 3 - длина волны 700 нм

области сбора фотодиода при заданном угле падения света к интегралу скорости генерации при перпендикулярном падении света на поверхность ячейки для наилучшей микролинзы. Данное отношение показывает угловую эффективность сбора носителей в ячейку.

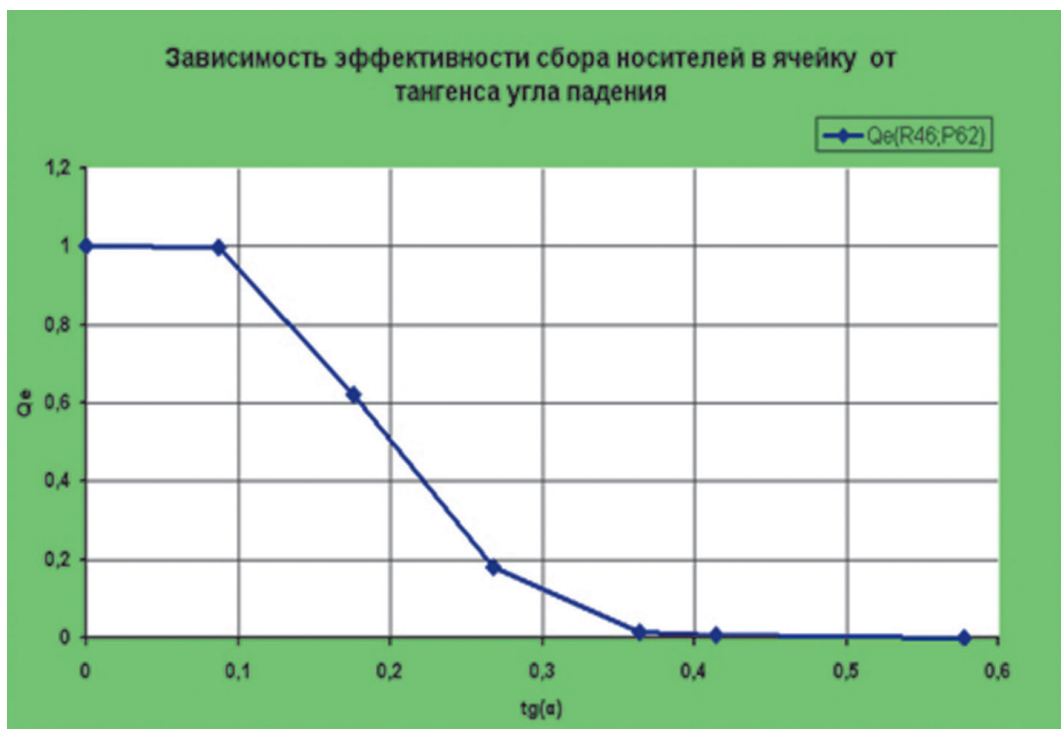

Puc. 7

Зависимость интеграла скорости фотогенерации в области сбора фотодиода от угла падения пучка света для наилучшей линзы 


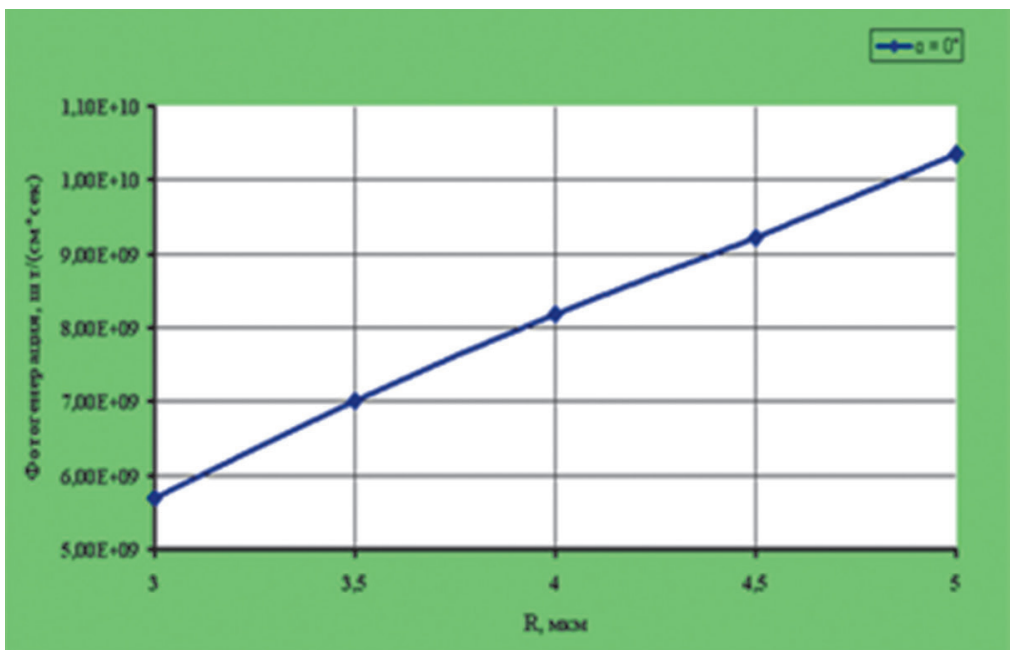

Puc. 8

Зависимость интеграла скорости фотогенеращии от радиуса микролинзы при угле падения светового потока 90 градусов

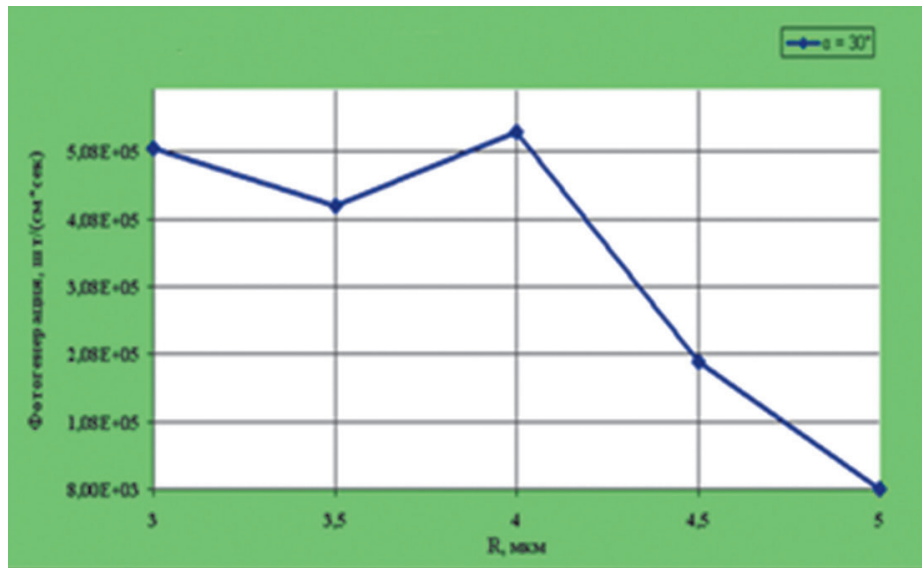

Puc. 9

Зависимость интеграла скорости фотогенерачии от радиуса микролинзы при угле падения светового потока 30 градусов

На рис. 8 дана зависимость интеграла скорости фотогенерации в области сбора фотодиода от радиуса линзы при угле падения светового потока 90 градусов, а на рис. 9 - для предельного для ПЗС угла падения 30 градусов.
В таблице приведены коэффициенты усиления линз с различными радиусами $R$ и толщинами постаментов $P$. Результаты таблицы наглядно демонстрируют, что коэффициент усиления изменяется в достаточно узких пределах.

\section{Таблица}

Сравнение коэффициента усиления $K$ микролинз с различной геометрией

\begin{tabular}{|l|l|l|l|}
\hline Длина волны & $\begin{array}{l}R=2,75 \text { мкм } \\
P=1 \text { мкм }\end{array}$ & $\begin{array}{l}R=3,0 \text { мкм } \\
P=1,5 \text { мкм }\end{array}$ & $\begin{array}{l}R=3,5 \text { мкм } \\
P=1,5 \text { мкм }\end{array}$ \\
\hline$\lambda=450$ нм & $K=1,75$ & $K=1,56$ & $K=1,29$ \\
\hline$\lambda=555$ нм & $K=1,72$ & $K=1,57$ & $K=1,30$ \\
\hline$\lambda=700$ нм & $K=1,73$ & $K=1,57$ & $K=1,30$ \\
\hline
\end{tabular}


Тем не менее повышение фоточувствительности ячейки более чем в 1,5 раза является очень хорошим показателем для данной характеристики.

\section{Заключение}

Разработанный метод приборно-технологического моделирования эффективности микролинз фоточувствительных ПЗС-ячеек в среде Sentaurus TCAD (Synopsys) позволяет подобрать основные параметры микролинзы по критерию максимизации её фоточувствительности. Получены зависимости коэффициента усиления линзы от геометрических параметров микролинзы, которые позволяют повысить фоточувствительность ПЗС-ячеек.

Метод обладает высокой производительностью и нацелен на применение в процессе проектирования фоточувствительных ПЗС и КМОП-фотодиодных СБИС.

\section{Благодарности}

Авторы выражают благодарность магистранту МИЭМ НИУ ВШЭ Морозовой Екатерине Игоревне за скрупулёзную отработку методики моделирования и многочисленные результаты расчётов, способствовавшие её дальнейшему совершенствованию.

\section{Лumepamypa}

1. Haekwan Oh, Geunyoung Kim, Hyunwoo Seo, Yotak Song, Keekeun Lee, Sang Sik Yang Fabrication of micro-lens array using quartz wet etching and polymer. Sensors and Actuators A: Physical, 2010, vol.164, pp. 161-167.

2. Ph Nussbaumyx, R Völkely, H P Herzigy, M Eisnerz and S Haselbeckz Design, fabrication and testing of microlens arrays for sensors and microsystems. Pure Applied Opt. 6 (1997), pp.617-636.

3. T. O. Körner, R. Gull Combined optical/electrical simulation of CCD cell structures by means of the finite-difference time-domain method. IEEE
Transactions on Electron Devices, 2000, vol. 47, issue. 5, pp. 931-938.

4. T. Satoh et al. Optical limitations to cell size reduction in it-ccd image sensors. IEEE Transaction Electron Devices, 1997, vol. 44, pp. 1599-1603.

5. H. Mutoh Simulation for 3-D optical and electrical analysis of CCD. IEEE Transaction Electron Devices, 1997, vol. 44, pp. 1604-1610.

6. Sentaurus TCAD. Industry-standard process and device simulators. [Электронный pecypc]. URL:https://www.google.ru/url?sa $=$ t\&rct $=j \& q=\&$ esrc $=\mathrm{s} \&$ source $=$ web\& $\mathrm{cd}=\& \mathrm{ved}=2$ ahUKEwiL $-\mathrm{dr} 5$ zYPqAhUeAhAIHXUeB9QQFjAAegQIARAB\&u $\mathrm{rl}=\mathrm{https} \% 3 \mathrm{~A} \% 2 \mathrm{~F} \% 2 \mathrm{Fwww}$.synopsys.com $\% 2 \mathrm{Fcon}$ tent $\% 2$ Fdam $\% 2$ Fsynopsys $\% 2$ Fsilicon $\% 2$ Fdatashe ets $\% 2$ Fsentaurus_ds.pdf\&usg=AOvVaw14aNGDc mgKndduxcjAR05v

\section{References}

1. Oh Haekwan, Kim Geunyoung, Seo Hyunwoo, Song Yotak, Lee Keekeun, Yang Sang Sik. Fabrication of microlens array using quartz wet etching and polymer. Sensors and Actuators A: Physical, 2010, vol.164, pp. 161-167.

2. Nussbaumyx Ph., Völkely R., Herzigy H. P., Eisnerz M., Haselbeckz S. Design, fabrication and testing of microlens arrays for sensors and microsystems. Pure Applied Opt. 6 (1997), pp. 617-636.

3. Körner T. O., Gull R. Combined optical/electrical simulation of CCD cell structures by means of the finite-difference time-domain method. IEEE Transactions on Electron Devices, 2000, vol. 47, iss. 5, pp. 931-938.

4. Satoh T. et al. Optical limitations to cell size reduction in it-CCD image sensors. IEEE Transaction Electron Devices, 1997, vol. 44, pp. 1599-1603.

5. Mutoh H. Simulation for 3-D optical and electrical analysis of CCD. IEEE Transaction Electron Devices, 1997, vol. 44, pp. 1604-1610.

6. Sentaurus TCAD. Industry-standard process and device simulators, available at: https://www.google. ru/url? sa $=t \& r c t=j \& q=\&$ esrc $=s \&$ source $=$ web $\& c d=$ \&ved=2ahUKEwiL-dr5zYPqAhUeAhAIHXUeB 9QQFjAAegQIARAB\&url=https $\% 3 \mathrm{~A} \% 2 \mathrm{~F} \% 2 \mathrm{Fw}$ ww.synopsys.com $\% 2 \mathrm{~F}$ content $\% 2 \mathrm{Fdam} \% 2 \mathrm{Fsynops}$ ys $\% 2$ Fsilicon $\% 2$ Fdatasheets $\% 2$ Fsentaurus_ds.pdf \&usg=AOvVaw14aNGDcmgKndduxcjAR05v 


\title{
УДК 621.3.049.77 \\ DOI: 10.36845/2073-8250-2020-257-2-37-46 \\ ИССЛЕДОВАНИЕ ВЛИЯНИЯ ЭЛЕКТРОФИЗИЧЕСКИХ ХАРАКТЕРИСТИК НА ПАРАМЕТРЫ КОМПАКТНЫХ МОДЕЛЕЙ КОМПОНЕНТОВ СВЕРХВЫСОКОЧАСТОТНЫХ МОНОЛИТНЫХ ИНТЕГРАЛЬНЫХ СХЕМ
}

\begin{abstract}
А.А. Попов, Д.В. Билевич, А.С. Сальников, А.А. Калентьев
Томский государственный университет систем управления и радиоэлектроники (ТУСУР) 634050, г. Томск, пр-кт Ленина, д. 40

В работе представлены результаты исследования влияния параметров технологических материалов на значения элементов эквивалентных схем пассивных и активных компонентов СВЧ монолитных интегральных схем. Получены зависимости элементов эквивалентной схемы МДМ конденсатора и катушки индуктивности, установлено, что наибольшее влияние на параметры ЭС моделей пассивных компонентов имеет толщина подложки. Представлены результаты исследования влияния длины затвора и глубины подзатворного рецесса на параметры малосигнальной модели полевого транзистора с затвором Шоттки. Для исследованных зависимостей получены одномерные модели, описывающие полученные зависимости.
\end{abstract}

Ключевые слова: электромагнитное моделирование, приборно-технологическое моделирование, виртуальная метрология, СВЧ монолитные интегральные схемы

\section{Сведения об авторах:}

Попов Артем Александрович, ORCID:0000-0001-6010-4459, artem.a.popov@tusur.ru; Билевич Дмитрий Вячеславович, ORCID:0000-0001-7421-7403,dmitrii.v.bilevich@tusur.ru; Сальников Андрей Сергеевич, к.т.н., ORCID:0000-0002-5827-9556, andrei.salnikov@main.tusur.ru; Калентьев Алексей Анатольевич, к.т.н., ORCID:0000-0001-7829-5345,aleksei.a.kalentev@tusur.ru

\section{STUDY ON THE INFLUENCE OF ELECTROPHYSICAL CHARACTERISTICS ON THE PARAMETERS OF COMPACT MODELS OF THE COMPONENTS USED IN RADIO FREQUENCY MONOLITHIC INTEGRATED CIRCUITS}

\author{
A.A. Popov, D.V. Bilevich, A.S. Salnikov, A.A. Kalentyev \\ Tomsk State University of Control Systems and Radioelectronics (TUSUR) \\ Russia, 634050, Tomsk, Lenina prosp., 40
}

In this paper we demonstrate the results of the study on how the geometric parameters effect the model parameters of passive and active components. As we found out, the substrate thickness has the greatest influence on the equivalent circuit model parameters of passive components. Paper demonstrates the influence of the gate length and the gate recess depth on the parameters of small-signal model of the MESFET. The obtained dependences are presented for the MIM capacitor model, inductor model and GaAs MESFET model.

Keywords: semiconductor device simulation, virtual metrology, microwave monolithic integrated circuit

Data of authors: Artem Aleksandrovich Popov, artem.a.popov@tusur.ru; Dmitry Vyacheslavovich Bilevich,dmitrii.v.bilevich@tusur.ru; AndreySergeevich Salnikov,Ph.D., andrei.salnikov@main.tusur.ru; Aleksey Anatolyevich Kalentyev, Ph.D., aleksei.a.kalentev@tusur.ru 


\section{Введение}

Современный подход к изготовлению полупроводниковых монолитных интегральных микросхем (МИС) позволяет изготавливать в едином технологическом процессе большое количество микросхем одного типа. Однако практически невозможно обеспечить протекание операционных технологических процессов равномерно по всей пластине $[1,2]$. При изготовлении интегральных схем присутствуют отклонения параметров технологического процесса, таких как плотность ионного пучка, температура разгонки примеси, абберация оптической системы и т. п. Описанные флуктуации приводят к тому, что геометрические размеры и параметры материалов получаемых структур варьируются в некотором диапазоне, что в свою очередь влияет на характеристики компонентов СВЧ МИС. Это влияние можно обнаружить и в значениях параметров компактных моделей, которые строятся на основе характеристик компонентов. Это даёт возможность получить выражения, связывающие параметры технологии и моделей элементов, изготовленных по этой технологии с помощью выражений, с меньшей вычислительной сложностью в сравнении с физико-технологическим моделированием.

Данный подход имеет сходные черты с подходом виртуальной метрологии - предсказание результата технологических операций по данным, получаемым с датчиков оборудования [3]. Однако в данной работе исследуется зависимость параметров элементов эквивалентных схем (ЭС), имеющих физический смысл, от параметров материалов и геометрии элементов СВЧ МИС. Данные зависимости анализировались для МДМ конденсатора, катушки индуктивности и полевого транзистора с барьером Шоттки (ПТШ). Для ПТШ исследовалось влияние длины затвора на параметры модели; из литературы известно, что уменьшение длины затвора повышает предельные частоты прибора [4], однако повышение это ограничивается короткоканальными эффектами $[5,6]$. Также известно, что для кремниевых МОП транзисторов технологические или электрофизические параметры могут быть включены в компактную SPICE-модель [7, 8].

В настоящей работе исследовались зависимости элементов эквивалентной схемы компонентов СВЧ МИС от параметров материалов и геометрии. В качестве варьируемых параметров, которые определяются технологией и влияют на параметры моделей, выбраны следующие: толщина подложки, диэлектрическая проницаемость подложки, толщина металлизации, ширина проводящих линий, ширина и положение затвора транзистора. Рассмотрены МДМ конденсатор, спиральная катушка индуктивности, ПТШ на GaAs подложке. Для получения характеристик элементов использовалось электромагнитное и физико-технологическое моделирование. Для описания полученных зависимостей использовались одномерные модели.

\section{Пассивные компоненты СВЧ МИС}

Расчёт характеристик пассивных компонентов СВЧ МИС (МДМ конденсатора и катушки индуктивности) при варьировании параметров материалов и геометрии проводился с использованием электромагнитного моделирования. При моделировании в качестве типовых параметров GaAs подложки были заданы толщина 100 мкм, диэлектрическая проницаемость подложки - 12,9, тангенс угла диэлектрических 
потерь - 0,001. В качестве диэлектрика для МДМ конденсатора был задан слой $\mathrm{Si}_{3} \mathrm{~N}_{4}$ с диэлектрической проницаемостью 5,9 и толщиной 0,15 мкм. Верхняя обкладка конденсатора имела квадратную форму со стороной 40 мкм. Толщина металлизации верхней обкладки конденсатора и спирали катушки индуктивности была выбрана 2 мкм, толщина нижней обкладки и контактной линии спирали - 1 мкм.

При исследовании влияния геометрических параметров на параметры модели конденсатора варьировались толщина подложки, диэлектрическая проницаемость подложки и высота верхней обкладки конденсатора. Построение модели конденсатора проводилось по методике, описанной в [9]. Эквивалентная схема конденсатора представлена на рис. 1.

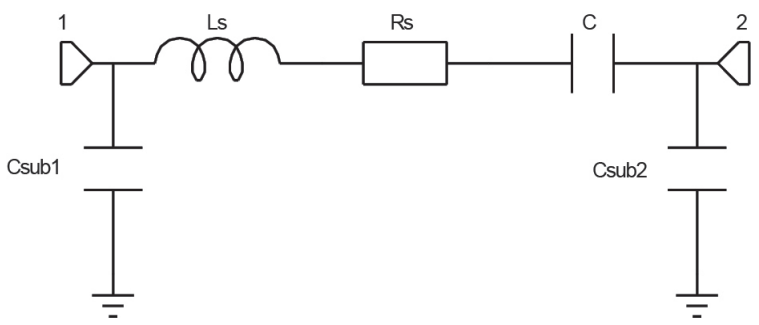

Puc. 1

Эквивалентная схема модели конденсатора

Номинальные значения параметров получены при толщине подложки 100 мкм. В исследованном диапазоне значения параметров отклоняются от номинального значения $L_{s}-$ не более $20 \%, C_{s u b 1}-$ не более $5 \%$ и $C_{\text {sub } 2}-$ не более $20 \%$. Из этого заключаем, что толщина подложки слабо влияет на данные параметры. На рис. 2 показаны значения элементов ЭС $C_{s u b 1}$ и $C_{s u b 2}$, а также для сравнения расчётная ёмкость отрезка МПЛ, имеющего размеры, совпадающие с размерами обкладки конденсатора [10]. Полученные характеристики имеют

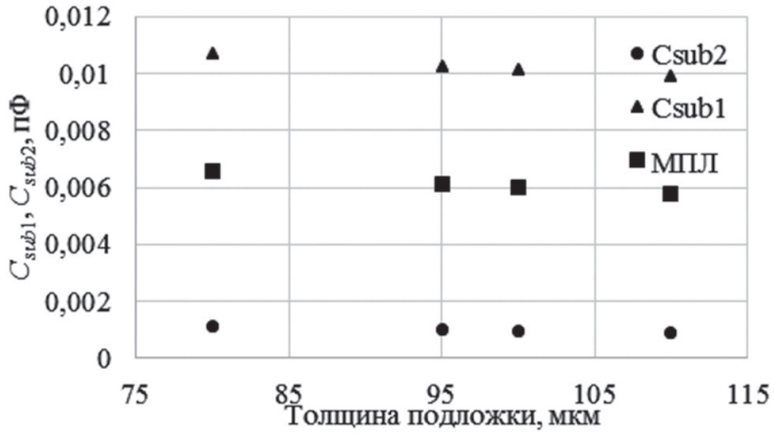

Puc. 2

Зависимость значений элементов ЭС модели конденсатора от толщины подложки

схожий характер зависимости, а значения имеют один порядок.

Качественно полученная теоретическая зависимость совпадает с зависимостью значений элементов от толщины подложки. Однако помимо эффектов, возникающих в МПЛ, наблюдаются посторонние эффекты, влияющие на значение элементов ЭС модели конденсатора, из-за чего наблюдается различие в значении ёмкости для МПЛ и для модели конденсатора.

Также исследования показали, что изменение толщины металлизации верхней обкладки слабо влияет на параметры модели конденсатора. Параметры полученных моделей представлены в табл. 1.

Из данных, приведённых в табл. 1, видно, что даже при увеличении толщины металлизации в 2,5 раза значения элементов остаются неизменными, кроме сопротивления $R_{s}$. Таким образом, можно заключить, что толщина металлизации слабо влияет на характеристики МДМ конденсатора. Слабая зависимость сопротивления от толщины объясняется, по-видимому, скин-эффектом, из-за которого эффективное сечение проводника приблизительно одинаково при толщинах больших скинслоя. Например, на частоте 1 ГГц для золота толщина скин-слоя равна 2,4 мкм. 
Значения элементов ЭС модели конденсатора

\begin{tabular}{|l|c|c|c|c|}
\hline $\begin{array}{l}\text { Толщина металлизации } \\
\text { верхней обкладки, мкм }\end{array}$ & 2 & 3 & 4 & 5 \\
\hline$L_{s}$, нГ & 0,053 & 0,052 & 0,052 & 0,051 \\
\hline$R_{s}$, Ом & 0,202 & 0,129 & 0,125 & 0,124 \\
\hline$C$, $Ф$ & 0,53 & 0,53 & 0,53 & 0,53 \\
\hline$C_{s u b 1}$, пФ & 0,01 & 0,01 & 0,01 & 0,01 \\
\hline$C_{s u b 2}$, пФ & 0,001 & 0,0011 & 0,0011 & 0,0012 \\
\hline
\end{tabular}

На следующем этапе проводилось исследование спиральной катушки индуктивности с шириной спирали 10 мкм, числом витков 2,5 и расстоянием между витками 10 мкм. Эквивалентная схема катушки представлена на рис. 3, для построения модели использовалась методика, описанная в [9].

В случае с катушкой индуктивности исследовалась взаимосвязь между параметрами модели и такими параметрами, как толщина подложки, диэлектрическая проницаемость подложки, толщина металлизации и ширина спирали. В ходе исследования было обнаружено, что каждый из геометрических параметров влияет на определённую группу параметров модели.

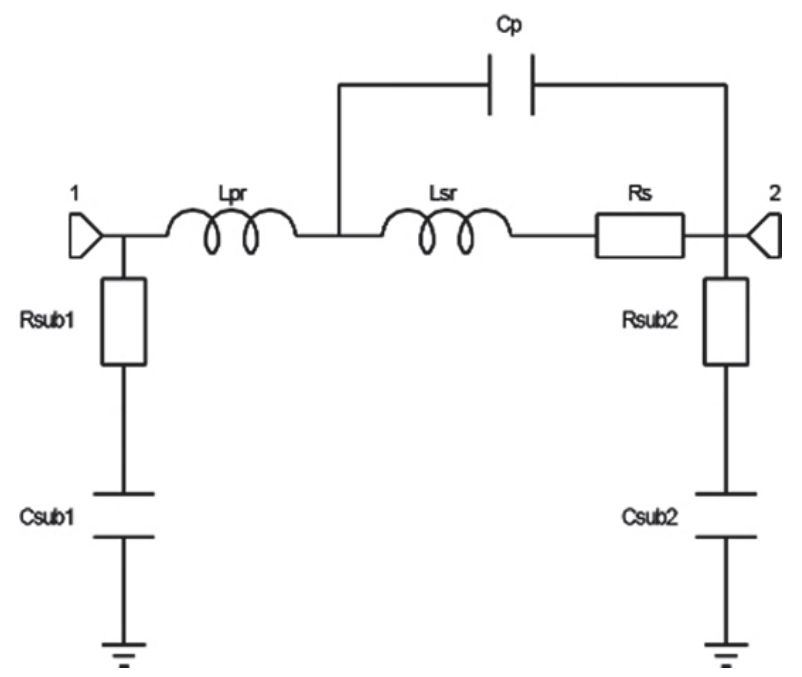

Puc. 3

Эквивалентная схема модели спиральной катушки индуктивности
Стоит отметить, что толщина подложки имеет взаимосвязь со всеми параметрами модели. Наибольшая зависимость от толщины подложки наблюдается на элементах $R_{\text {sub } 1 \text { и }} R_{\text {sub } 2}$ (рис. 4).

Из рис. 4 видно, что влияние толщины подложки на параметры модели катушки имеет линейный вид. Полученные уравнения, описывающие данные зависимости, имеют следующий вид:

$$
\begin{aligned}
& R_{\text {sub } 1}=0,079 h-3,7 ; \\
& R_{\text {sub } 2}=0,17 h-12,07,
\end{aligned}
$$

где $h$ - толщина подложки, мкм.

Коэффициент детерминации составил 0,95 и 0,97 для $R_{\text {sub } 1}$ и $R_{\text {sub2 } 2 \text { соответствен- }}$ но. При изменении толщины подложки на $\pm 20 \%$ наблюдается изменение значения па-

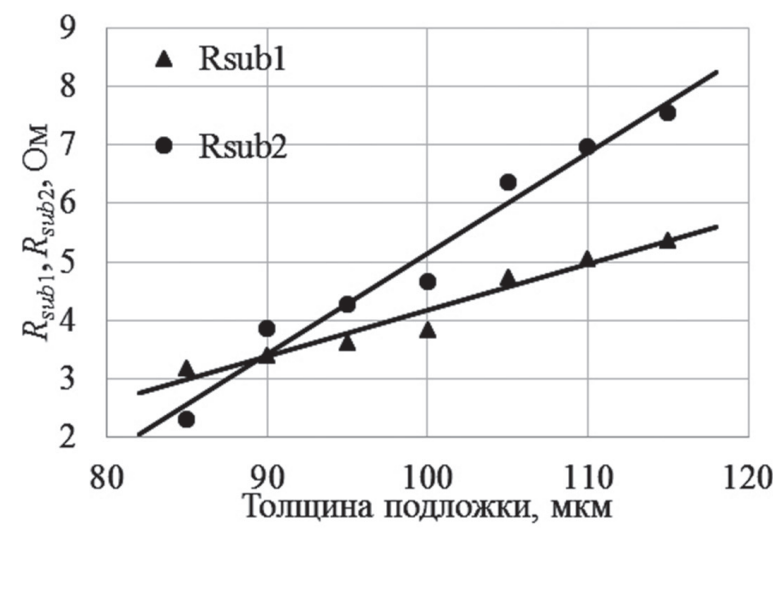

Puc. 4

Зависимость значений элементов ЭС модели катушки от толщины подложки 


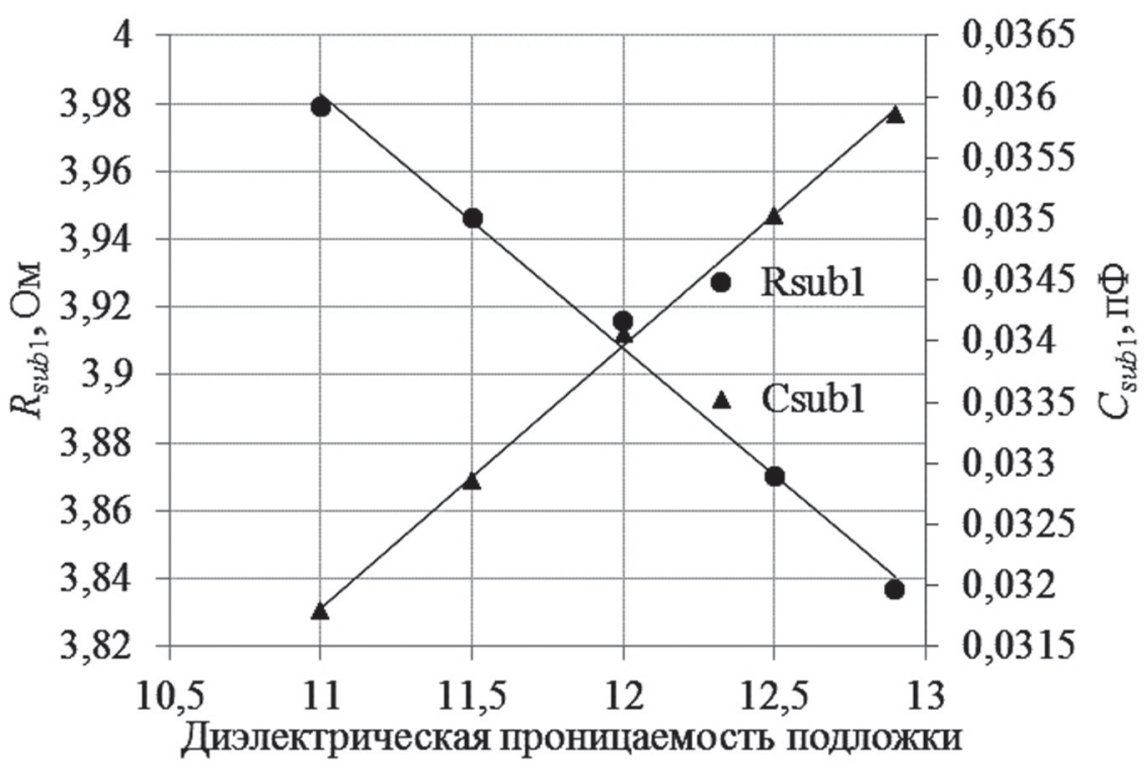

Puc. 5

Зависимость значений элементов ЭС модели катушки от диэлектрической проницаемости подложки

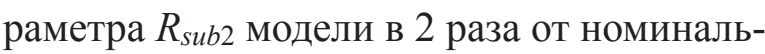
ного значения и в 1,5 раза для параметра $R_{s u b 1}$, полученных при толщине подложки 100 мкм.

Влияние значения диэлектрической проницаемости наблюдается только для элементов $R_{s u b 1}, R_{s u b 2}, C_{s u b 1}$ и $C_{s u b 2}$. Значительное влияние наблюдается для параметров $R_{s u b 1}$ и $C_{s u b 1}$ (рис. 5).

Полученные зависимости имеют линейный вид, уравнения, описывающие дан- ную зависимость, имеют следующий вид:

$$
\begin{aligned}
& C_{s u b 1}(\Pi \Phi)=0,002 \varepsilon+0,008 ; \\
& R_{s u b 1}=-0,075 \varepsilon+4,8,
\end{aligned}
$$

где $\varepsilon$ - диэлектрическая проницаемость подложки.

Коэффициент детерминации равен 0,99 в обоих случаях. Результаты численного эксперимента по изменению толщины металлизации и ширины спирали представлены в табл. 2, 3 .

Таблица 2

\begin{tabular}{|c|c|c|c|c|c|}
\hline Толщина металлизации, мкм & 2 & 3 & 4 & 5 & 6 \\
\hline$L_{p r}, \mathrm{H} \Gamma$ & 0,34 & 0,38 & 0,40 & 0,41 & 0,42 \\
\hline$L_{s r}, \mathrm{H} \Gamma$ & 0,77 & 0,70 & 0,66 & 0,63 & 0,61 \\
\hline$R_{S}, \mathrm{OM}_{\mathrm{M}}$ & 1,87 & 1,58 & 1,46 & 1,42 & 1,38 \\
\hline$C_{p}, \phi \Phi$ & 0,41 & 0,34 & 0,14 & 0,14 & 0,26 \\
\hline$C_{s u b 1}, \phi \Phi$ & 35,86 & 36,86 & 37,97 & 38,32 & 38,56 \\
\hline$C_{s u b 2, \phi \Phi}$ & 31,04 & 32,19 & 33,32 & 36,03 & 36,37 \\
\hline$R_{s u b 1}, \mathrm{OM}_{1}$ & 3,84 & 3,96 & 4 & 3,92 & 3,95 \\
\hline$R_{\text {sub } 2, \mathrm{OM}}$ & 4,662 & 4,57 & 4,57 & 2,67 & 2,63 \\
\hline
\end{tabular}

Значения элементов ЭС модели катушки в зависимости от толщины металлизации 


\section{Значения элементов ЭС модели катушки} в зависимости от ширины спирали

\begin{tabular}{|l|c|c|c|}
\hline Ширина спирали, мкм & 2 & 3 & 4 \\
\hline$L_{p r}, \mathrm{н} \Gamma$ & 0,34 & 0,34 & 0,34 \\
\hline$L_{s r}, \mathrm{H} \Gamma$ & 0,77 & 0,75 & 0,73 \\
\hline$R_{s}$, Ом & 1,87 & 1,79 & 1,74 \\
\hline$C_{p}, \phi \Phi$ & 0,41 & 1,56 & 2,83 \\
\hline$C_{\text {sub } 1, \phi \Phi}, \phi$ & 36 & 37 & 37 \\
\hline$C_{\text {sub } 2, \phi \Phi}, \mathrm{OM}$ & 31 & 31 & 33 \\
\hline$R_{\text {sub } 1}, \mathrm{OM}$ & 3,84 & 3,7 & 3,64 \\
\hline$R_{\text {sub } 2, \mathrm{OM}}$ & 4,66 & 4,77 & 3,78 \\
\hline
\end{tabular}

Анализируя полученные зависимости, можно заметить, что взаимосвязь между геометрическими параметрами и параметрами модели для катушки индуктивности имеет более выраженный характер, чем для МДМ конденсатора.

\section{GaAs полевой транзистор с барьером Шоттки}

Также исследовалась взаимосвязь геометрических параметров GaAs ПТШ и параметров эквивалентной схемы малосигнальной модели транзистора. Для получения параметров транзистора с разными значениями геометрических характеристик использовалось приборно-технологическое моделирование. Данный подход позволяет за короткое время получить большую выборку, при этом параметры будут хорошо контролируемы в широких пределах номинальных значений.

Моделируемый технологический процесс ПТШ включал следующие этапы: ионную имплантацию примеси в подложку для создания первоначальной примеси в подложке, имплантацию примеси для создания канала $n$-типа, осаждение затвоpa, осаждение ионов кремния для создания высоколегированных $n+$-контактных обла- стей стока и истока и осаждение контактов стока и истока. В качестве первоначальной примеси в подложке использовались ионы бериллия. Канал $n$-типа был создан на глубине 0,3 мкм при помощи имплантации ионов кремния в структуру. Для обеспечения коэффициента усиления полученного транзистора на уровне 17 дБ на частоте 2 ГГц общая ширина затвора была задана 600 мкм, длина затвора 1 мкм. Полученная структура ПТШ представлена на рис. 6 .

Для описания полученной структуры транзистора использовалась упрощённая эквивалентная схема малосигнальной модели, представленная в [11]. Упрощение

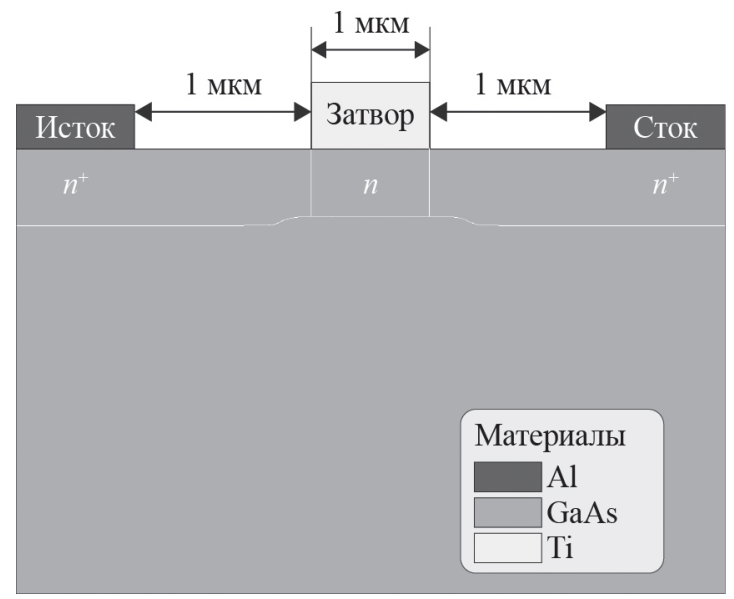

Puc. 6

Структура моделируемого ПТШ 
состоит в том, что из описанной схемы были удалены внешние элементы. Удалённые из схемы элементы описывают паразитное влияние контактных площадок и подводящих линий, которые отсутствуют в численном эксперименте. Для получения $S$-параметров проводилось моделирование в режиме малого сигнала в диапазоне частот от 0,01 до 12 ГГц в рабочей точке $U_{\mathrm{Cи}}=3 \mathrm{~B}, U_{3 и}=-0,2 \mathrm{~B}$. Верхняя частота для численного эксперимента определяется граничной частотой моделируемого прибора. Упрощённая эквивалентная схема малосигнальной модели транзистора представлена на рис. 7.

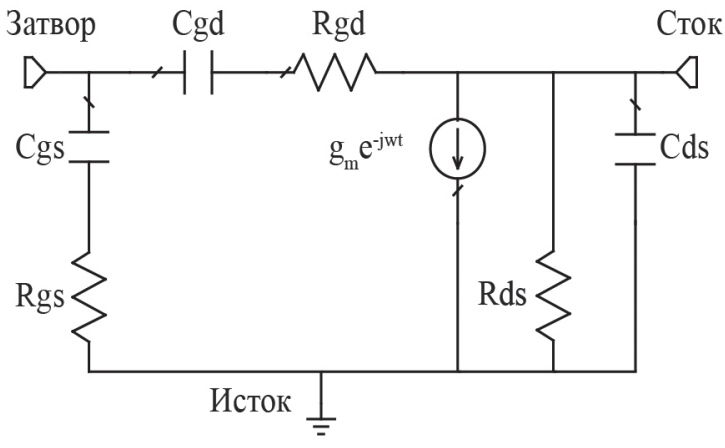

Puc. 7

Эквивалентная схема полевого транзистора с затвором Шоттки в условиях малого сигнала
Экстракция модели проводилась по методике, описанной в [12]. Полученная модель для начальной структуры практически идеально описывает технологическую модель. Сравнение результатов приборно-технологического моделирования (измерения) и моделирования ЭС (модель) представлено на рис. 8. Общая ошибка моделирования $S$-параметров не превысила $1 \%$, что позволяет сделать вывод о применимости используемой ЭС для описания характеристик, полученных при помощи приборно-технологического моделирования.

На первом этапе проводилось исследование влияния длины затвора на параметры модели транзистора. Диапазон изменения значения длины затвора был задан от 0,15 до 3 мкм, при этом расстояние между контактами затвор-сток и затвор-исток оставалось неизменным и было равно 1 мкм. Анализ малосигнальных моделей показал, что зависимости обоих параметров $C_{g d}$ и $C_{g s}$ имеют квадратичный вид. На рис. 9 показаны полученные зависимости параметров модели от длины затвора.

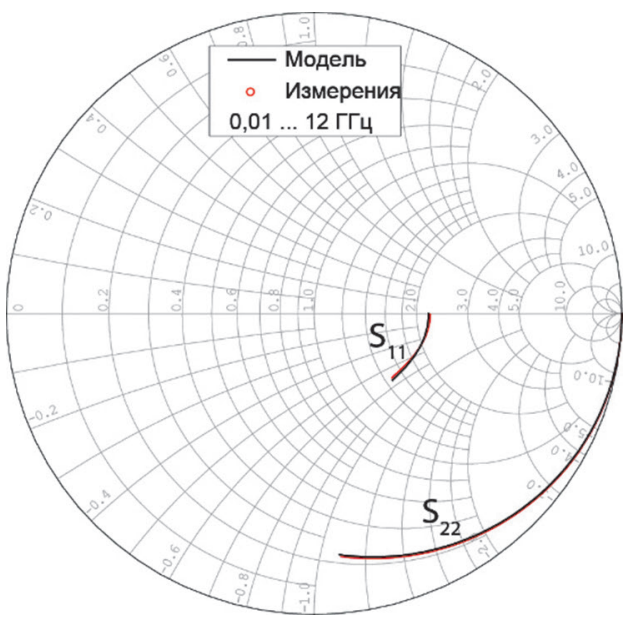

a)

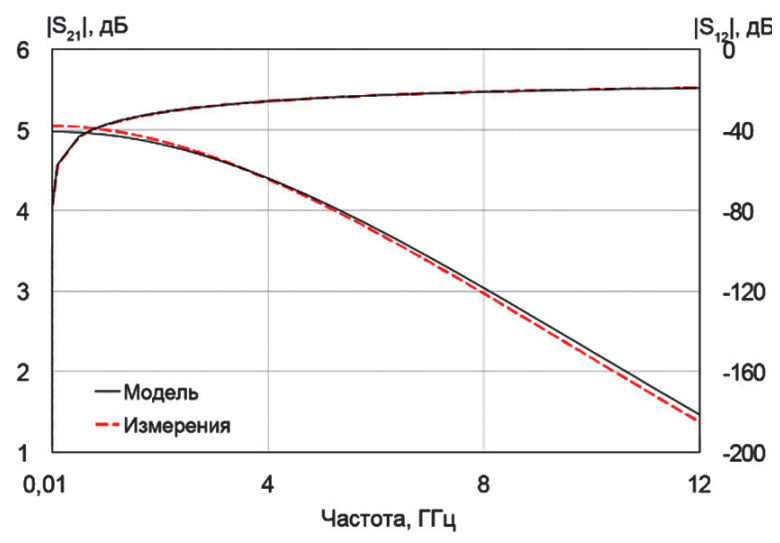

б)

Puc. 8

Результат моделирования S-параметров 


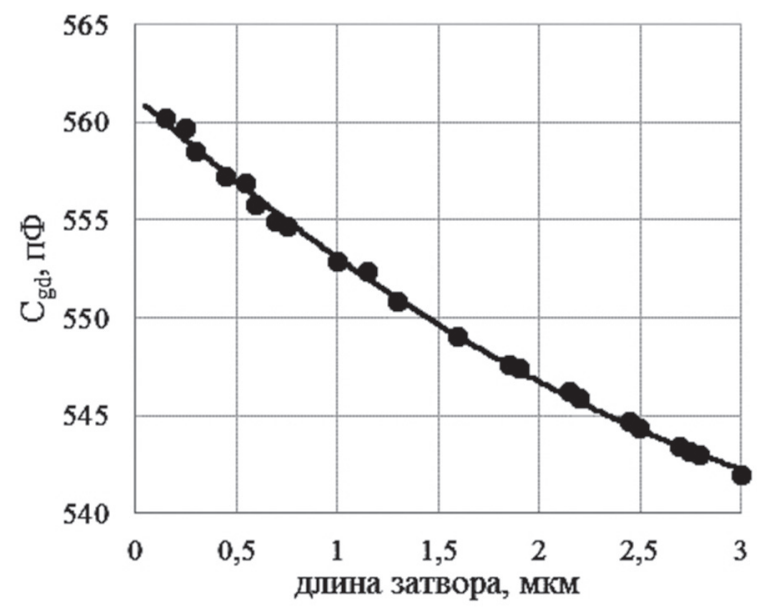

a)

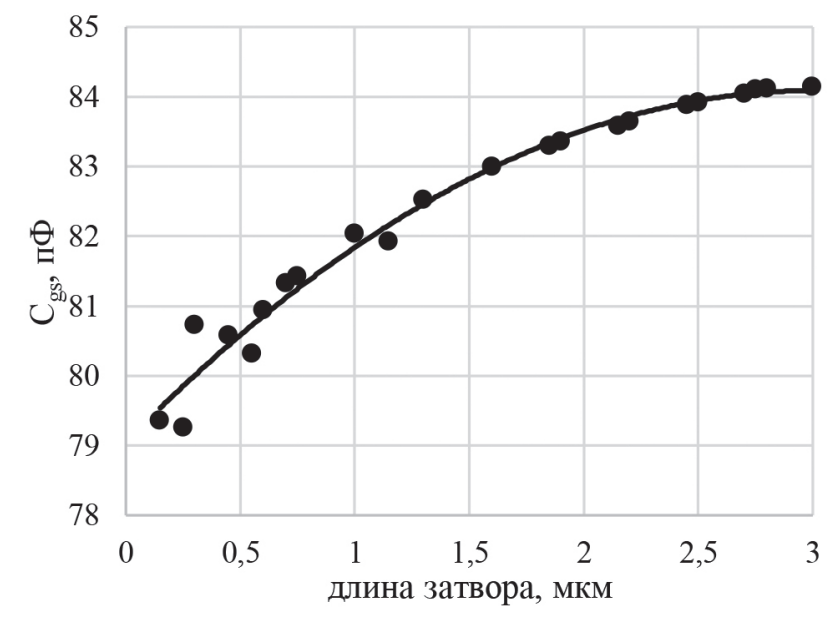

б)

Puc. 9

Зависимость значения элементов $C_{g d}\left(\right.$ a) $и C_{g s}$ (б) от длины затвора транзистора

Полученные уравнения, описывающие данные зависимости, имеют следующий вид: $\mathrm{C}_{g d}(\Pi \Phi)=0,94 L^{2}-9,15 L+561,3$; $C_{g s}(\Pi \Phi)=-0,56 L^{2}+3,35 L+79$, где $L$ - длина затвора, мкм.

Коэффициент детерминации равен 0,99 и 0,98 для $C_{g d}$ и $C_{g s}$ соответственно. Как можно заметить на рис. 9б, при низких значениях длины затвора наблюдается сильный разброс значения. При дальнейшем уменьшении длины затвора начнут действовать короткоканальные эффекты, для учёта которых необходимо будет усложнять приборно-технологическую модель, что может привести к изменению характера зависимости ёмкостей от длины затвора при малых значениях данной величины. Поэтому минимальное значение длины затвора в эксперименте составило 0,15 мкм.

На втором этапе проводилось исследование влияния глубины подзатворного рецесса на параметры модели транзистора. В рамках данного эксперимента значение глубины рецесса изменялось от 0 до 0,25 мкм с шагом 0,05 мкм. Результаты показали, что глубина рецесса влияет в большей степени на значение элемента
$C_{g s}$, которое изменяется от 84 до 531 пФ. При этом зависимость имеет нелинейный характер, как показано на рис. 10.

Данный характер зависимости приближен к экспоненциальной, уравнение, описывающее данную зависимость, имеет следующий вид:

$$
C_{g s}(\Pi \Phi)=452,7 \mathrm{e}^{-7,9 d},
$$

где $d$ - глубина подзатворного рецесса, мкм.

Коэффициент детерминации равен 0,89. Влияния геометрических параметров транзистора на остальные элементы схемы обнаружено не было.

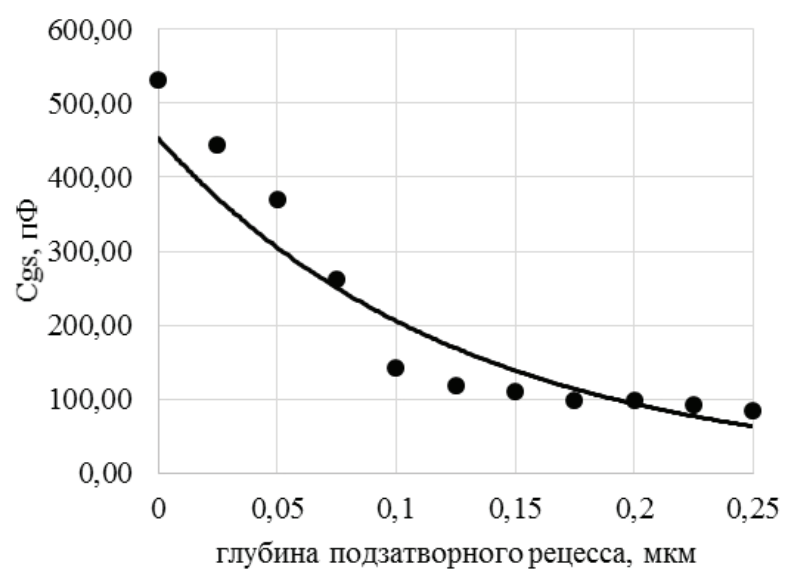

Puc. 10

Зависимость значения элемента $C_{g s}$ от глубины подзатворного рецесса 
Полученные результаты свидетельствуют о том, что исследуемые геометрические параметры влияют исключительно на значения ёмкостных параметров модели. Для каждой из найденных зависимостей были выведены уравнения, описывающие характер данных зависимостей.

\section{Выводы}

В ходе проведённых исследований было обнаружено, что зависимость между геометрическими параметрами пассивных компонентов и элементов ЭС моделей пассивных элементов выражена только в случае со спиральной катушкой индуктивности. Наибольшее влияние имеет толщина подложки, при изменении значения толщины подложки на 20 \% значение сопротивлений $R_{s u b 1}$ и $R_{s u b 2}$ изменяется от 3,18 до 5,37 Ом и от 2,3 до 7,56 Ом соответственно. В ходе исследований были построены одномерные модели, описывающие взаимосвязь между геометрическими параметрами и соответствующими параметрами модели. Данные модели представлены в виде уравнений и в дальнейшем будут использоваться для построения многомерной модели, позволяющей описывать значения параметров модели в зависимости от полученной геометрии.

Эксперименты, проводимые при помощи приборно-технологического моделирования, показали, что существует зависимость между длиной затвора ПТШ на основе GaAs и ёмкостями $C_{g d}$ и $C_{g s}$ ЭС малосигнальной модели транзистора, в то время как глубина подзатворного рецесса имеет значительное влияние на параметр $C_{g s}$, при этом вид зависимости приближён к экспоненциальному. В дальнейшем на основе полученных зависимостей планируется построение поведенческих регрес- сионных моделей. Такие модели позволят при проектировании учесть технологический разброс параметров компонентов СВЧ МИС.

Исследование выполнено при финансовой поддержке РФФИ в рамках научного проекта № 18-37-00293.

\section{Лumepamypa}

1. Nassif S.R. Modeling and analysis of manufacturing variations // Proc. Cust. Integr. Circuits Conf, 2001, pp. 223-228.

2. Multi-wafer virtual probe: Minimum-cost variation characterization by exploring wafer-to-wafer correlation / W. Zhang, X, Li, E. Acar, F. Liu, R. Rutenbar // IEEE ACM Int. Conf. Comput. Des. Dig. Tech. Pap. ICCAD, 2010, pp. 47-54.

3. A virtual metrology system for semiconductor manufacturing / P. Kang, H. Lee, S. Cho, D. Kim, J. Park, C. Park, S. Doh // Expert Syst. Appl. Elsevier Ltd, 2009, vol. 36, no. 10, pp. 12554-12561.

4. Nummila K., Delay time analysis for short gatelength GaAs MESFETs / K. Nummila, A.A. Ketterson, I. Adesida // Solid State Electron, 1995, vol. 38, no. 2, pp. 517-524.

5. Short-Channel Effects and Drain-Induced Barrier Lowering in Nano.meter-Scale GaAs MESFET's / A.A James, I.G. Thayne, C.D.W. Wilkinson, S.P. Beaumont, N.P. Johnson, A.H. Kean, C.R. Stanley // IEEE Trans. Electron Devices, 1993, vol. 40, no. 6, pp. 1047-1052.

6. Lakhdar N. Effect of gate engineering in submicron GaAs MESFET for microwave frequency applications / N. Lakhdar, B. Lakehal // J. Semicond, 2016, Vol. 37, no. 4.

7. Maiti C.K. Strain-engineered MOSFETs // C.K. Maiti, T.K. Maiti. - Boka-Raton: Taylor \& Francis Group, 2013, 288 p.

8. Langer U. Scientific computing in electrical engeneering / U. Langer, W. Amrhein, W. Zulehner// St. Wolfgang, Austria 2016, 263 p.

9. Добуш, И. М. Разработка методик и программ- 
ного обеспечения для автоматического построения моделей базовых элементов СВЧ монолитных интегральных схем / И. М. Добуш [и др.] // Наноиндустрия. - 2019. - № спецвыпуск. C. 453-462.

10. Saduki M. Approximate Formulas for the Capacitance of Microstrip Line / M. Saduki, S.M. Musa, S.R. Nelatury // Proceedings 2007 IEEE SoutheastCon, Richmond, VA, 2007, pp. 427-432.

11. Crupi G., On the small signal modeling of advanced microwave FETs: A comparative study / G. Crupi, D.M.M.P. Schreurs, A. Caddemi // Int. J. RF Microw. Comput. Eng, 2008, vol. 18, no. 5, pp. 417-425.

12. Jeon M. A Technique for Extracting Small-Signal Equivalent-Circuit Elements of HEMTs / M.Y. Jeon, B.G. Kim, Y.J. Jeon,Y.H. Jeong. // IEICE Trans. Electron, 1999, vol. E82-C, no. 11. pp. 1968-1976.

\section{References}

1. Nassif S. R. Modeling and analysis of manufacturing variations. Proc. Cust. Integr. Circuits Conf, 2001, pp. 223-228.

2. Zhang W. Li X., Acar E., Liu F., Rutenbar R. Multi-wafer virtual probe: Minimum-cost variation characterization by exploring wafer-to-wafer correlation. IEEE ACM Int. Conf. Comput. Des. Dig. Tech. Pap. ICCAD, 2010, pp. 47-54.

3. Kang P., Lee H., Cho S., Kim D., Park J., Park C., Doh S. A virtual metrology system for semiconductor manufacturing. Expert Syst. Appl. Elsevier Ltd, 2009, vol. 36, no. 10, pp. 12554-12561.

4. Nummila K., Ketterson A.A., Adesida I. Delay time analysis for short gate-length GaAs MESFETs. Solid State Electronics, 1995, vol. 38, no. 2, pp. 517-524.
5. James A.A, Thayne I.G., Wilkinson C.D.W., Beaumont S.P., Johnson N.P., Kean A.H., Stanley C.R. Short-Channel Effects and Drain-Induced Barrier Lowering in Nano.meter-Scale GaAs MESFET's. IEEE Trans. Electron Devices, 1993, vol. 40, no. 6, pp. 1047-1052.

6. Lakhdar N., Lakehal B. Effect of gate engineering in submicron GaAs MESFET for microwave frequency applications. J. Semiconductor, 2016, vol. 37 , no. 4 .

7. Maiti C.K., Maiti T.K. Strain-engineered MOSFETs. Boka-Raton: Taylor \& Francis Group, 2013, 288 p.

8. Langer U., Amrhein W., Zulehner W. Scientific computing in electrical engeneering. St. Wolfgang, Austria 2016, 263 p.

9. Dobush I. M. Razrabotka metodik i programmnogo obespecheniya dlya avtomaticheskogo postroeniya modelej bazovyh elementov SVCH monolitnyh integral'nyh skhem [Development of techniques and software for computer-assisted modeling of basic components of microwave monolithic integrated circuits]. Nanoindustry, 2019, no. special issue, pp. 453-462.

10. Saduki M., Musa S.M., Nelatury S.R. Approximate Formulas for the Capacitance of Microstrip Line. Proceedings 2007 IEEE SoutheastCon, Richmond, VA, 2007, pp. 427-432.

11. Crupi G., Schreurs D.M.M.P., Caddemi A. On the small signal modeling of advanced microwave FETs: A comparative study. Int. J. RF Microw. Comput. Eng, 2008, vol. 18, no. 5, pp. 417-425.

12. Jeon M.Y., Kim B.G., Jeon Y.J., Jeong Y.H. A Technique for Extracting Small-Signal EquivalentCircuit Elements of HEMTs. IEICE Trans. Electronics, 1999, vol. E82-C, no. 11. pp. 1968-1976. 


\title{
АНАЛИЗ БОЛЬШОГО МАССИВА РЕЗУЛЬТАТОВ ИСПЫТАНИЙ ИЗДЕЛИЙ ЭЛЕКТРОННОЙ ТЕХНИКИ НА ИМПУЛЬСНУЮ ЭЛЕКТРИЧЕ- СКУЮ ПРОЧНОСТЬ
}

\author{
Д. О. Ваничкин, И. Я. Гантман, А. В. Левко \\ АO «НПП «Пульсар», 105187, Москва, Окружной пр., 27
}

Проведён анализ большого массива экспериментальных данных, полученных испытательным иентром АO «НПП «Пульсар» в ходе испытаний изделий электронной техники на импульсную электрическую прочность, проведённых при выполнении опытно-конструкторских работ по заказу Минпромторга России. Результаты анализа скомпонованы и представлены в виде диаграмм, графиков и таблии с учётом методических основ испытаний, назначения и классификациионной группы испытываемых изделий, технологии их изготовления.

Ключевые слова: импульсная электрическая прочность, одиночный импульс напряжения, испытания изделий электронной техники

Сведения об авторах: Денис Олегович Ваничкин, vanichkin@pulsarnpp.ru; Илья Яковлевич Гантман; Алексей Владимирович Левко

\section{ANALYSIS OF THE LARGE ARRAY OF RESULTS OBTAINED DURING THE PULSED MODE DIELECTRIC BREAKDOWN TESTING OF ELECTRONIC DEVICES}

\author{
D.O. Vanichkin, I.Ya. Gantman, A.V. Levko \\ S\&PE Pulsar JSC, 105187, Moscow, Okruzhnoy pr., 27
}

In this paper we perform the analysis of the large array of experimental data obtained by the testing center of S\&PE Pulsar JSC during the dielectric breakdown testing of electronic devices under pulsed operation mode. Tests were carried out as part of the development work commissioned by the Ministry of Industry and Trade of Russia. The results of the analysis are arranged as diagrams, graphs and tables, taking into account the methodological basis, purpose, classification group and manufacturing method of each device under test.

Keywords: pulsed dielectric strength, single voltage pulse, testing of electronic devices

Data on authors: Denis Olegovich Vanichkin,vanichkin@pulsarnpp.ru; Ilya Yakovlevich Gantman; Aleksey Vladimirovich Levko 


\section{Введение}

Испытания изделий электронной техники (ИЭТ) на импульсную электрическую прочность (ИЭП) при воздействии одиночных импульсов напряжения (ОИН) проводились в соответствии с требованиями регламентирующих документов [1-4]. При проведении испытаний использовался генератор ОИН с выходным импедансом 2,5 Ом, позволяющий получать ОИН трапецеидальной формы в диапазоне от 100 нс до 10 мкс.

К настоящему моменту (март 2020 года) за время работы испытательного центра АО «НПП «Пульсар» на ИЭП было испытано более 1600 образцов 212 типов различных изделий в рамках 119 опытно-конструкторских работ (ОКР). Накопленный материал и практический опыт позволяют сделать ряд выводов и обобщений, касающихся основных результатов и методологии испытаний.

Исследованы более трёх десятков СВЧ усилителей мощности и операционных усилителей, значительная выборка смесителей частот и генераторов, управляемых напряжением. Из дискретных изделий про- ведены испытания большого количества биполярных и полевых транзисторов, полупроводниковых диодов. Диаграмма, иллюстрирующая распределение количества типов испытанных изделий различных классов, приведена на рис. 1.

Если говорить о классификационной группе изделий [5], то больше всего было испытано интегральных микросхем, дискретных изделий и различного рода модульных сборок (рис. 2). Ввиду того, что различие между микросборками, модулями и модулями СВЧ зачастую условное, по группам изделия распределялись в зависимости от общих технических условий, использовавшихся в соответствующей работе.

\section{Понятие критичного включения}

Согласно [4], ИЭП изделие характеризуется максимально допустимым значением амплитуды ОИН, после воздействия которого значения параметров-критериев ИЭП изделия соответствуют установленным нормам. Таким образом, в ходе испытаний определяются параметры ОИН, при которых гарантированно не происхо-
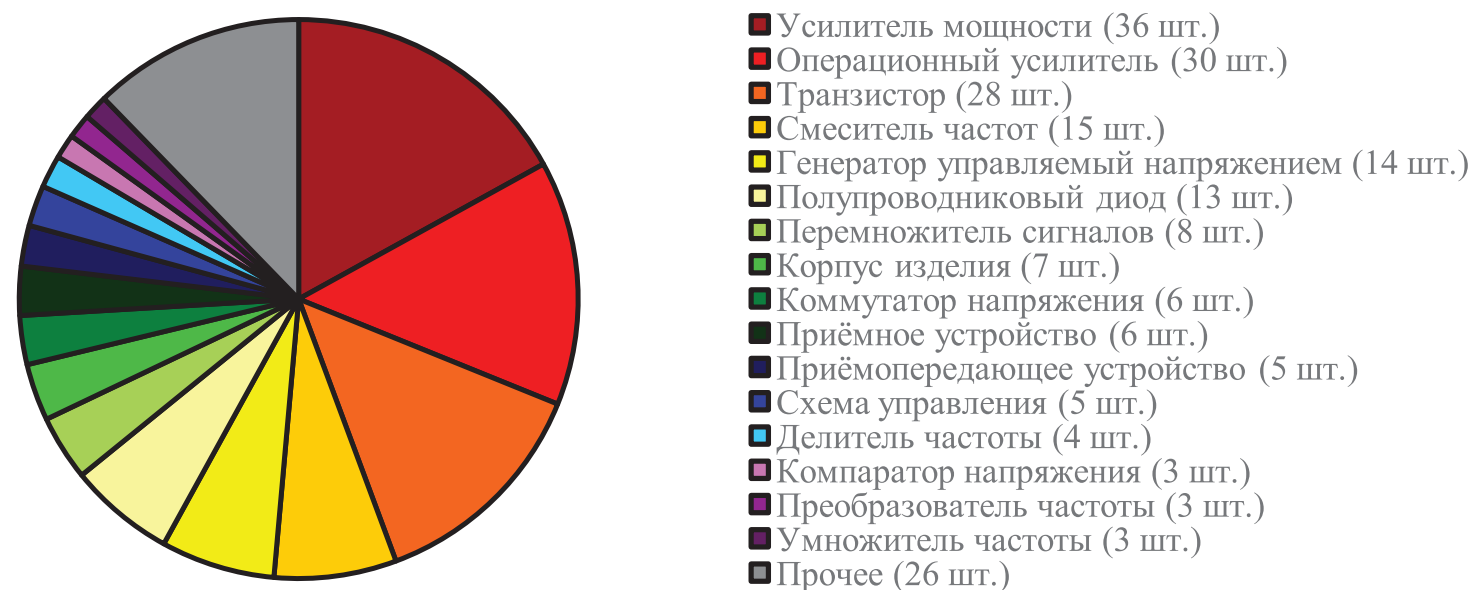

Puc. 1

Распределение ИЭТ, испьтанных на ИЭП, по функциональному назначению 


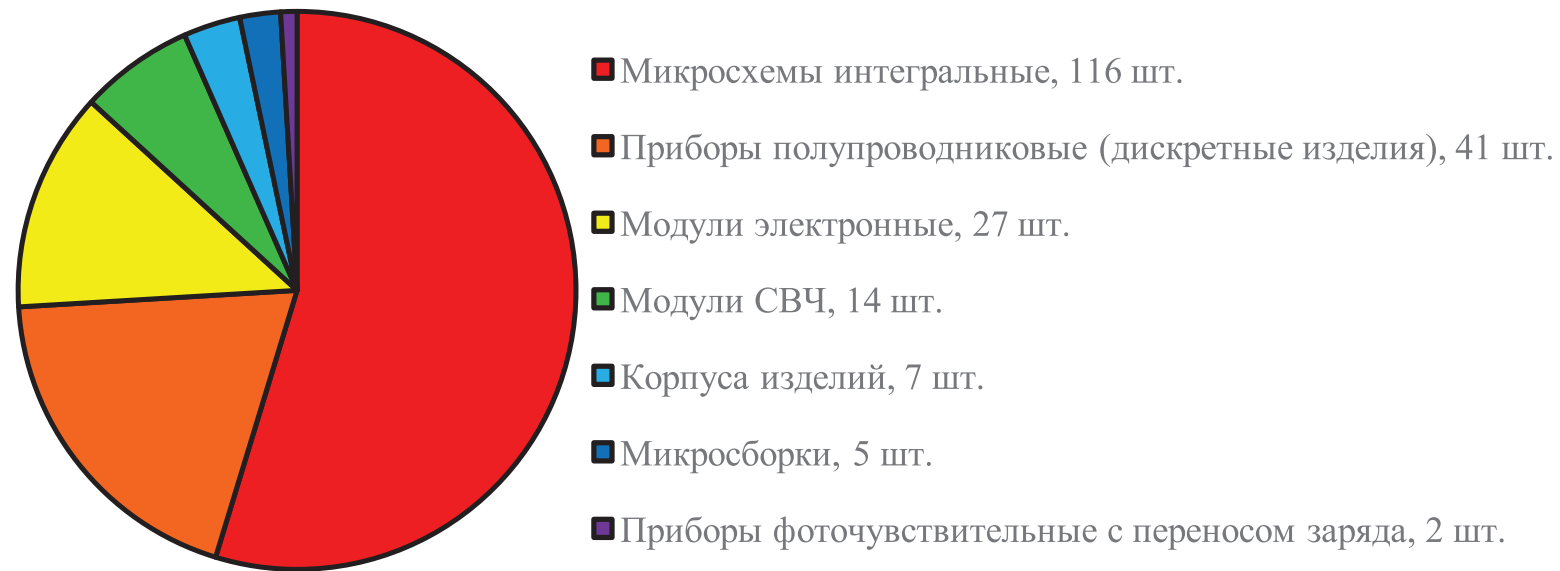

Puc. 2

Распределение ИЭТ, испытанных на ИЭП, по классификационным группам

дит отказ изделия при подаче импульса в любом включении. На практике удобно пользоваться не введённым в стандартах термином критичное включение. При проведении испытаний под критичным включением понимается то включение, в котором при заданной длительности ОИН

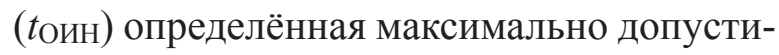
мая амплитуда ОИН (UОин) минимальна. В понятие включения входит выбранная пара выводов, между которыми произво- дится испытательное воздействие, электрический режим испытываемого изделия при подаче ОИН, а также полярность, в которой подаётся импульс.

Понятно, что в условиях испытаний, когда выборка изделий ограничена, критичное включение определяется формально наименьшим полученным значением

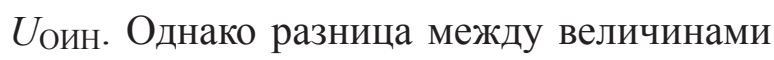

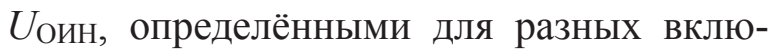
чений, может быть очень мала. Для того

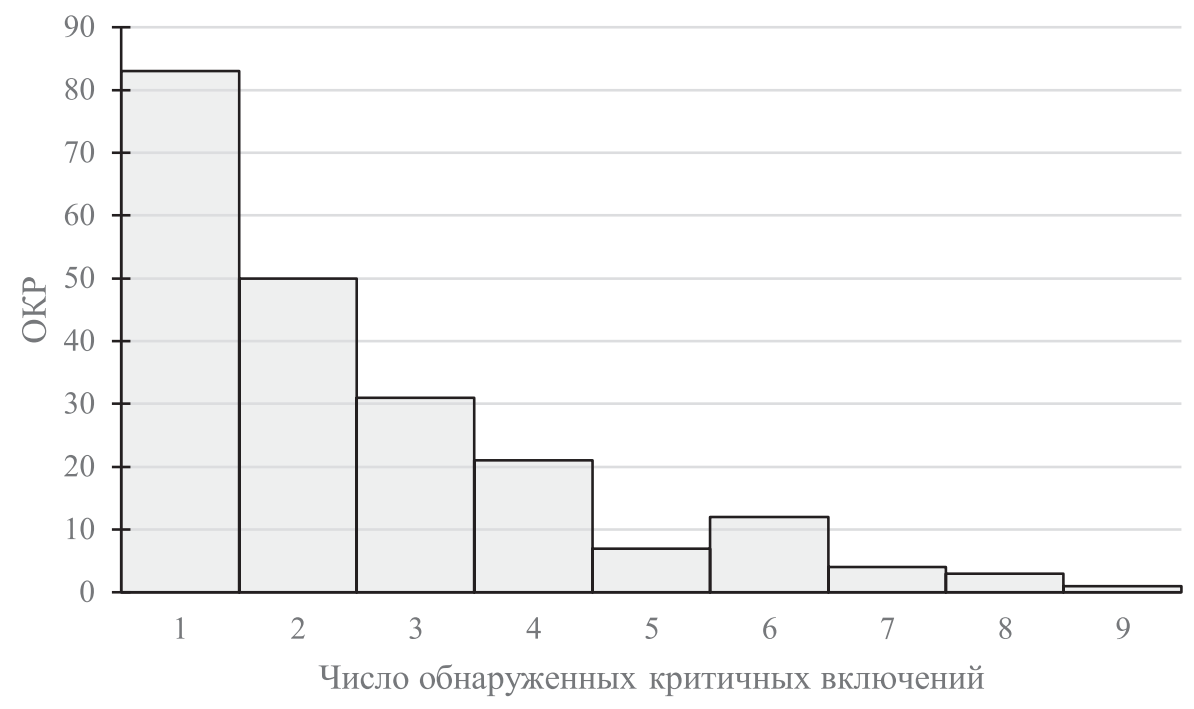

Puc. 3

Количество выявленных критичных включений в разных ОКР 
чтобы установить истинное критичное

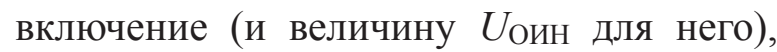
требуется применить методы статистической обработки результатов испытаний. Зачастую для одного включения используется одно изделие, поэтому применить анализ на основе статистики на практике не всегда возможно. На полученную величину $U_{\mathrm{Oин}}$ оказывают влияние технологический разброс характеристик изделия, погрешность средств измерения, методическая погрешность, связанная с шагом импульса, случайная ошибка при измерениях и т. д.

В данной работе определим критичное включение как любое включение, $U_{\text {оин ко- }}$ торого больше обнаруженного минималь-

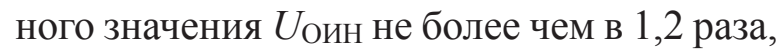
то есть на один двадцатипроцентный шаг увеличения амплитуды ОИН при испытаниях (в соответствии с методикой испытаний). Таким образом, у одного изделия может быть несколько включений, попадающих под определение критичных.

На рис. 3 приведены сведения о количестве выявленных критичных включе- ний в различных ОКР. Следует отметить, что реальное число критичных включений может быть больше, так как не все из них могут быть установлены в ходе испытаний.

\section{Количество изделий для испытаний и понятие группы выводов изделия}

Большая часть ОКР выполнялась по заказам Министерства промышленности и торговли Российской Федерации в части Департамента радиоэлектронной промышленности, частные программы и методики испытаний (ПМИ) на ИЭП согласовывались с представителем заказчика - ФГУП «МНИИРИП».

В процессе согласования мы столкнулись с понятием группы выводов, которое не фигурирует в нормативной документации. С точки зрения экспертной организации, все включения можно разделить на три группы - включения, связанные со входами, с выходами и с выводами питания изделий. Подобный подход прослеживается в ряде публикаций $[6,7]$. На рис. 4

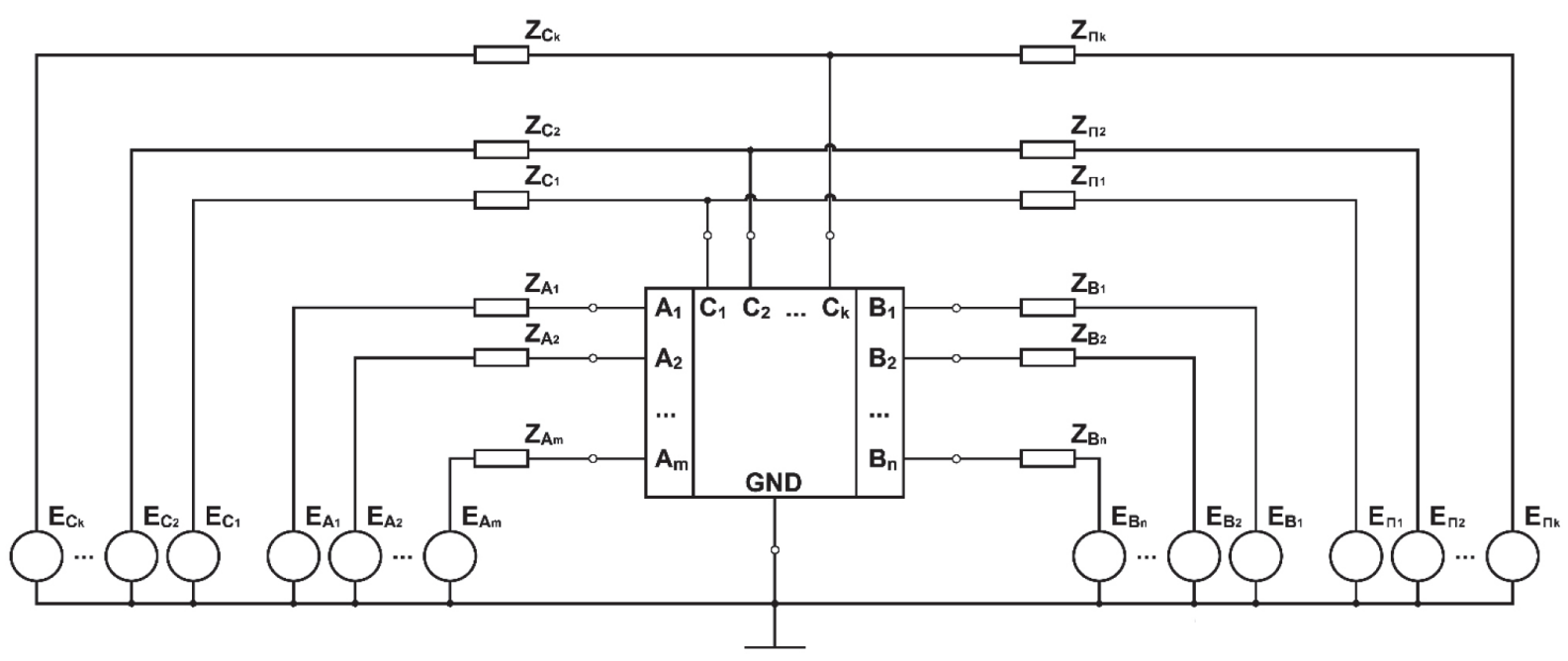

Puc. 4

Типовая эквивалентная схема воздействия ОИН, вызванных ЭМИ, на выводы ИЭТ: $A$ - входы изделия, $B$-выходы, $C$ - выводы питания, $G N D$ - общий вывод; $E_{A}, E_{B}, E_{C}, Z_{A}, Z_{B}$ и $Z_{C}-$ параметры эквивалентного генератора ОИН (ЭДС и выходной импеданс соответственно), $E_{\Pi}$ и $Z_{\Pi}$ - ЭДС и выходной импеданс источников питания, задающих электрический реэсим изделия 
приведена взятая из работы [5] «типовая эквивалентная схема воздействия ОИН, вызванных электромагнитным импульсом (ЭМИ), на выводы ИЭТ». Здесь А - входы изделия, В - выходы, С - выводы питания, GND - общий вывод. В общем случае в рамках данного подхода в процессе испытаний предписывается рассматривать следующие включения: « $\mathrm{A}_{1}-\mathrm{GND}$ », ..., «A $\mathrm{A}_{\mathrm{m}}-\mathrm{GND} »,\left\langle\mathrm{~B}_{1}-\mathrm{GND} », \ldots,\left\langle\mathrm{B}_{\mathrm{n}}-\mathrm{GND} »\right.\right.$, « $\mathrm{C}_{1}-\mathrm{GND} », \ldots$, « $\mathrm{C}_{\mathrm{k}}-\mathrm{GND}$ » (каждое включение - при обеих полярностях подаваемого ОИН). Таким образом, в рамках данного подхода для испытания изделия требуется $2 \cdot(\mathrm{m}+\mathrm{n}+\mathrm{k})$ образцов для каждого значения длительности ОИН.

С другой стороны, при воздействии ЭМИ за счёт антенных свойств проводных и кабельных линий на внешних выводах изделия возникают наведённые электростатические потенциалы $\varphi_{\mathrm{A} 1}, \ldots, \varphi_{\mathrm{Am}}$, $\varphi_{\mathrm{B} 1}, \ldots, \varphi_{\mathrm{Bn}}, \varphi_{\mathrm{C} 1}, \ldots, \varphi_{\mathrm{Ck}}$. Можно считать, что в общем случае эти потенциалы возникают и существуют одновременно, так как время прохождения ЭМИ сквозь аппаратуру много меньше длительности процесса протекания наведённого заряда через нагрузку внутри аппаратуры. В соответствии c регламентирующей документацией задача анализа сложной системы, в которой возникают множественные электрические перегрузки на различных элементах рассматриваемого изделия, сводится к более простой задаче анализа влияния единичной перегрузки независимо для каждой из пар выводов. Но если на выводе $\mathrm{A}_{1}$ возникает потенциал $\varphi_{\mathrm{A} 1}$, а на выходе $\mathrm{B}_{1}$ - потенциал $\varphi_{\mathrm{B} 1}$, почему нужно рассматривать только включения, связанные с общим выводом («A $\mathrm{A}_{1}-\mathrm{GND}$ » и «B $\left.\left.\mathrm{B}_{1}-\mathrm{GND}\right)\right)$ ? Почему не нужно рассматривать включение « $\mathrm{A}_{1}-\mathrm{B}_{1} »$, если вследствие воздействия ЭМИ между этими выводами образовалось напряжение $U_{\mathrm{AB}}=\varphi_{\mathrm{A} 1}-\varphi_{\mathrm{B} 1}$ ? Причём потенциалы $\varphi_{\mathrm{A} 1}$ и $\varphi_{\mathrm{B} 1}$ будут зависеть от расположения относительно векторов электрического и магнитного полей ЭМИ проводов и кабелей, соединённых с выводами $\mathrm{A}_{1}$ и $\mathrm{B}_{1}$, наличия и вида их экранирования, качества заземления и даже от конфигурации электрической схемы испытываемого изделия. То есть в общем случае $\varphi_{\text {A1 }}$ и $\varphi_{\text {B1 }}$ будут различны, а $U_{\mathrm{AB}} \neq 0$.

Регламентирующая документация не содержит каких-либо инструкций, касающихся выбора включений для определения максимально допустимой амплитуды ОИН. Предполагается, что в процессе испытаний должны быть рассмотрены все возможные варианты. В этом случае для проведения испытаний при каждом значении длительности ОИН требуется как минимум $\frac{n !}{(n-2) !}$ образцов, где $n$ - общее число выводов изделия. В общих технических условиях для микросхем [8] и микросборок [9] число образцов для испытаний установлено и привязано к степени интеграции. Для испытаний на ИЭП при степени интеграции ИС1 положено испытывать 20 образцов, а при ИС8 - всего 4, при этом каким именно образом нужно обеспечить достоверность и информативность испытаний, не указано.

Уменьшить число включений при испытаниях можно на основании анализа особенностей конструктивно-технологического исполнения, типовой схемы включения изделия и реальных условий его применения в радиоэлектронной аппаратуре. Ниже приводятся некоторые принципы, на основании которых может быть сокращён объём испытаний.

1. Если возможно физически обосновать, что изделие в данном включении способно выдержать ОИН большей амплиту- 
ды, чем в другом включении, в таком более стойком включении изделие может не подвергаться испытательному воздействию.

2. При наличии у изделия выводов, не чувствительных к импульсным электрическим перегрузкам амплитудой до 5 кВ, на включения с этими выводами испытательное воздействие не подаётся, например, в случае, когда входом изделия является первичная обмотка трансформатора, пробивное напряжение между обмотками которого превышает 5 кВ.

3. Изделия, выводы которых (например, вход и/или выход) выполнены в виде волновода, не испытываются во включениях, связанных с этими выводами.

4. В случае, если ранее испытательной лабораторией были получены данные по ИЭП конструктивно-технологических аналогов испытуемых изделий, могут быть использованы полученные ранее сведения об ИЭП в наиболее чувствительных к ОИН включениях, ориентировочных границах области отказа в этих включениях (с обоснованием возможности такого использования результатов и ссылкой на протоколы предыдущих испытаний).

5. Данные об ИЭП сложносоставных изделий (модулей, микросборок и т. п.) могут быть получены при испытании отдельных компонентов, входящих в их состав.

6. При наличии включений, механизм воздействия ОИН и вид отказа в которых не будет зависеть от полярности ОИН, изделие может быть испытано при одной полярности.

7. При наличии в составе изделия однотипных каскадов проводятся испытания только одного из каскадов, при этом полагается, что при испытании остальных каскадов будет получен аналогичный результат.
8. Сведения о реальных условиях применения изделия используются для определения критичных и некритичных включений. Например, если в реальной схеме при применении изделия ОИН не может быть наведён на данную пару выводов, связанное с ней включение не рассматривается для испытаний.

Решение использовать понятие группы выводов в виде «X - GND» может быть компромиссом (с нашей точки зрения, необоснованным), уменьшающим количество рассматриваемых во время испытания включений, и соответственно, уменьшающим требуемое количество образцов изделий. Однако даже в этом случае проблема нехватки образцов и выбора включений не может быть решена полностью.

Будем обобщённо считать выводами питания (С) выводы, к которым в типовой схеме присоединяются источники постоянного напряжения, питающие один или несколько каскадов испытываемого изделия. Входами (А) назовём любые выводы изделия, на которые в типовой схеме включения подаётся сигнал и которые не являются выводами питания, - непосредственные входы изделий (на частоте и по постоянному напряжению), выводы управления, выводы коррекции и подстройки и т. д. Выходами (В) будем считать выводы, с которых сигнал снимается, - непосредственные выходы, различные выводы контроля состояния изделий и прочее.

Тогда включения вида « $\mathrm{A}_{\mathrm{i}}-\mathrm{GND»}$ относятся к группе входов, « $\mathrm{B}_{\mathrm{i}}-\mathrm{GND}$ » пе выходов, « $\mathrm{C}_{\mathrm{i}}-\mathrm{GND}$ » - к группе питания. С нашей точки зрения, имеют право на существование включения других видов. Назовём включения вида « $\mathrm{A}_{\mathrm{i}}-\mathrm{A}_{\mathrm{j}}$ 》 группой вход-вход, включения вида « $\mathrm{B}_{\mathrm{i}}-\mathrm{B}_{\mathrm{j}}$ »группой выход-выход, а включения вида 


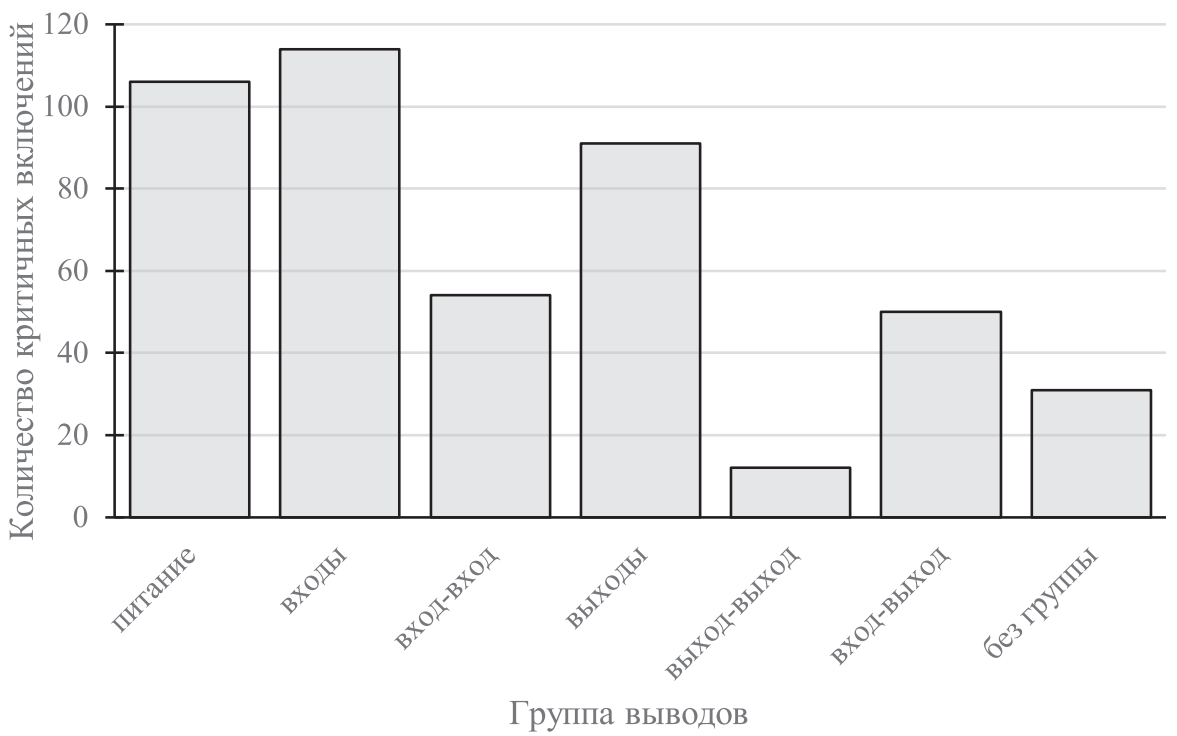

Puc. 5

Количество критичных включений по группам выводов

« $\left.\mathrm{A}_{\mathrm{i}}-\mathrm{B}_{\mathrm{j}}\right\rangle-$ вход-выход. Здесь $\mathrm{i}$ и $\mathrm{j}-$ порядковые номера выводов. На рис. 5 представлено распределение критичных включений по группам выводов для всех испытанных изделий (при $t_{\mathrm{OиH}}=1$ мкс). Включения вида $\left\langle\mathrm{A}_{\mathrm{i}}-\mathrm{C}_{\mathrm{j}}\right\rangle,\left\langle\mathrm{B}_{\mathrm{i}}-\mathrm{C}_{\mathrm{j}}\right\rangle$ и $\left\langle\mathrm{C}_{\mathrm{i}}-\mathrm{C}_{\mathrm{j}}\right\rangle$ не приведены, так как по ним практически отсутствуют данные (изделия не испытывались в данных включениях в связи с малым количеством образцов). Включения, для которых затруднительно однозначно установить группу или же группа зависит от способа включения (включения, связанные с выводами полупроводниковых диодов, биполярных транзисторов и т. д.), выведены в отдельную группу (без группы).

Из рис. 5 видно, что включения, отличные от вида «X - GND», являются определяющими ИЭП изделий в значительном проценте случаев. Превалирование отказов по группам входы, выходы и питание в некоторой мере можно объяснить тем, что в большей части последних работ именно эти группы были согласованы в ПМИ с представителем заказчика и иные группы выводов для испытания не рассматривались, то есть получившееся распределение в некоторой мере искусственное.

Для всех испытанных изделий было посчитано количество включений (количество требуемых образцов для испытаний) с учётом возможности их сокращения посредством теоретического рассуждения. Произведено сравнение этой величины с реальным числом предоставленных образцов (рис. 6).

При этом было выделено пять случаев. В первом, наиболее благоприятном случае, образцов хватило для прямого перебора всех включений при всех значениях длительности ОИН. При этом образцов было достаточно как для сбора статистики отказов (не менее двух образцов на каждое включение), так и для проведения дополнительных исследований с целью установления физического механизма отказа.

Во втором случае образцов хватило для прямого перебора всех возможных включений, при этом был предоставлен незначительный запас образцов для проведения 


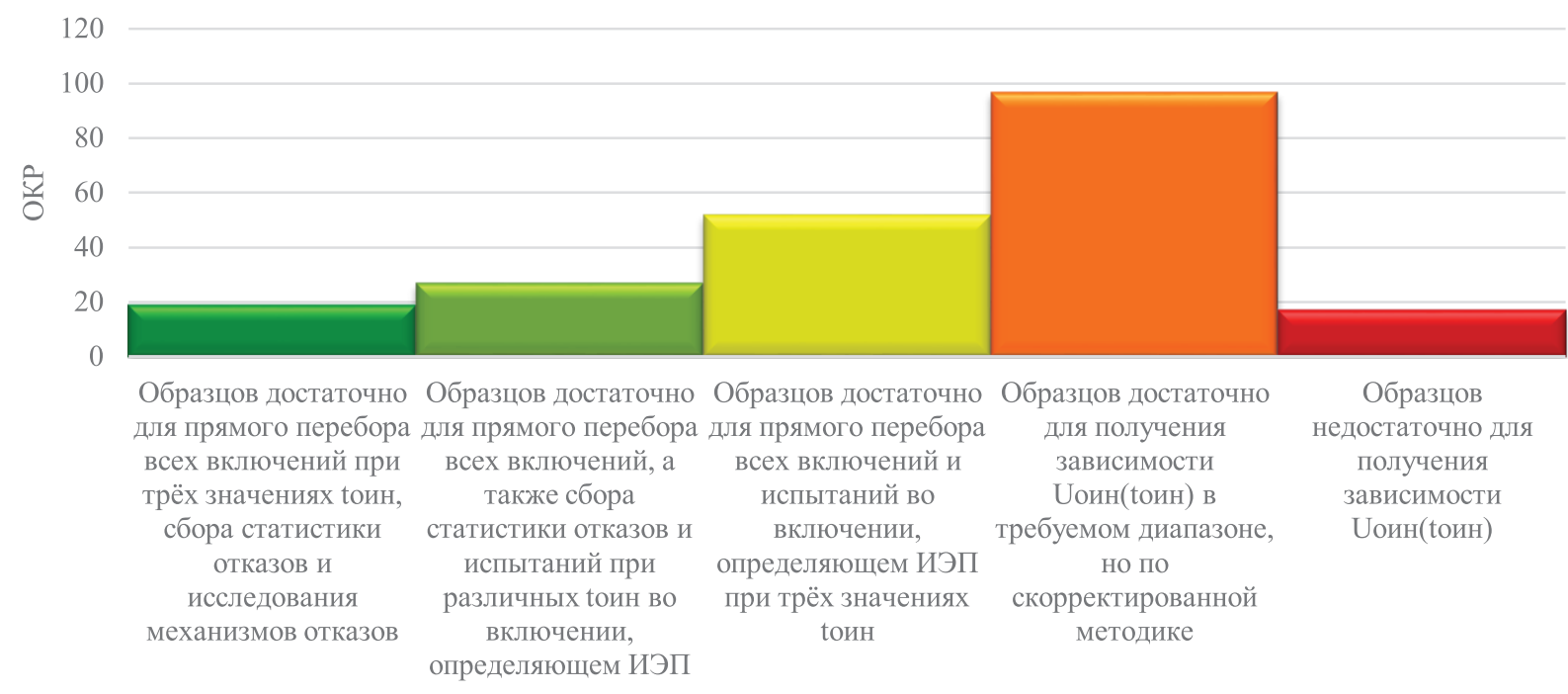

Puc. 6

Сравнение количества образиов изделий, предоставленных для испытаний, с требуемым количеством

предварительных испытаний с целью установления ориентировочной границы области отказа, а также для сбора статистики отказов в некоторых включениях, определяющих ИЭП изделия.

Третья группа - предоставлено ровно то количество образцов, которое было необходимо для перебора всех включений, а также два дополнительных образца для испытания изделия во включении, определяющем ИЭП изделия при двух других значениях $t_{\mathrm{Oин}}$.

К четвёртой, наиболее многочисленной группе, отнесены работы, в которых переданных образцов оказалось недостаточно для прямого перебора необходимых включений, но при этом число образцов было не менее трёх. Для проведения испытаний использовалась скорректированная методика, не предполагающая прямого перебора включений с доведением изделия до отказа в каждом из них. В рамках этой методики первое изделие используется для определения включения, наиболее чувствительного к воздействию ОИН, - задаётся начальная (минимальная) амплитуда импульса и производятся последовательные испытательные воздействия (ИВ) на выводы изделия в каждом из выбранных включений. Измерение параметров-критериев годности изделия производится до и после каждого ИВ. После того, как при заданной амплитуде импульса подвергнутся воздействию все выбранные включения испытуемого изделия, амплитуда ОИН генератора повышается и последовательное ИВ на выводы изделия повторяется. Это происходит до тех пор, пока в одном из включений не происходит отказ изделия. Это включение объявляется определяющим ИЭП изделия и в нём обычным способом испытываются два других образца при двух других значениях

Данная методика не позволяет выявить все чувствительные к данному виду воздействия включения, но зато позволяет на ограниченной выборке гарантировать определённую величину стойкости изделия в целом. Также следует отметить, что при таком подходе ИВ, подаваемые на одно 
включение, могут оказывать влияние на величину максимально допустимой амплитуды, которая будет получена для другого включения. Это может происходить вследствие накопления скрытых повреждений. Однако, во-первых, скрытые повреждения могут привести к заниженному результату испытаний, но не к завышенному (консервативная оценка), то есть по результатам испытаний можно будет гарантировать, что воздействие ОИН с полученной ампли-

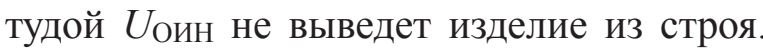
Во-вторых, скрытые повреждения возникают и при обычной методике испытаний, проявляясь в виде так называемого аддитивного эффекта, который также может влиять на результат испытания консервативным образом.
И к последней группе отнесены работы, в которых число образцов изделий для испытаний было меньше трёх, то есть получение зависимости $U_{\text {оин }}\left(t_{\mathrm{O}}\right)$ в в предписываемом стандартами диапазоне оказалось невозможно. В первую очередь это многокомпонентные изделия (модули), сложные в производстве и обладающие высокой стоимостью изготовления.

Интересно сравнить количество включений (и соответственно, требуемое количество образцов) для испытаний (М) с количеством внешних выводов изделия (N) напрямую (рис. 7). Видно, что в общем случае $\mathrm{M}=2 \cdot \mathrm{N}$ (граница отмечена чёрной прерывистой линией), хотя в части случаев требуется меньше образцов. Требования к количеству образцов нормативная

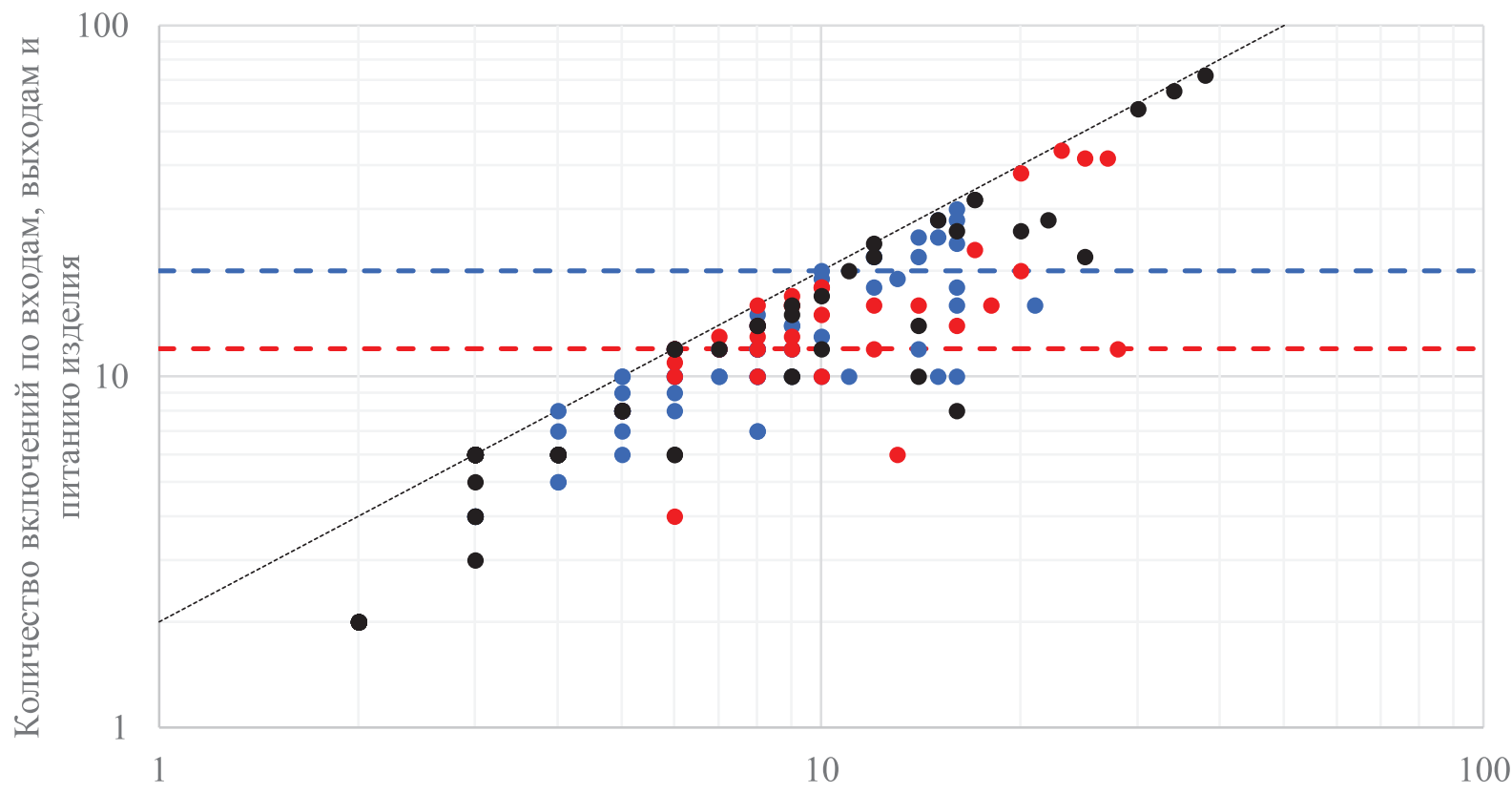

Количество внешних выводов изделия

- Микросхемы со степенью интеграции ИС1 и ИС2

- Микросхемы со степенью интеграции ИСЗ и ИС4

• Изделия прочих классификационных групп

Puc. 7

Сравнение количества внешних выводов изделия с количеством включений, в которых необходимо испытать изделие при условии, что посчитаны только включения по группам выводов входы, выходы и питание при единственной длительности ОИН 
документация устанавливает только для изделий, относящихся к классификационным группам микросборки и микросхемы. Для изделий со степенью интеграции ИС1 и ИС2 эта величина составляет 20 штук (синяя прерывистая линия), а для ИС 3 и ИС4 - 12 штук (красная прерывистая линия) $[8,9]$. Если считать, что для испытания изделия в одном включении требуется один образец (испытания разрушающие), то для всех точек, лежащих выше соответствующей прямой, образцов для прямого перебора включений не хватит.

Таким образом, можно сделать вывод о том, что в настоящее время методика испытаний, предписываемая нормативными документами, не соответствует реальной производственной ситуации. Способ определения количества включений и требуемого количества образцов никак не регламентируется. В тех случаях, когда число образцов для испытаний указано в явном виде, способ обеспечения достоверности и информативности испытаний не устанавливается.

\section{Влияние разброса параметров- критериев годности изделий на показатели ИЭП}

С точки зрения общей физики технологический разброс электрофизических параметров изделия в выборке должен влиять на разброс величин, характеризующих ИЭП изделий этой выборки при условии, что все изделия были испытаны в одном включении и при одной длительности ОИН.

В большинстве случаев при испытаниях нет возможности в одной работе испытывать несколько изделий в одном включении, осуществляя сбор статистики отказов (рис. 6). Однако в некоторых работах такие результаты были получены. Сравним относительные величины статистического разброса измерявшихся параметров-критери-

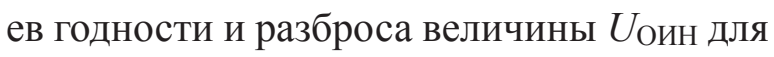
этих случаев. Для каждого измерявшегося параметра-критерия годности вычислялась величина $\Delta_{X}$, характеризующая статистический разброс относительно средней величины значения параметра:

$$
\Delta_{\mathrm{X}}=\frac{\sigma \cdot t_{\alpha, n}}{\overline{\mathrm{X}}} \cdot 100 \%,
$$

где $\overline{\mathrm{X}}$ - среднее значение измерявшегося параметра-критерия годности $\mathrm{X}$ для всех изделий, испытанных в данном включении (не менее двух); $\sigma$ - среднеквадратичное отклонение; $t_{\alpha, n}$ - коэффициент Стьюдента при доверительной вероятности $\alpha=0,95$ для числа изделий $n$, испытанных в данном включении.

Аналогичная величина вычисляется для максимально допустимой амплитуды ОИН $\left(U_{\text {Oин }}\right)$ и полной энергии импульса, предшествующего отказу (Еоин):

$$
\begin{aligned}
& \Delta_{\mathrm{U}}=\frac{\sigma \cdot t_{\alpha, n}}{\overline{\mathrm{U}_{\mathrm{Oй}}}} \cdot 100 \% ; \\
& \Delta_{\mathrm{E}}=\frac{\sigma \cdot t_{\alpha, n}}{\overline{\mathrm{E}_{\text {ОИН }}}} \cdot 100 \%,
\end{aligned}
$$

где $\overline{\mathrm{U}_{\text {оин }}}$ и $\overline{\mathrm{E}_{\text {оин }}}$ - средние значения вели-

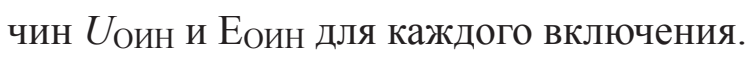

На рис. 8 представлены зависимости $\Delta_{\mathrm{U}}\left(\Delta_{\mathrm{X}}\right)$ и $\Delta_{\mathrm{E}}\left(\Delta_{\mathrm{X}}\right)$. Видно, что сделать вывод о каком-либо характере влияния технологического разброса параметров на уровень ИЭП затруднительно - малому разбросу может соответствовать значительное расхождение в результатах испытаний, и наоборот, при значительном разбросе параметров определённая в одном и том же включении максимально допустимая амплитуда ОИН может быть практически одинаковой. 

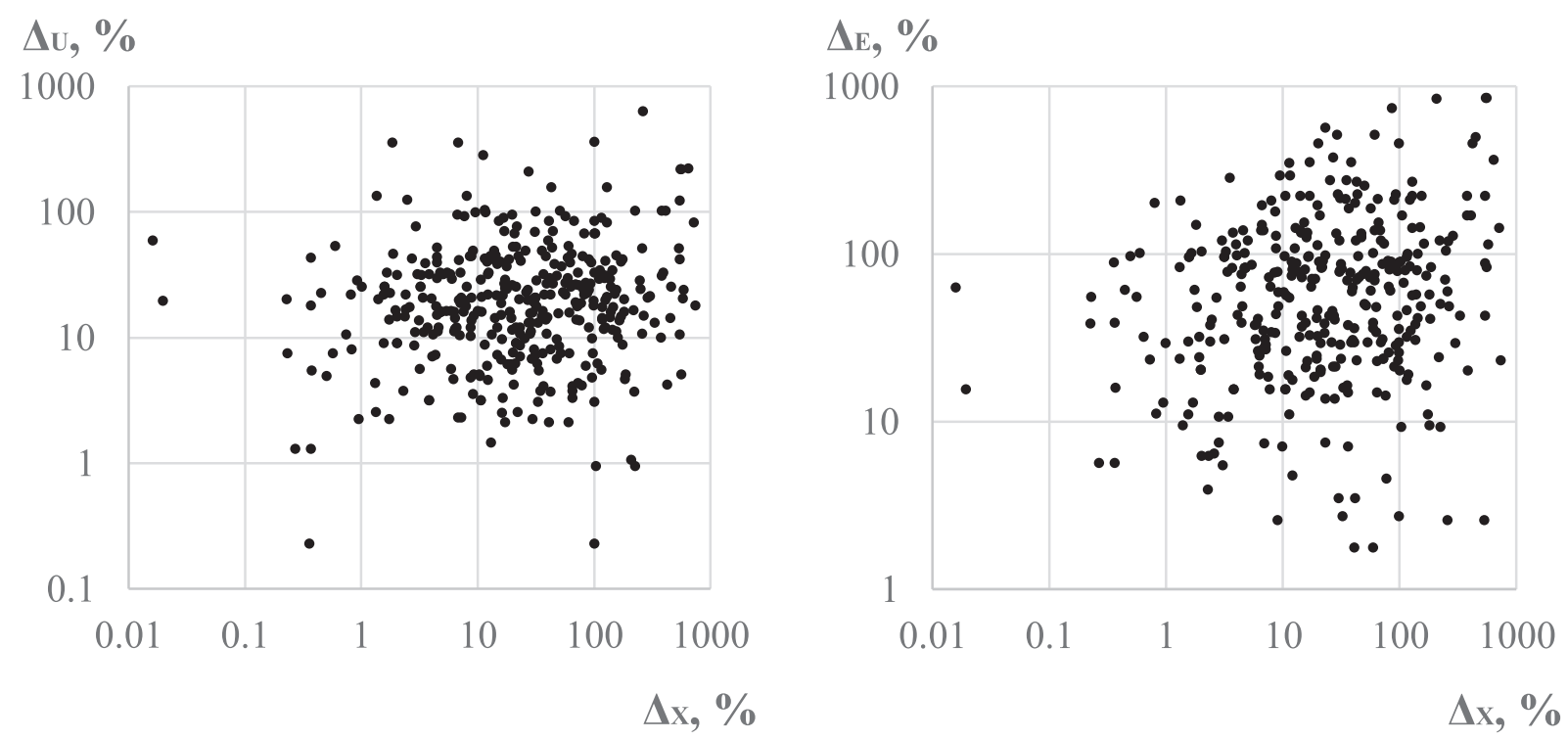

Puc. 8

Зависимости $\Delta_{\mathrm{U}}\left(\Delta_{\mathrm{X}}\right)$ и $\Delta_{\mathrm{E}}\left(\Delta_{\mathrm{X}}\right)$

Этому может быть несколько причин. Во-первых, возможенвыборпараметров-критериев, при котором сами параметры обеспечивают функциональный контроль, но физически мало связаны с процессами электрического пробоя. Во-вторых, электрические параметры-критерии годности изделий могут быть связаны с электрофизическими параметрами полупроводниковых структур не напрямую, а посредством нелинейных зависимостей. Во-третьих, для обеспечения требуемого диапазона значений параметра могут использоваться подстроечные элементы, обеспечивающие соответствующий режим работы изделия. Это характерно для СВЧ модулей и микросборок.

\section{Анализ причин отказов}

В [4] целью испытаний указывается определение фактических показателей ИЭП при воздействии ОИН от стандартизованного генератора «с учётом доминирующих видов и механизмов отказа». Однако напрямую нормативная документация не предписывает выявлять по результатам испытаний конкретный механизм. Тем не менее любые рассуждения о природе импульсной электрической прочности невозможны без понимания сути физических процессов, происходящих в изделии при испытательном воздействии.

При проведении испытаний можно выделить основные методы определения механизма отказа:

- анализ принципиальной электрической схемы изделия, топологической схемы кристалла, чертежа слоевого среза активных структур;

- наблюдение с помощью характериографа вольт-амперных характеристик пар выводов изделий до и после воздействия;

- анализ эпюр отклика изделия (осциллограмм импульсов тока и напряжения) при подаче ОИН;

- визуальный осмотр кристалла с помощью микроскопа;

- анализ изменения параметров-критериев годности и электрических режимов функционирования изделия вследствие испытательного воздействия. 
В отдельных случаях для определения физической сути отказа может применяться широкий спектр лабораторных методов исследования, в частности:

- различные методы измерения электрофизических параметров изделия, в том числе с использованием зондовой установки;

- исследование изменения электрических параметров изделия в диапазоне температур;

- исследование поведения образцов при радиационном воздействии, в первую очередь при воздействии гамма-квантов, альфа-частиц или нейтронов.

Возникавшие и обнаруженные во время испытаний механизмы отказов можно разделить на несколько категорий.

1. Эффекты, связанные с выделяющейся в отдельных областях исследуемого изделия мощностью при воздействии ОИН. Эти эффекты характеризуются большой величиной импульсного тока, и соответственно, импульсной мощности, вследствие чего происходит проплавление и закорачивание областей полупроводниковой структуры. Такие эффекты можно разделить на несколько групп.

a) Обрыв траверсы между контактными площадками кристалла и корпуса. Отказ определяется визуально с помощью микроскопа.

б) Перегорание дорожки металлизации на кристалле. В отличие от прочих эффектов, связанных с разрушением металлических элементов на кристалле (например, вспучивание и образование каверн на металлизации над областью, в которой произошло тепловыделение), перегорание дорожки характеризуется обрывом, наблюдаемым в соответствующей цепи с помощью характериографа. Чаще всего перегоревшую дорожку можно обнаружить визуально. Следует отметить, что при зондовом измерении обрыв может быть связан и с образованием каверны под зондом. В этом случае возможно восстановить электрический контакт повторной установкой зонда на неповреждённую часть контактной площадки.

в) Вторичный тепловой пробой (ВТП) $p-n$ перехода. Если из анализа электрической схемы видно, что воздействие ОИН приходится на $p$ - $n$ переход, смещаемый импульсным напряжением в обратном направлении, вторичный тепловой пробой определяется по характерной «ступеньке» (рис. 9а), возникающей в момент перехода лавинного или туннельного пробоя в тепловой, что приводит к необратимому разрушению $p$ - $n$ перехода. Следует отметить, что «ступенька» может возникать в различных случаях и не является надёжным критерием развития именно теплового пробоя.

г) Тепловой перегрев на границе металл-полупроводник, при котором в локальной области достигается температура плавления эвтектики. В этом случае происходят процессы, которые могут привести к возникновению отказов: образованию расплава на границе металл-полупроводник, ускоренной диффузии примесей вследствие высокого коэффициента диффузии в расплаве, перемещению примесей под действием электрического поля. Так как в процессе испытания амплитуда ОИН постепенно увеличивается с некоторым шагом, импульсная мощность также нарастает постепенно до тех пор, пока выделившейся за время импульса энергии не станет достаточно для возникновения отказа. Поэтому, в отличие от предыдущих эффектов, в данном случае возможен сильный дрейф электрических параметров-критериев годности 
a)

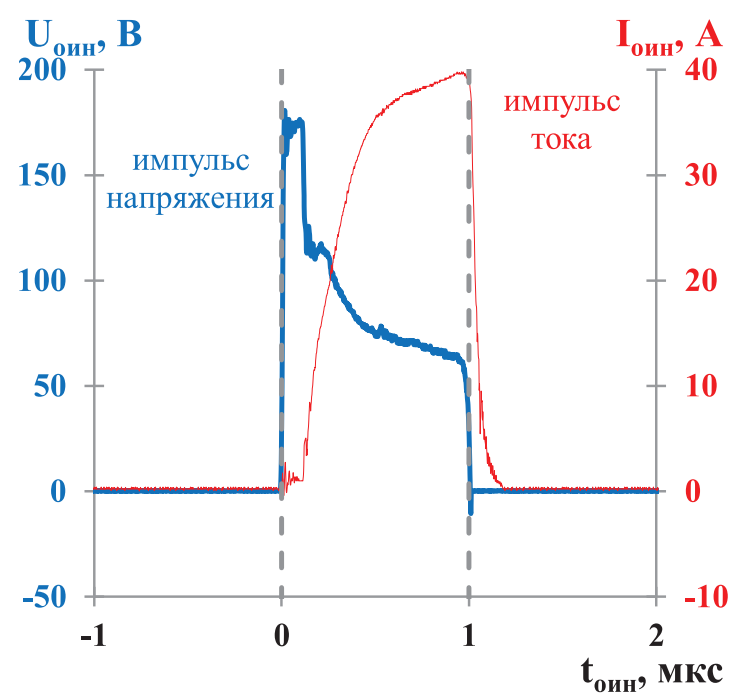

б)

\section{Uоин, $\mathbf{B}$}

Іоин, $\mathbf{A}$

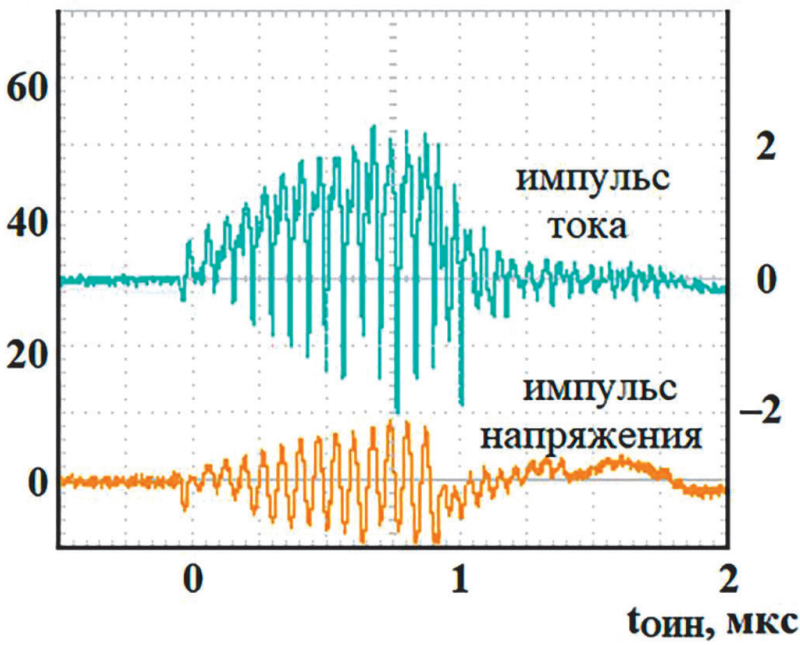

Puc. 9

Иллюстрация формы импульсов тока и напряжения при вторичном тепловом пробое обратносмещённого эмиттерного р-п перехода биполярного транзистора (а) и резонансе в колебательном контуре выходного каскада СВЧ-модуля генератора, управляемого напряжением (б)

при воздействии ОИН предпороговой амплитуды. Характерным видом отказа является параметрический, хотя возможен и катастрофический отказ, при котором тем не менее наблюдается изменение параметров в пределах норм ТУ по мере приближения к амплитуде отказа.

д) При испытаниях СВЧ изделий часто можно наблюдать генерацию в паразитных (или даже не в паразитных) LC-контурах при воздействии ОИН (рис. 9б). В этом случае можно говорить о резонансных эффектах, то есть подобный вид осциллограммы будет наблюдаться, когда частота генератора ОИН будет равна частоте собственных колебаний контура. А это означает, что возникновение резонанса зависит от электрической схемы построения генератора ОИН.

е) Дважды с помощью характериографа наблюдалось возникновение паразитной многослойной структуры с тиристорной вольт-амперной характеристикой. При этом активация (открывание) происходила при подаче между анодом и катодом этой структуры низковольтного сигнала (не более 5 В) с частотой 200 Гц, то есть величина $d U / d t$ составляла не более $4 \cdot 10^{3} \mathrm{~B} / \mathrm{c}$. При подаче ОИН длительностью более 1 мкс в данном включении также наблюдалось резкое увеличение импульсного тока после превышения амплитудой ОИН порога в 5 В. В конечном итоге происходил вторичный тепловой пробой и наблюдался катастрофический отказ.

2. Программный сбой многофункционального модуля. В общем случае, исходя из методики испытаний, программные сбои при воздействии ОИН не фиксируются в качестве отказа изделия, так как измерение параметров-критериев годности производится после испытательного воздействия и требует отдельной процедуры задания электрического режима посредством программатора. Перезагрузка устройства устраняет возникший сбой и изделие работает в штатном режиме, параметры-крите- 
рии годности измеряются в пределах норм ТУ и испытания продолжаются. Однако в том случае, когда программируемое изделие не нуждается в повторном программном задании режимов (хранит программу в своей памяти), возможно зафиксировать параметрический отказ изделия. Если подобный сбой не приведёт к какому-нибудь катастрофическому вторичному эффекту (например, выгорание каскада под действием напряжения питания, заданного изза сбоя не в штатном режиме), после перепрограммирования работоспособность изделия восстановится.

3. Пробой диэлектрика. В первую очередь идентифицируется при анализе принципиальной электрической схемы, когда видно, что ОИН воздействует на ёмкостный элемент или затвор транзистора с изолированным затвором. На осциллограмме импульса напряжения также может наблюдаться ступенька. Однако ток утечки через диэлектрик до момента пробоя очень маленький и в отличие от лавинного тока $p$ - $n$ перехода в большинстве случаев не может быть зафиксирован осциллографом.

4. При испытании полупроводниковых диодов и полевых транзисторов с изолированным затвором при воздействии ОИН может возникнуть инжекция и встраивание носителей заряда в слой окисла. Это может привести к параметрическому отказу таких параметров, как обратный ток диода, ток утечки через затвор полевого транзистора, величина его порогового напряжения. Данный вид параметрического отказа может быть обратимым, однако время рассасывания встроенного заряда может составлять единицы и даже десятки минут. С формальной точки зрения при измерении параметров-критериев годности после воздействия ОИН необходимо констатировать параметрический отказ. Определить данный механизм отказа можно повторным измерением параметров-критериев годности спустя некоторое время после воздействия. Чаще всего дрейф вольт-амперной характеристики, связанный с рассасыва-

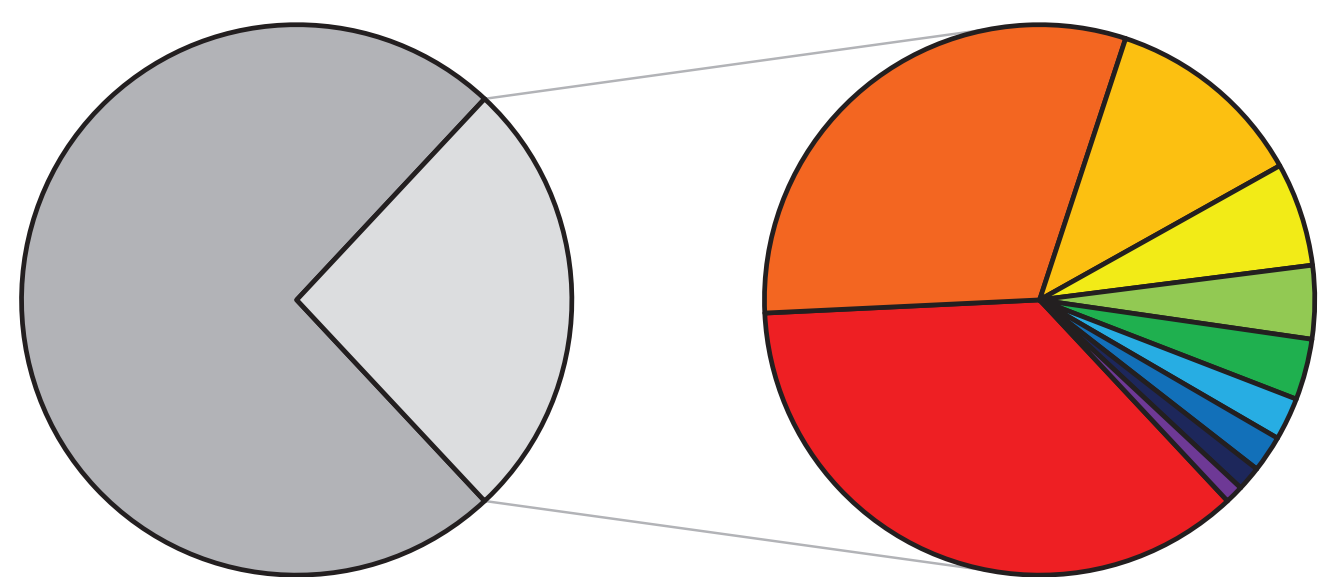

口Нет данных (73,9\%)

口Пробой диэлектрика (3,1%)

口Паразитный динистор (0,9%)

- Сбой программы $(0,4$ \%)
口ВТП р-п перехода (9,4%)

口Генерация (1,6\%)

口Нет отказа $(0,7 \%)$

口Обрыв траверсы (0,3%)
口Тепловой перегрев (8,0 \%)

口Перегорание дорожки $(1,1 \%)$

口Встраивание заряда $(0,6$ \%)

Puc. 10

Наблюдавшиеся механизмы отказов 
нием заряда, виден непосредственно во время измерения на характериографе.

Однако в большинстве случаев анализ причины отказа не проводился или был невозможен.

Наиболее распространённые виды отказа из обнаруженных - вторичный тепловой пробой $p$ - $n$ перехода и тепловой перегрев при протекании большого тока через низкоомную нагрузку (рис. 10). Следует отметить, что приведённое на диаграмме распределение отказов по механизмам может количественно сильно отличаться от реального, так как в 73,9 \% случаев механизм установлен не был.

В процессе испытаний механизм отказа зачастую не может быть выявлен, однако, как правило, указывается тип отказа - отмечается выход параметров-критериев годности за нормы ТУ (параметрический отказ) или фиксируется полное разруше- ние образца, при котором изделие не может функционировать (катастрофический отказ). Из статистики типов отказа сложно выявить какие-либо закономерности, однако можно отметить, что импульсы более короткой длительности чаще приводят к возникновению параметрического отказа, чем импульсы большей длительности.

\section{Характерные значения величины максимально-допустимой амплитуды ОИН}

На рис. 11 приведено распределение

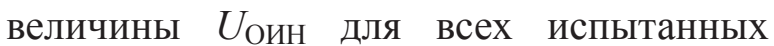
включений всех изделий по частоте возникновения отказа ( $U_{\mathrm{OиH}}$ округлялась до ближайшего целого числа по правилам округления). Из рисунка видно, что при величине выходного импеданса генератора ОИН $R_{\Gamma}=2,5$ Ом $80 \%$ значений максимально допустимой амплитуды ОИН, опреде-

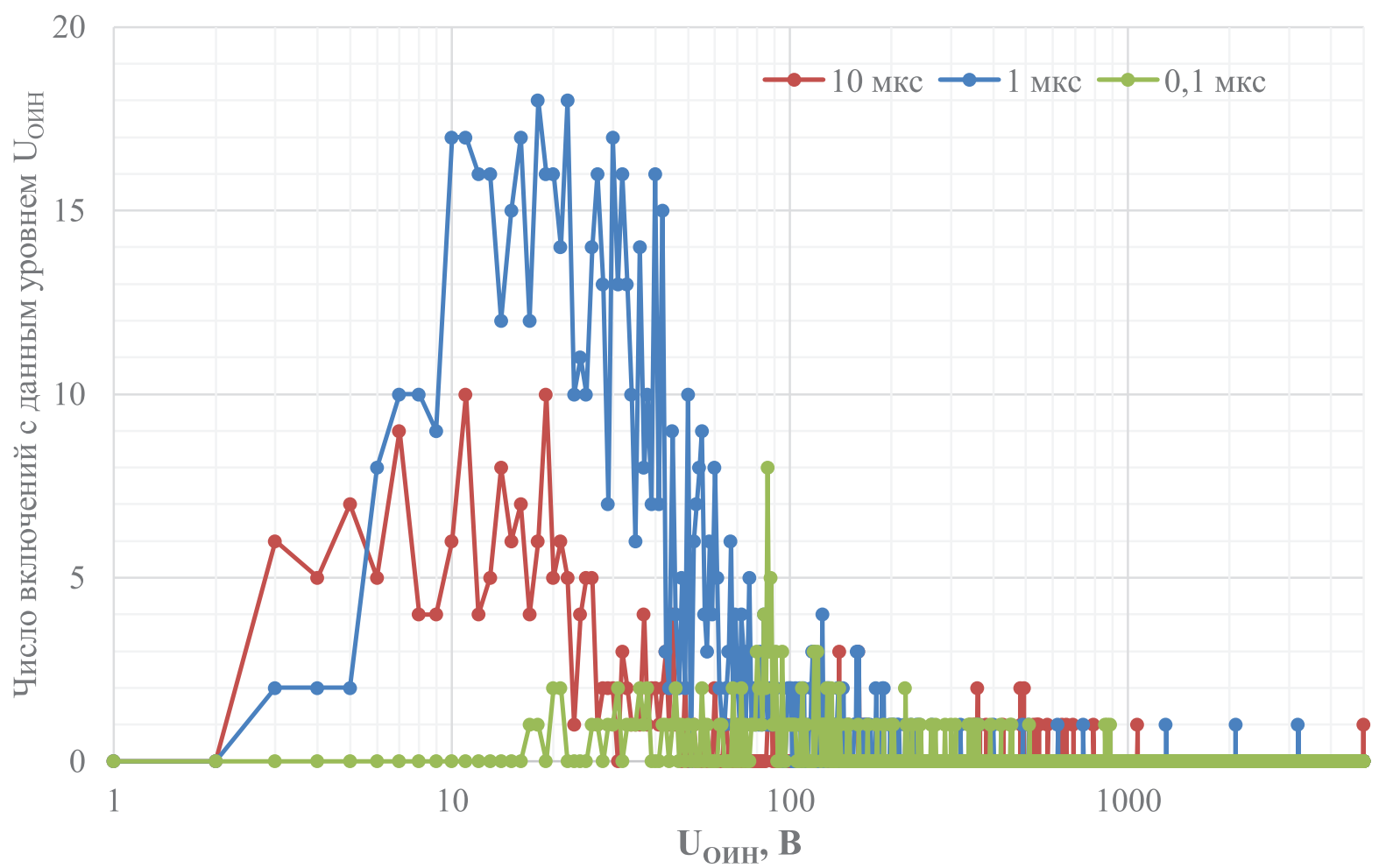

Puc. 11

Распределение включений по уровню отказа 
лённой по результатам испытаний, лежит в диапазоне между 5 и 70 В для $t_{\mathrm{Oин}}=1$ мкс, между 3 и 55 В для $t_{\mathrm{Oин}}=10$ мкс и между 40 и 250 В для $t_{\mathrm{O}}=0,1$ мкс.

Диапазон характерных величин $U_{\mathrm{O}}$, полученных с помощью генератора с $R_{\Gamma}=2,5$ Ом, лежит в области более низких значений по сравнению с результатами, приводимыми в работах $[6,7]$ и полученными с помощью генератора с $R_{\Gamma}=50$ Ом. Это соответствует результатам, полученным в работе [10].

Исходя из данных, приведённых на рис. 11, можно отметить, что наблюдалось как минимум 14 включений, в которых величина максимально допустимой амплитуды ОИН оказалась менее 5 В. Так как в соответствии с нормативной документацией генератор ОИН должен обеспечивать возможность подавать на выводы изделия импульсы с амплитудой от $5 \mathrm{~B}$, для данных включений установление характерной ве-

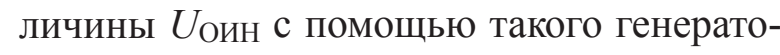

ра было бы невозможно. Эти 14 включений принадлежат десяти различным изделиям, которые испытывались в разных работах независимо друг от друга.

Также следует отметить, что в восемнадцати случаях величина $U_{\mathrm{O}}$, характеризующая ИЭП изделия, оказывалась меньше напряжения питания этого изделия в типовой схеме включения (отказ происходил по группе выводов, не связанной с питанием). Таким образом, выбор начальной амплитуды подаваемого ОИН по величине напряжения питания изделия не во всех случаях может быть оправдан.

Целью проведения испытаний на ИЭП является установление величины $U_{\text {Оин }}$ в диапазоне длительностей ОИН [1]. На рис. 12 приведены типичные зависимости

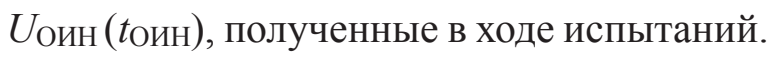
Можно отметить, что одиночным импульсам меньшей длительности соответствуют большие величины максимально допустимой амплитуды.

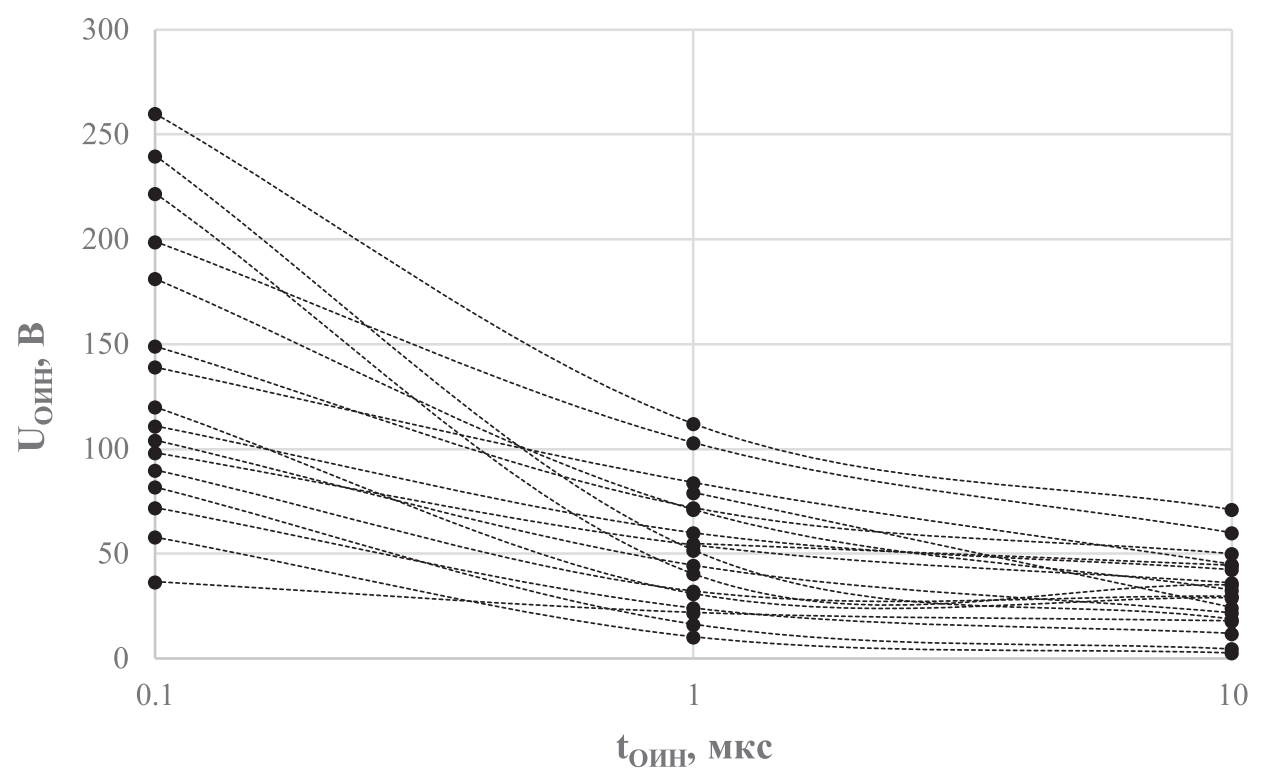

Puc. 12

Зависимости UОин от длительности прямоугольного импульса, полученные с помощью генератора ОИН с выходным импедансом 2,5 Ом 
Обобщение результатов испытаний в зависимости от технологии

\section{изготовления изделий}

По результатам испытания большого объёма ЭКБ можно сделать вывод, что максимально допустимая величина амплитуды ОИН в целом не зависит от технологии изготовления (рис. 13). Видимо, это связано с тем, что величина напряжения пробоя $p$ - $n$ перехода больше зависит от соотношения концентраций легирующей примеси и характерных размеров соответствующих областей $p$ - $n$ перехода.

\section{Некоторые методические аспекты испытаний на ИЭП}

Амплитуда ОИН при испытаниях постепенно повышается до выхода изделия за нормы ТУ. Шаг такого повышения в критической области отказа изделия по нормативным документам $[2,3]$ не должен превышать $20 \%$ от амплитуды последнего воздействовавшего импульса, при этом рекомендуемое значение - менее $10 \%$ [4]. Таким образом, заложенная в норматив- ной документации идеология предполагает уменьшение коэффициента приращения амплитуды для достижения большей точности при определении максимально допустимого значения амплитуды ОИН. Коэффициент приращения амплитуды определим следующим образом:

$$
k_{\text {пр }}=\frac{U_{n+1}-U_{n}}{U_{n}} \cdot 100 \%,
$$

где $n$ - порядковый номер воздействия в данном включении при испытаниях.

Проблема выбора шага импульса подробно рассматривалась в [11]. На рис. 14 приведено полученное по всем испытанным образцам распределение округлённой по правилам округления величины $k_{\text {пр }}$ между импульсом, предшествующим отказу, и импульсом, в результате которого отказ произошёл.

Несмотря на наличие аргументов в поль-

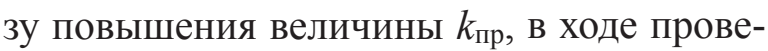
дённых испытаний мы руководствовались требованиями нормативной документации, выбирая маленький шаг приращения. Это, с одной стороны, увеличивает ошибку

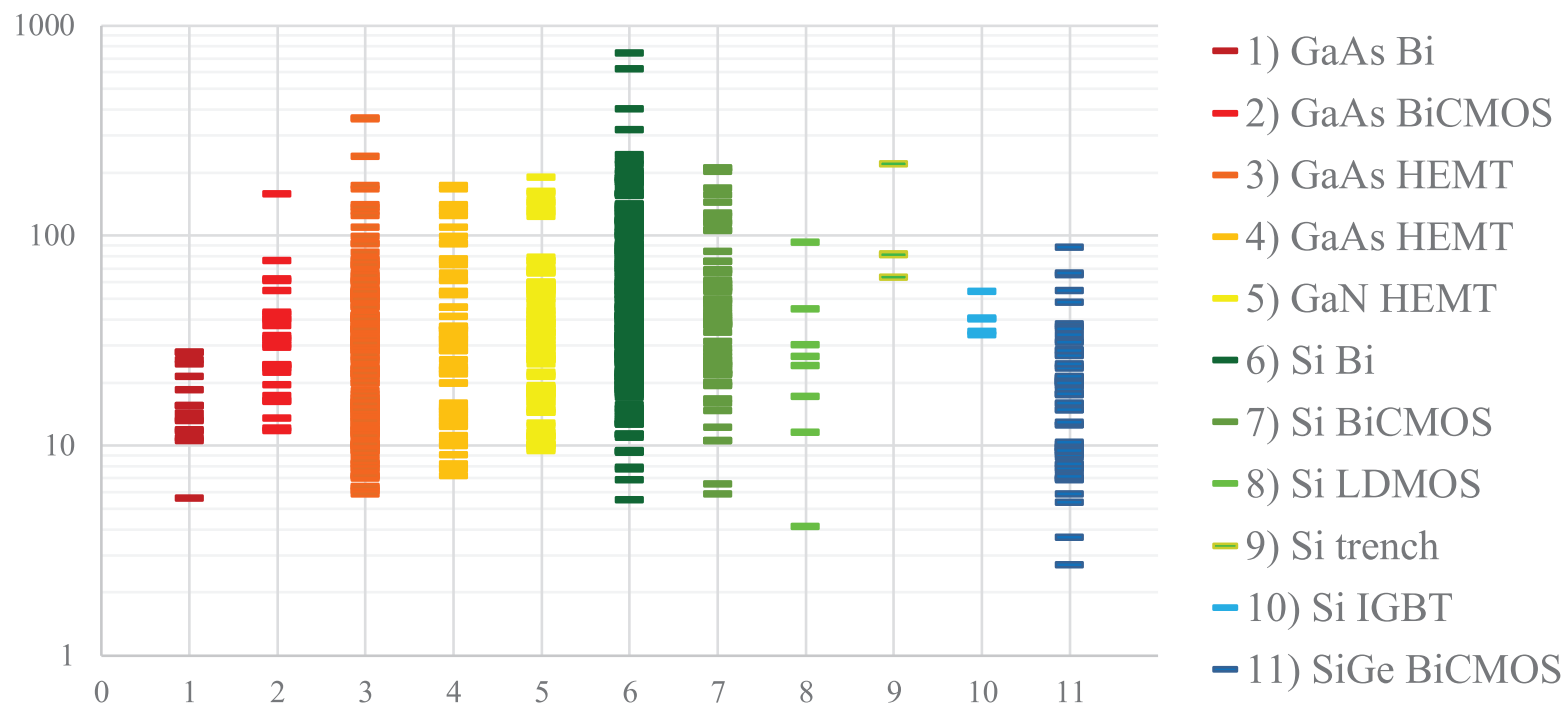

Puc. 13

Уровни отказов в критичных включениях, сгруппированные по технологиям исполнения изделий; результаты приведены для длительности ОИН 1 мкс 


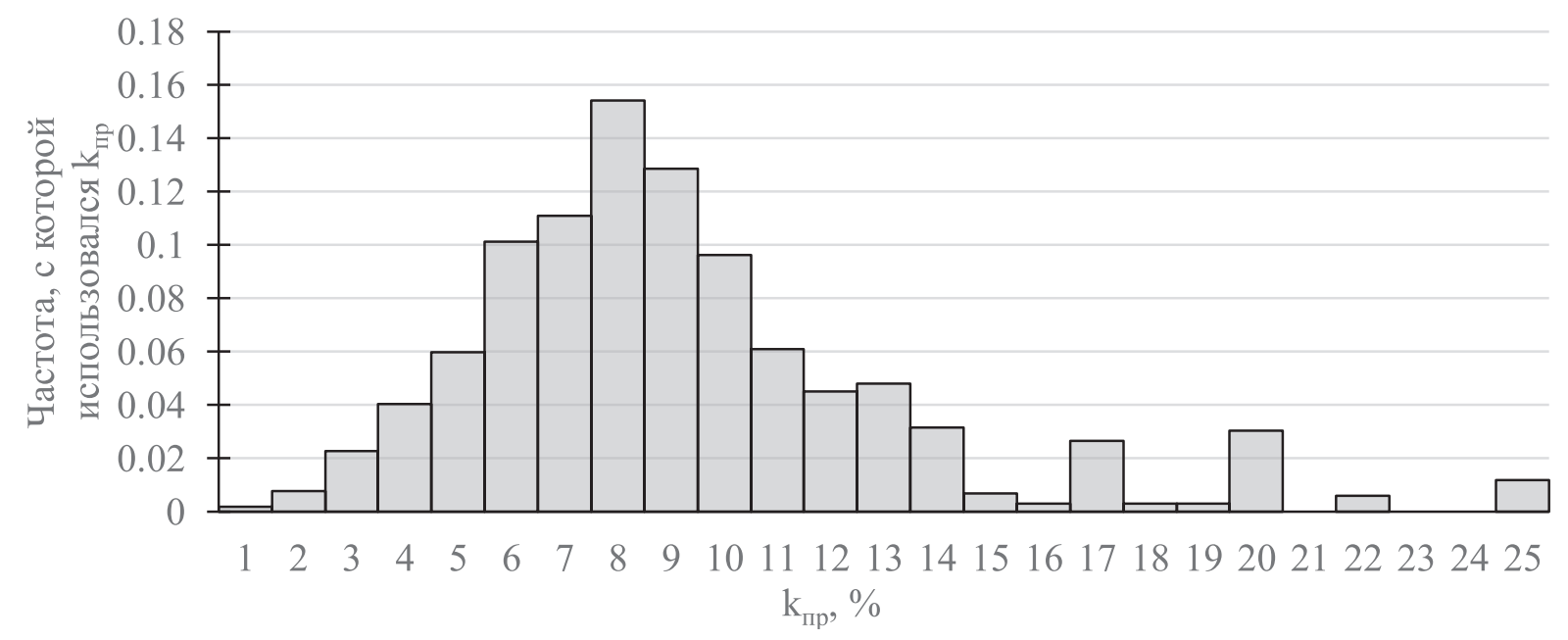

Puc. 14

Распределение величины $k_{n p}$, получившееся в ходе проведённых испытаний большого количества образиов

определения величины $U_{\mathrm{Oин}}$, связанную с тем, что импульсная перегрузка подаётся на изделие многократно, но, с другой стороны, уменьшает методическую ошибку, связанную с величиной шага при опреде-

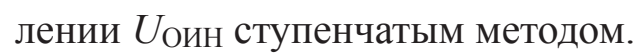

Увеличение амплитуды импульса с $k_{\text {пр }}>$ $20 \%$ (рис. 14) связано с тем, что при предварительном определении границы критической области отказа используется грубая оценка. При испытаниях изделий при $U_{\text {оин }}<5$ В изменение $U_{\text {оин с шагом } 1 \mathrm{~B}}$ также означает величину $k_{\text {пр }}>20 \%$.

Ещё одной методической особенностью испытаний является требование нормативной документации проводить испытания в активном электрическом режиме изделия. При этом существует оговорка, согласно которой напряжение питания допускается не подавать в случае, если показатели ве-

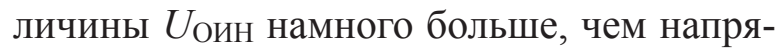
жение питания. Поэтому в большей части включений изделия испытывались либо только в электрическом режиме, либо только без него. Однако в ряде случаев одни и те же включения были испытаны как с по- дачей напряжения на выводы питания, так и без подачи.

На рис. 15 приведено сравнение результатов испытаний различных ИЭТ в активном электрическом режиме и без него. В верхней части чёрными столбцами (правая ось ординат) показана определён-

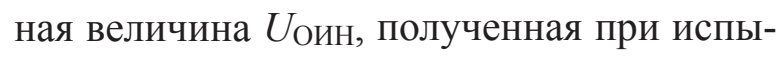
таниях без режима, а в нижней части - с режимом. Оранжевыми столбцами (левая ось ординат) показана разница в процентах между этими величинами, отнесённая к наименьшей из них $(\Delta U)$.

Таким образом, можно отметить три группы включений. В первой из них (красная область) при отсутствии электрического режима ИЭП оказывалась существенно ниже, чем с заданным электрическим режимом. Во второй (зелёная область) - наоборот. А в третьей группе (синяя область) разница между полученными значениями максимально допустимой амплитуды составляла не более $20 \%$, то есть можно считать, что в этих включениях наличие или отсутствие электрического режима не играет роли. 


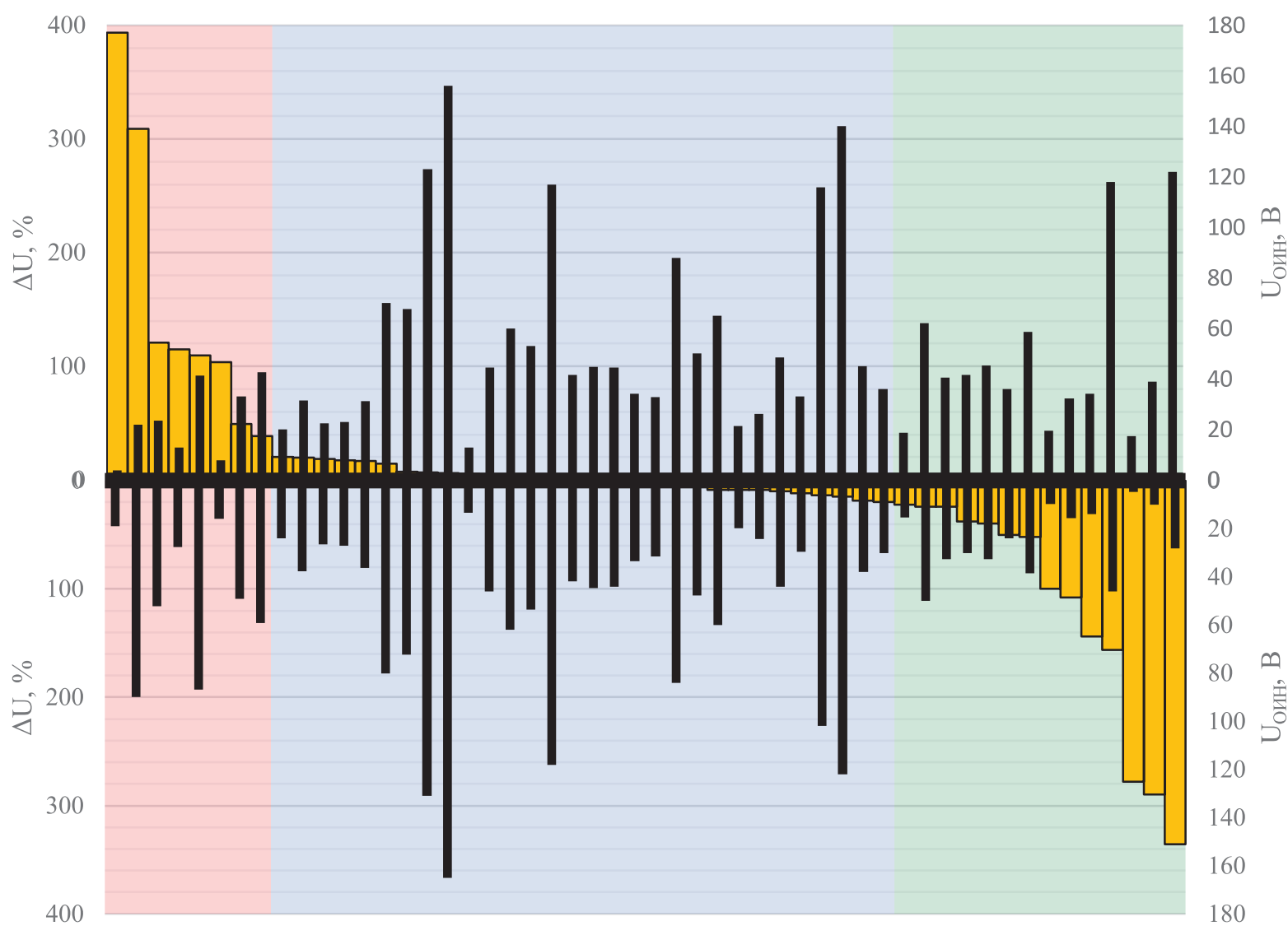

Puc. 15

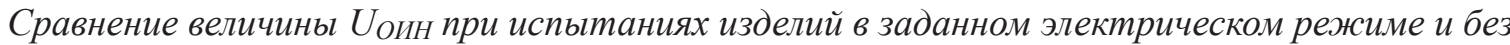
него. Чёрными столбиами показаны уровни Uоин: сверху - без режима, снизу - с режсимом.

Оранжевыми столбиами показана величина $\triangle U$. Таким образом, в красной области сгруппированы случаи, когда ИЭП изделия без электрического режима существенно ниже, чем с режимом, в зелёной области - наоборот, а в синей области - влияние электрического режима отсутствует.

Таким образом, можно сделать вывод о том, что наличие электрического режима не всегда означает более низкие показатели ИЭП, что противоречит исходной идеологии регламентирующей документации.

Большая часть изделий, ИЭП которых без напряжения питания меньше, чем с ним, представляет собой схемы на основе полевых транзисторов. В работе [12] проводилось исследование влияния электрического режима на показатели ИЭП полевых транзисторов. Были рассмотрены несколько типов изделий. В таблице для всех рассматриваемых транзисторов пе- речислены включения, в которых изделия были испытаны, а также показатели ИЭП для данных включений - максимально допустимое значение амплитуды ОИН ( $\left.U_{\text {оин }}\right)$ и максимальное значение амплитуды тока в таком импульсе (Іоин).

При подаче испытательного воздействия между затвором и истоком транзистора № 1 (включения $1,2,4)$ катастрофическая деградация подзатворного окисла наступает после превышения амплитудой ОИН порогового значения пробоя этого окисла электрическим полем импульса. При этом полярность ОИН не играет никакой роли, 
Результаты испытаний транзисторов № 1 и № 2

Таблица

\begin{tabular}{|c|c|c|c|c|}
\hline № & Включение & Электрический режим & $U_{\text {оин, } \mathrm{B}}$ & 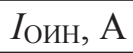 \\
\hline \multicolumn{5}{|c|}{ кремниевый полевой $n$-канальный МОП транзистор со встроенным каналом (№ 1) } \\
\hline 1 & затвор «-» $\div$ исток «+» & $U_{3 И}=-5 \mathrm{~B}, U_{\mathrm{CИ}}=30 \mathrm{~B}$ & 88 & 0,00 \\
\hline 2 & затвор $«-» \div$ исток «+» & без режима & 84 & 0,00 \\
\hline 3 & затвор «+»» $\div$ исток «-»» & $U_{3 и}=-5 \mathrm{~B}, U_{\mathrm{Cи}}=30 \mathrm{~B}$ & 22 & 0,00 \\
\hline 4 & затвор «+» $\div$ исток «-»» & без режима & 90 & 0,00 \\
\hline 5 & сток «+» $\div$ исток «-» & $U_{3 и}=-5 \mathrm{~B}, U_{\mathrm{CИ}}=30 \mathrm{~B}$ & 118 & 0,00 \\
\hline 6 & сток «+» $\div$ исток «-» & $U_{3 И}=-5 \mathrm{~B}, U_{\mathrm{CИ}}=0 \mathrm{~B}$ & 135 & 0,00 \\
\hline 7 & сток «+» $\div$ исток «-» & без режима & 46 & 9,2 \\
\hline 8 & сток «-» $\div$ исток «+»» & $U_{3 И}=-5 \mathrm{~B}, U_{\mathrm{CИ}}=0 \mathrm{~B}$ & 122 & 0,00 \\
\hline 9 & сток «-» $\div$ исток «+» & без режима & 28 & 15,4 \\
\hline \multicolumn{5}{|c|}{ GaN полевой $n$-канальный транзистор с барьером Шоттки (№ 2) } \\
\hline 10 & затвор «-» $\div$ исток «+» & без режима & 44 & 0,01 \\
\hline 11 & затвор «+»» $\div$ исток «-»» & без режима & 17 & 1,0 \\
\hline 12 & сток «+» $\div$ исток «-» & $U_{3 и}=-2,5 \mathrm{~B}, U_{\mathrm{Cи}}=0 \mathrm{~B}$ & 39 & 0,9 \\
\hline 13 & сток «+» $\div$ исток «-»» & без режима & 10 & 1,0 \\
\hline 14 & сток $«-» \div$ исток $«+»$ & $U_{3 и}=-2,5 \mathrm{~B}, U_{\mathrm{CИ}}=0 \mathrm{~B}$ & 3,5 & 0,3 \\
\hline 15 & сток «-» $\div$ исток $«+» »$ & без режима & 19 & 0,8 \\
\hline
\end{tabular}

а постоянное смещение затвор-исток незначительно влияет на максимально допустимую амплитуду ОИН, складываясь с ней в соответствии с полярностью подаваемого импульса. Если же между стоком и истоком приложено рабочее напряжение $\left(U_{\mathrm{Cи}}=30 \mathrm{~B}\right)$, а испытательное воздействие подаётся таким образом, что ОИН открывает закрытый постоянным смещением на затворе канал (включение 3), за время импульса происходит деградация транзистора по механизму теплового пробоя вследствие протекания большого тока в области канала от источника питания в цепи стока. Таким образом, транзистор выходит из строя не за счёт энергии импульса, а за счёт собственного источника питания вследствие воздействия ОИН. ИЭП в таком включении гораздо ниже, чем в любом другом включении по затвору (22 В против $84,88$ и 90$)$.
$\mathrm{He}$ менее важным является наличие электрического режима при подаче ОИН между стоком и истоком. Приложенное постоянное смещение сток-исток $\left(U_{\mathrm{Cn}}\right)$ при закрытом канале с учётом знака добавляется к амплитуде ОИН (включения 5, 6, 8). При этом ток через канал не превышает утечки до тех пор, пока не произойдёт пробой обратносмещённого $p$ - $n$ перехода и транзистор не выйдет из строя.

Состояние канала (открытое/закрытое) оказывает различное влияние на стойкость изделия к ОИН в зависимости от концентраций легирующих примесей, технологии и топологии. В самом простом случае через открытый канал (включения 7, 9) протекает большой импульсный ток и транзистор выходит из строя по механизму теплового пробоя. Разница показателей ИЭП в этих двух включениях обусловлена несимметричностью стока и истока. В другом 
случае (транзистор № 2) закрытый канал может обладать меньшей стойкостью к воздействию ОИН, чем открытый (включения $14,15)$. Это может быть связано с тем, что электрическим полем импульса при определённом уровне напряжения происходит локальный пробой в некоторой области $p$ - $n$ перехода между $n$-каналом и обеднённой областью барьера Шоттки под затвором и вся энергия от протекающего тока выделяется в небольшом объёме, в то время как при протекании тока через открытый канал тепловыделение происходит по всей площади его сечения и критический разогрев (критическая плотность тока) возникает при бо́льших значениях амплитуды ОИН.

Не всегда ИЭП изделий на полевых транзисторах в пассивном электрическом режиме меньше, чем в активном, но возможность этого необходимо учитывать при испытаниях.

\section{Заключение}

- Изделие электронной техники может иметь несколько включений, чувствительных к воздействию ОИН. Методика испытаний, соответствующая нормативной документации, не позволяет выявить их все во всех практических случаях.

- Разделение включений по группам выводов входы, выходы и питание помогает в некоторой мере сократить объём испытаний, однако обоснованность подобного подхода вызывает сомнения.

- В значительной части практических случаев предоставляемого количества образцов для испытаний оказывается недостаточно для проведения испытаний в строгом соответствии с идеологией, заложенной в нормативную документацию.

- Необходимы корректировка нормативных документов и оптимизация ме- тодики испытаний в части требований к порядку испытаний и количеству испытываемых изделий.

- Из разброса параметров-критериев годности изделий по величине в общем случае нельзя сделать однозначный вывод о разбросе показателей ИЭП.

- При проведении испытаний изделий на воздействие ОИН по существующей нормативной документации конкретный физический механизм отказа в большинстве случаев не может быть установлен.

- Показатели ИЭП изделий могут лежать за пределами установленного нормативной документацией диапазона (от 5 В до 5 кВ).

- Технология изготовления изделий в целом не влияет на показатели ИЭП.

- В отсутствие электрического режима ИЭП изделия может быть существенно ниже, чем с заданным электрическим режимом. Особенно это характерно для схем на полевых транзисторах.

\section{Литература}

1. ГОСТ РВ 20.57 415-98.

2. ГОСТ 5962-004.10-2012. Изделия электронной техники. Микросхемы интегральные. Методы испытаний. Испытания на стойкость к воздействию специальных факторов и импульсную электрическую прочность : изд.офиц. : государственный военный стандарт: введен 2013-07-01 / Федер. агентство по техн. регулированию и метрологии. - М.: Стандартинформ, 2013. - 22 с.

3. ОСТ 11 073.013-2008.

4. РД В 319.03.30-98. Изделия электронной техники, квантовой электроники и электротехнические военного назначения. Испытания на импульсную электрическую прочность.

5. ГОСТ РВ 20.39.411-97.

6. Скоробогатов, П.К. Импульсная электрическая прочность изделий ЭКБ. / П.К. Скоро- 
богатов // Научно-технический сборник «Радиационная стойкость электронных систем «Стойкость-2015», 2015, Лыткарино. - М.: НИЯУ «МИФИ». - 2015. - 252 с.

7. Шемонаев, А.Н. Экспериментальное исследование показателей импульсной электрической прочности в активном и пассивном режимах работы КМОП интегральных микросхем / А. Н. Шемонаев, К. А. Епифанцев, П. К. Скоробогатов // Тезисы докладов 21-й Всероссийской научно-технической конференции по радиационной стойкости электронных систем «Стойкость-2018», научно-технический сборник, 5-6 июня 2018 г. - г. Лыткарино. - 139 с.

8. ОСТ В 11 0998-99. Микросхемы интегральные. Общие технические условия: изд. офиц.: утв. 2004-01-01.- 23 c.

9. ОСТ В 11 1009-2001. Многокристальные модули, микросборки. Общие технические условия. -139 с.

10. Ванин, В.И. Зависимость импульсной электрической прочности полупроводниковых приборов от выходного сопротивления генераторов одиночных импульсов напряжения / В.И. Ванин // Научно-технический сборник «Радиационная стойкость электронных систем «Стойкость-2011», 07-08 июня 2011, Лыткарино. - М.: НИЯУ «МИФИ». - 2011. - Вып. 14. - С. 95.

11. Аврасин, Э.Т. Анализ интерпретации результатов испытаний изделий полупроводниковой электроники на импульсную электрическую прочность / Э. Т. Аврасин, Д.О. Ваничкин, Э.Н. Вологдин, И.Я. Гантман // Материалы XV научно-технической конференции «Пульcap - 2017», Твердотельная электроника. Сложные функциональные блоки РЭА, 27-29 сентября 2017, Москва - Дубна. - М.: АО «НПП «Пульсар». - С.236.

12. Ваничкин, Д.О. Влияние электрического режима на импульсную электрическую прочность полевых транзисторов / Д.О. Ваничкин, Э.Н. Вологдин, И.Я. Гантман // Материалы
XV научно-технической конференции, «Пульcap - 2017», Твердотельная электроника. Сложные функциональные блоки РЭА, 27-29 сентября 2017, Москва - Дубна. - М.: АО «НПП «Пульсар». - С. 240.

\section{References}

1. GOST RV 20.57 415-98.

2. GOST 5962-004.10-2012. Izdeliya elektronnoy tekhniki. Mikroskhemy integral'nyye. Metody ispytaniy. Ispytaniya na stoykost' $\mathrm{k}$ vozdeystviyu spetsial'nykh faktorov i impul'snuyu elektricheskuyu prochnost' [Electronic products. Integrated circuits. Testing methods. Special factors failure testing and pulsed mode dielectric breakdown testing], Moscow, 2013.

3. OST 11 073.013-2008.

4. RD V 319.03.30-98. Izdeliya elektronnoy tekhniki, kvantovoy elektroniki i elektrotekhnicheskiye voyennogo naznacheniya. Ispytaniya na impul'snuyu elektricheskuyu prochnost' [Electronic, quantum electronic and military-grade electrical products. Pulsed mode dielectric breakdown testing].

5. GOST RV 20.39.411-97

6. Skorobogatov P. K. Impul'snaya elektricheskaya prochnost' izdeliy EKB [Pulsed dielectric strength of electronic devices]. Radiatsionnaya stoykost' elektronnykh sistem, "Stoykost'-2015”, Moscow, National Research Nuclear University MEPhI, 2015, $252 \mathrm{p}$.

7. Shemonaev A. N., Epifantsev K. A., Skorobogatov P. K. Eksperimental'noye issledovaniye pokazateley impul'snoy elektricheskoy prochnosti $\mathrm{v}$ aktivnom i passivnom rezhimakh raboty KMOP integral'nykh mikroskhem [Experimental study of the pulsed mode dielectric strength in CMOS integrated circuits during active and passive operation] Radiatsionnaya stoykost' elektronnykh sistem, “Stoykost'-2018”, Lytkarino, 2018, 139 p.

8. OST V 11 0998-99. Mikroskhemy integral'nyye. Obshchiye tekhnicheskiye usloviya [Integrated circuits. General specifications]. Moscow, 1999. 
9. OST V 11 1009-2001. Mnogokristal'nyye moduli, mikrosborki. Obshchiye tekhnicheskiye usloviya [Multi-chip modules, microassemblies. General specifications]. Moscow, 2001.

10. Vanin V. I. Zavisimost' impul'snoy elektricheskoy prochnosti poluprovodnikovykh priborov ot vykhodnogo soprotivleniya generatorov odinochnykh impul'sov napryazheniya [Dependence of the pulsed dielectric strength of semiconductor devices on the output resistance of single voltage pulse generators]. Radiatsionnaya stoykost' elektronnykh sistem, “Stoykost'-2011”, Moscow, National Research Nuclear University MEPhI, 2011, iss. 14, pp 95.

11. Avrasin E. T., Vanichkin D. O., Vologdin E. N., Gantman I. Ya. Analiz interpretatsii rezul'tatov ispytaniy izdeliy poluprovodnikovoy elektro- niki na impul'snuyu elektricheskuyu prochnost' [Analysis of the interpretation of the semiconductor devices pulsed dielectric breakdown testing results]. Materialy XV nauchno-tekhnicheskoy konferentsii «Pulsar - 2017», Tverdotel'naya elektronika. Slozhnyye funktsional'nyye bloki REA, Moscow, S\&PE Pulsar JSC, 2017, pp. 236. 12. Vanichkin D. O., Vologdin E. N., Gantman I. Ya. Vliyaniye elektricheskogo rezhima na impul'snuyu elektricheskuyu prochnost' polevykh tranzistorov [Influence of the electric mode on the pulsed dielectric strength of field-effect transistors]. Materialy XV nauchno-tekhnicheskoy konferentsii «Pulsar - 2017», Tverdotel'naya elektronika. Slozhnyye funktsional'nyye bloki REA, Moscow, S\&PE Pulsar JSC, 2017, pp.240. 


\title{
РАЗРАБОТКА МЕТОДИКИ И КОНСТРУКЦИИ ИСПЫТАТЕЛЬНОГО СТЕНДА ДЛЯ ОТБРАКОВОЧНЫХ ИСПЫТАНИЙ ТВЕРДОТЕЛЬНЫХ СВЧ МОДУЛЕЙ
}

\author{
А.Ю. Кирьянов \\ АО «НПП «Пульсар», 105187, Москва, Окружной проезд, д. 27
}

Требуемые показатели надёжности СВЧ модулей невозможно обеспечить без проведения технологических испытаний. Наличие испытательных стендов является необходимым условием для успешного ввода в эксплуатаиию сложных технических объектов, имеющих большое количество критичных параметров. Для решения поставленной задачи рассматривается обоснование методики испытаний и конструкиии стенда для проведения отбраковочных испытаний твердотельных СВЧ модулей.

Ключевые слова: надёжность, методика испытаний, испытательный стенд

Сведения об авторах: Кирьянов Александр Юрьевич, kirjanov_aj@pulsarnpp.ru

\section{DEVELOPMENT OF THE METHODOLOGY AND THE DESIGN OF THE TEST FACILITY FOR SCREENING TESTS OF SOLID-STATE MICROWAVE MODULES}

\author{
A.Yu. Kiryanov \\ S\&PE Pulsar JSC, 105187, Moscow, Okruzhnoy proezd, 27
}

The required reliability of microwave modules cannot be achieved without prescreening tests. Test facilities serve as a prerequisite for the successful commissioning of complex technical devices with a large number of critical parameters. To attain this goal, I consider the test methodology and the test facility design for conducting screening tests of solid-state microwave modules.

Keywords: reliability, test methodology, test facility

Data of author: Alexander Yurievich Kiryanov, kirjanov_aj@pulsarnpp.ru 


\section{Введение}

Одной из основных задач при разработке и производстве СВЧ модулей является обеспечение требуемых показателей надёжности. Достижение требуемых показателей надёжности невозможно без проведения масштабных функциональных и метрологических проверок. Один из основных этапов технологического процесса изготовления модулей - технологические отбраковочные испытания модулей. Наличие испытательных стендов является необходимым условием для успешного ввода в эксплуатацию сложных технических объектов, имеющих большое количество критичных параметров.

\section{Объект испытаний}

Для разработки методики испытаний и конструкции испытательного стенда рассмотрим твердотельный СВЧ модуль на примере импульсного усилителя мощности УМИ-2750-800М. Общий вид твердотельного СВЧ модуля представлен на рис. 1.

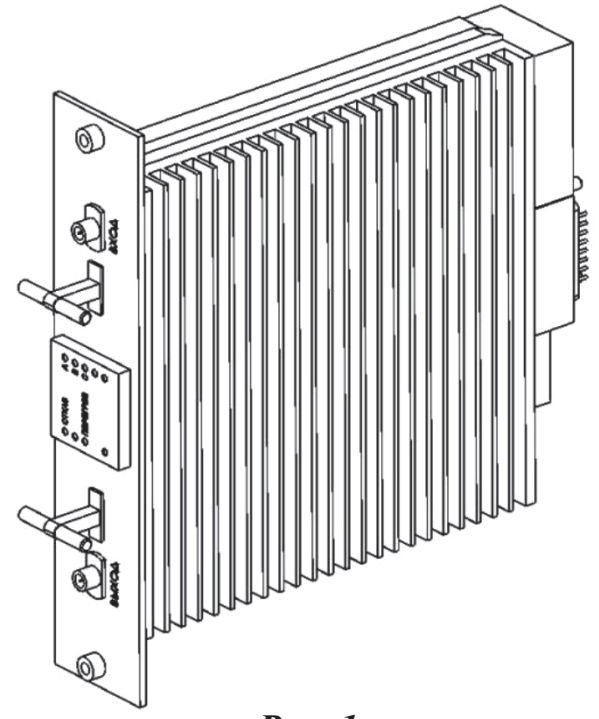

Puc. 1

Твердотельный СВЧ модуль
Воспользуемся некоторыми данными из технических условий [1], используемых в разработке методики и конструкции испытательного стенда для проведения отбраковочных испытаний модуля:

1. Требования к конструкции:

- общий вид, габаритные, установочные и присоединительные размеры модуля должны соответствовать габаритному чертежу;

- масса модуля должна быть не более 14 кг;

- охлаждение воздушное при температуре охлаждающего воздуха не более $+50^{\circ} \mathrm{C}$, температура на корпусе модуля не более $+60^{\circ} \mathrm{C}$.

2. Требования к электрическим параметрам и режимам эксплуатации:

- напряжение питания - трёхфазная сеть $380 \mathrm{~B} \pm 10 \%, 50$ Гц $\pm 5 \%$;

- мощность потребления по цепи 380 В - не более 500 Вт;

- напряжение питания схемы управления $+27 \mathrm{~B} \pm 10 \%$;

- ток потребления по цепи $27 \mathrm{~B}$ - не более $0.25 \mathrm{~A}$;

- уровень входной мощности 2...4 Вт;

- суммарная длительность радиоимпульсов - не более 300 мкс;

- минимальная скважность - не менее 9 ед.;

- выходная импульсная мощность - не менее 800 Вт. 


\section{Методика испытаний}

При выборе режима и условий технологического прогона СВЧ модулей устанавливают следующие основные параметры [2]:

- $t_{\text {и }}$ - длительность импульсов СВЧ мощности;

- $Q$ - скважность импульсов СВЧ мощности;

- $\mathrm{P}_{\text {и }}$ - мощность, рассеиваемая в течение импульса;

- $\mathrm{T}_{\text {окр }}$ - температура окружающей среды (воздуха) на входе системы принудительного охлаждения;

- напряжение питания модуля $U_{\text {п }}$, а также время периодического включения

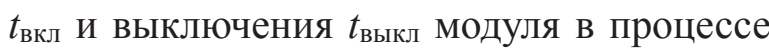
прогона.

Очевидно, что режимы отбраковочных испытаний необходимо выбирать максимально жёсткими, чтобы выявить все скрытые дефектные модули:

- значения $\mathrm{P}_{\text {и, }} Q, t_{\text {и, }}, \mathrm{T}_{\text {окр }}$ устанавливают равными максимально допустимым значениям по ТУ;

- напряжение питания выбирают, на $10 \ldots 20 \%$ превышающее значение, установленное в ТУ;

- время работы модуля во включённом состоянии заведомо должно превышать время достижения теплового равновесия в структуре активных элементов СВЧ режима (как правило, составляет несколько часов);

- время нахождения модуля в выключенном состоянии должно быть не менее времени охлаждения активных тепловыделяющих элементов до температуры окру- жающей среды (как правило, составляет около 10 минут).

Для проведения отбраковочных испытаний принимаем следующие значения основных параметров:

- напряжение питания - трёхфазная сеть (380 В $\pm 10 \%, ; 50$ Гц $\pm 5 \%)$;

- напряжение питания схемы управления $27 \mathrm{~B} \pm 10 \%$;

- период повторения импульсов $\mathrm{T}_{\text {и }}=$ $2.7 \mathrm{Mc}$;

- длительность импульсов $\tau_{\text {и }}=300$ мкс;

- входная импульсная мощность $\mathrm{P}_{\text {вх.и }}=$ 4 Вт;

- температура корпуса модуля $+60^{\circ} \mathrm{C}$;

- время нахождения модуля во включённом состоянии 45 мин;

- время нахождения модуля в выключенном состоянии 15 мин;

- продолжительность испытаний модуля 72 часа в соответствии с [3].

\section{Конструкция испытательного стенда}

В соответствии с методикой испытательный стенд состоит из следующих блоков: блок задания температуры (БЗТ), блок контроля и управления (БКУ), блок нагрузок (БН), блок приборный (БПр), блок генератора (БГ), блок питания (БП).

Структурная схема испытательного стенда показана на рис. 2.

Блок задания температуры предназначен для контроля и регулирования температуры корпуса СВЧ модуля.

Блок контроля и управления служит для обеспечения управления питающим напря- 
жением 540 В и служебным напряжением 27 В, измерения потребляемого тока модулями, входной и выходной мощности СВЧ сигнала модулей, управления режимами работы модулей, контроля заданных пара- метров и отображения их в реальном режиме времени на ЖК дисплее.

Блок нагрузок служит для обеспечения рассеяния выходной СВЧ мощности на нагрузке. Для охлаждения нагрузок исполь-

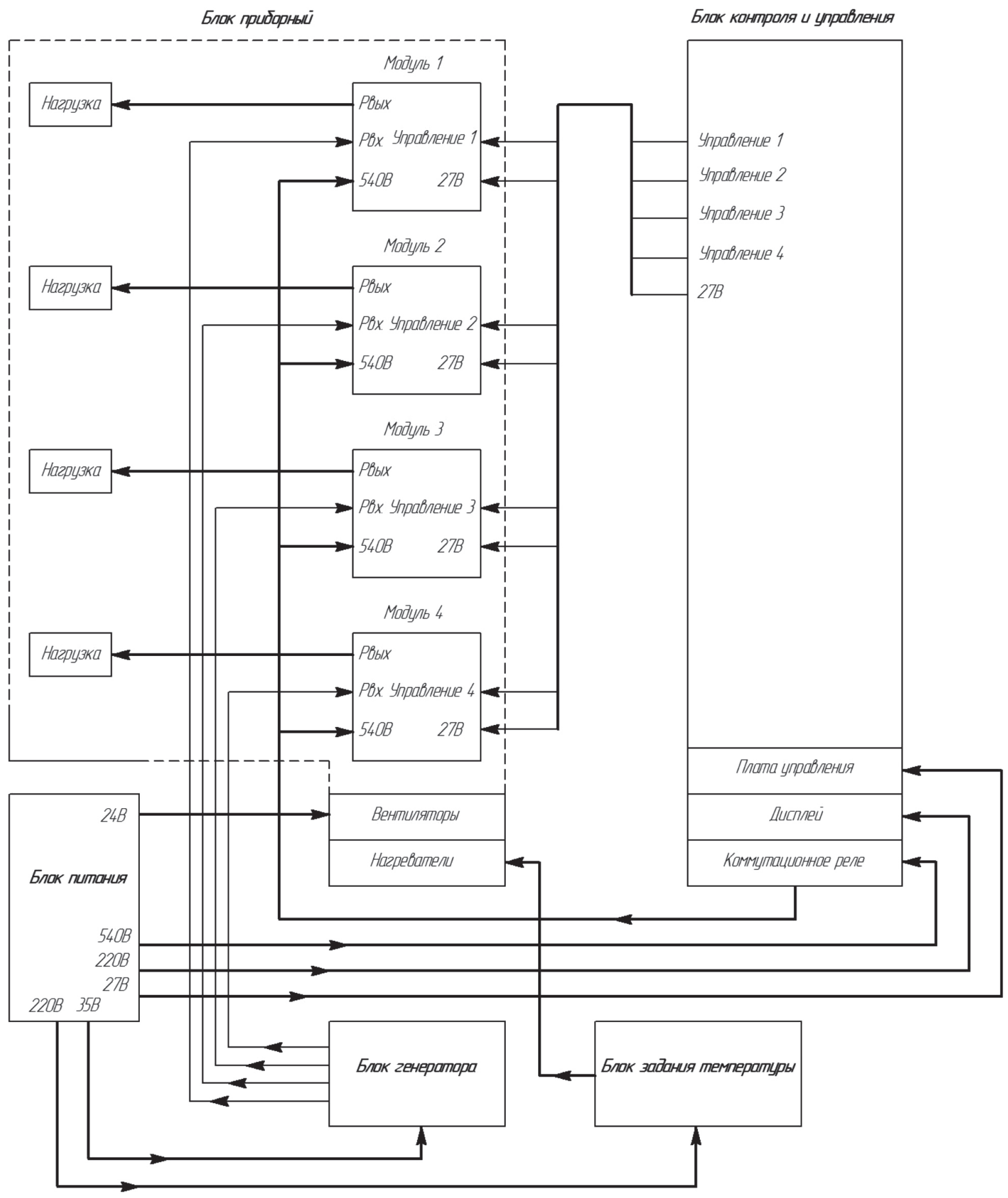

Puc. 2

Структурная схема испытательного стенда 
зуется электровентилятор, находящийся в составе приборного блока.

Блок приборный предназначен для стабилизации температуры корпуса каждого СВЧ модуля.

Стабилизация температуры корпуса каждого СВЧ модуля осуществляется в отдельном контуре принудительного конвективного теплообмена (далее контур), в который устанавливаются испытуемые приборы. В контуре располагаются: сам модуль, который вследствие самостоятельного разогрева нагревает воздух в контуpe, вентилятор, предназначенный для создания принудительного потока воздуха, управляемый нагреватель, служащий для поддержания заданной температуры воз- духа, и термопары для измерения температуры воздушного потока воздуха. На рис. 3 показана конструкция контура конвективного теплообмена.

Блок генератора содержит в своём составе генератор СВЧ и делитель мощности. СВЧ сигнал с делителя мощности поступает на СВЧ вход испытуемого модуля. На лицевой панели блока расположены разъёмы для подключения СВЧ кабелей.

Блок питания предназначен для осуществления работы блоков стенда и испытуемых модулей. На лицевой панели блока питания расположены переключатель с вольтметром для контроля вторичных источников питания и индикаторы состояния фаз сети питания стенда.

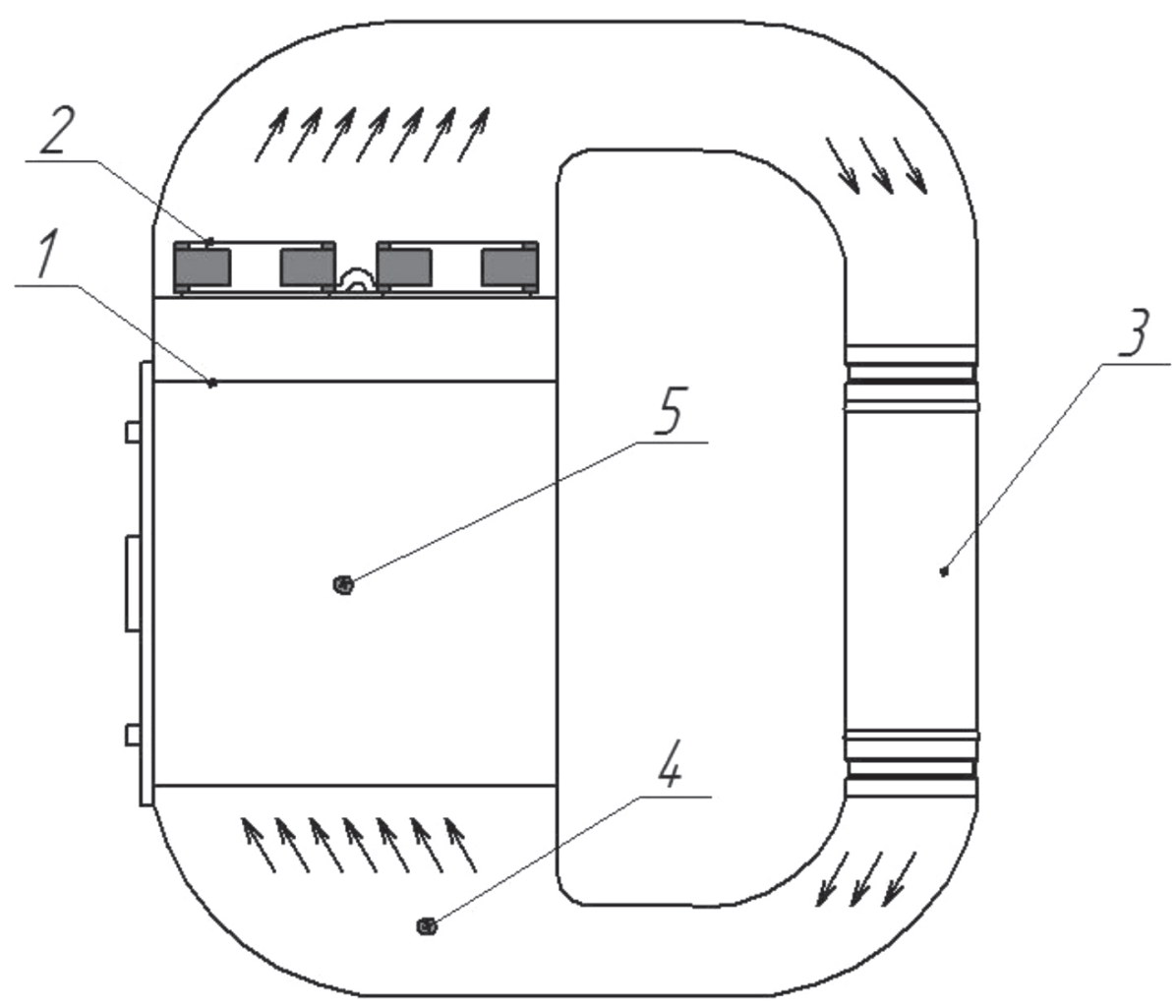

Puc. 3

Конструкиия контура конвективного теплообмена: 1 - СВЧ модуль;

2-вентилятор; 3 - нагреватель; 4, 5 - датчики температуры 
Внешний вид испытательного стенда представлен на рис. 4.

Динамический режим обеспечивает следующий режим работы модулей: 45 ми-

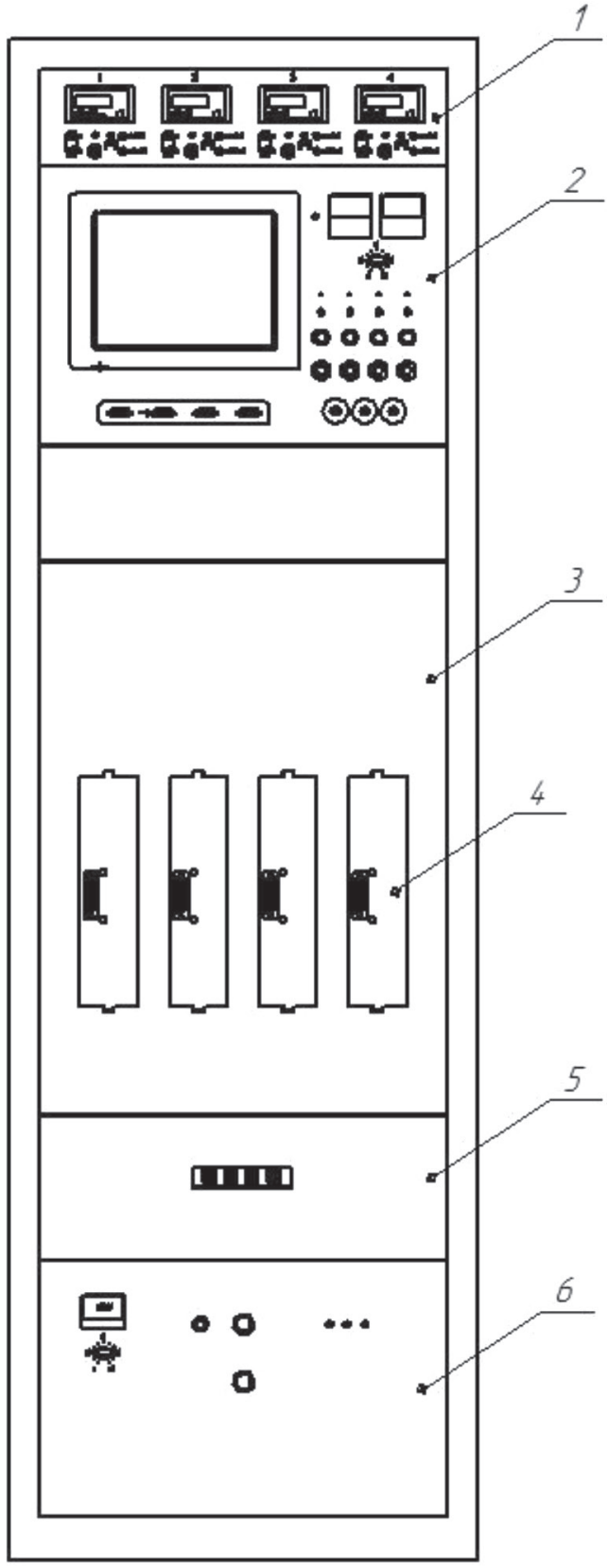

Puc. 4

Внешний вид испытательного стенда: 1 - блок задания температуры; 2 - блок контроля и управления; 3 - блок приборный, 4 - отсек для размещения СВЧ модуля;

5 - блок генератора; 6 - блок питания нут работы модуля с подачей высокого напряжения 380 В и входного СВЧ сигнала и 15 минут режима ожидания без подачи высокого напряжения и входного СВЧ сигнала. Подключение модулей к стенду производится посредством высокочастотных кабелей, снабжённых разъёмами.

Контролируемые значения электрических величин модулей отображаются на ЖК дисплее промышленного компьютера, который также обрабатывает и фиксирует измеренные данные.

\section{Заключение}

В статье рассмотрены общие принципы разработки методики и конструкции испытательного стенда для отбраковочных испытаний твердотельных СВЧ модулей.

Одна из особенностей испытательного стенда состоит в том, что тепловое воздействие на модули осуществляется в раздельных, не зависимых друг от друга камерах, что исключает взаимное влияние модулей друг на друга в период испытаний, позволяет задавать и поддерживать с высокой точностью тепловой режим испытаний, регистрировать более достоверные показания температуры для каждого модуля.

С учётом повышающихся требований к испытательному оборудованию разработан испытательный стенд, соответствующий современным требованиям проектирования испытательных систем, с возможностью автоматического управления, контроля и регистрации параметров испытуемых изделий. 


\section{Лuтература}

1. Модуль СВЧ. Усилитель мощности импульсный УМИ-2750-800М. Технические условия. БКВП.434816.153 ТУ.

2. Гришаков, М.Н. Отбраковочные испытания твердотельных СВЧ модулей / М.Н. Гришаков, В.Ф. Синкевич, П.В. Таран // Электронная техника. Серия 2. Полупроводниковые приборы. 2009. - Вып. 2 (223). - C. 78-82.

3. РД В 319.02.24-99. Комплексная система контроля качества. Аппаратура, приборы, устройства и оборудование военного назначения. Оценка метрологического обеспечения. - Мытищи, 1999. - 136 c.

\section{References}

1. Modul SVCH. Usilitel' moshchnosti impul'snyy UMI-2750-800M. Tekhnicheskiye usloviya. [Microwave module. Pulsed power amplifier UMI2750-800M. Specifications._БКВП.434816.153 ТУ.

2. Grishakov M. N., Sinkevich V. F., Taran P. V. Otbrakovychnyye ispytaniya tverdotel'nykh SVCH moduley[Screeningtests ofsolid-statemicrowavemodules]. Electronic Engineering. Series 2. Semiconductor Devices, 2009, iss. 2(223), pp. 78-82.

3. РД В 319.02.24-99. Kompleksnaya sistema kontrolya kachestva. Apparatura, pribory, ustroystva i oborudovaniye voyennogo naznacheniya. Otsenka metrologicheskogo obespecheniya [Integrated quality control system. Instruments, devices, and equipment for military applications. Assessment of metrological service], Mytishchi, 1999, 136 p. 


\section{ПРАВИЛА ОФОРМЛЕНИЯ АВТОРСКИХ МАТЕРИАЛОВ ДЛЯ ЖУРНАЛА}

1. Журнал «Электронная техника. Серия 2. Полупроводниковые приборы» - информационное научно-техническое издание, рассчитанное на специалистов твердотельной электроники и смежных отраслей науки и техники. В журнале публикуются материалы по разработке и производству полупроводниковых СВЧ приборов, интегральных схем, приборов силовой и фотоэлектроники, твердотельных модулей РЭА, физическому и технологическому моделированию полупроводниковых приборов, технологии создания, методам измерения и испытаний, экономике и организации производства изделий твердотельной электроники.

2. Журнал публикует статьи, обзоры, краткие сообщения, письма в редакцию, информацию о конференциях, совещаниях, семинарах, тематических выставках, сообщения о новых книгах и рецензии наних.

3. Материалы должны содержать новые результаты исследований, не предоставленные ранее к печати в других изданиях, и представлять интерес для читателей.

4. Вместе со статьёй в редколлегию предоставляются официальное направление от учреждения, в котором выполнена работа, и документ, подтверждающий возможность открытой публикации (акт экспертизы).

5. Все материалы предоставляются в двух вариантах: электронная копия (в формате MS Word) по электронной почте - journal@pulsarnpp.ru и бумажный оригинал (рукопись подписывают все авторы) по адресу - 105187, г. Москва, Окружной проезд, д. 27.

6. Текст должен быть выполнен в редакторе MS Word, формат страницы - A4, ориентация книжная, шрифт - Times New Roman, кегль - 12, интервал - 1,5. Поля: левое - 25 мм, правое - 15 мм, верхнее и нижнее - 30 мм. Страницы нумеруются.

7. Название статьи не должно содержать сокращений и условных обозначений.

8. Следует строго соблюдать единообразие терминов, единиц измерения, сокращений, условных обозначений. Все буквенные обозначения должны быть расшифрованы при первом упоминании.

9. Формулы следует печатать с новой строки. Нумерация строчных формул - сквозная, в круглых скобках, прижатых к правому краю. Простые формулы выполняются с помощью функции Вставка Символ. Сложные формулы выполняются в редакторе формул MS Word. Не принимаются формулы, выполненные в виде рисунков. Расшифровка буквенных обозначений формул в тексте должна быть выполнена в текстовом редакторе. Не допускается расшифровка буквенных обозначений формул в редакторе формул. Буквы латинского алфавита, обозначающие физические величины, набираются курсивом, цифры при этом - прямым шрифтом. Буквы греческого и русского алфавитов набираются шрифтом прямого начертания. Шрифтом латинского алфавита в прямом начертании набираются: числа подобия, все математические функции, температурные значения, условные математические сокращения, химические элементы и соединения.

10. Иллюстративные материалы (рисунки, чертежи, схемы и т. д.) должны быть размещены в тексте как объекты MS Word, а также прилагаться отдельными файлами, выполненными в графических редакторах Adobe Illustrator, Adobe Photoshop, Corel Draw, Microsoft Project, Origen Pro, MS Office. Фoтографии должны быть выполнены в формате tiff c разрешением 300 dpi (цветовая кодировка CMYK). Иллюстрации должны быть выполнены таким образом, чтобы все точки и кривые были видны и не слились при уменьшении. Количество рисунков должно быть минимальным и пропорциональным объёму статьи. Обозначения в рисунках должны быть выполнены на русском языке.

11. Цифровые данные оформляются в таблицу. Каждая таблица должна иметь порядковый номер и название. Сокращения слов в таблицах не допускаются, за исключением единиц измерения.

12. Ссылки на литературные источники в тексте приводятся в квадратных скобках, в конце статьи библиографический список. Список приводится на русском языке (Литература) и оформляется в соответствии с требованиями ГОСТ 7.0.5-2008 «Библиографическая ссылка. Общие требования и правила составления» и на английском языке (References) в соответствии с требованиями международных БД.

13. Помимо текста статьи автором предоставляются в электронном виде на русском и английском языках: индекс УДК; название статьи; краткая (до 500 печатных знаков) аннотация; ключевые слова (в среднем 5-7); сведения об авторах (полное ФИО всех авторов, учёная степень, звание, полное название организации в именительном падеже, адрес организации, адрес электронной почты авторов, контактный телефон).

14. Решение о принятии статьи к публикации, доработке или отказе принимается редколлегией, о чём сообщается автору.

15. Плата за публикацию рукописей не взимается. 


\section{FORMAL RULES FOR PERSONAL WORKS SUBMITTED TO JOURNAL}

1. Journal «Electronic Engineering. Series 2. Semiconductor Devices» is an informational research and scientific edition for solid-state electronic reseachers and engineers. It contains materials on researchand production of microwave semiconductor devices, integrated circuits, power and photoelectronic devices, solid-state radioelectronic modules, physical and technological modeling of semiconductor devices, production techniques, measuring and testing methods, economics and management of solid- state electronic production.

2. Journal is publishing review articles, discussion articles, short reports, letters to Editors, information about conferences, meetings, seminars, thematic exhibitions, notifications on a new books and their reviews.

3. Articles must comprise relevant research results, not published previously in other editions and must be interest for theaudience.

4. Articles must be submitted with formal reference from the institution in which it was executed and a document confirming the permission on publication (certificate ofexamination).

5. All materials (articles, letters, etc.) should be submitted in digital format (MS Word file) on the email of the Editor - journal@pulsarnpp.ru and on paper (manuscript should be signed by all authors) sent to the address - 105187, 27, Okruzhnoy proezd, Moscow.

6. Text requirements: MS Word format, page size A4, portrait layout, font - Times New Roman, size 12 with halfline spacing. Fields: left $25 \mathrm{~mm}$, right $15 \mathrm{~mm}$, upper and lower $30 \mathrm{~mm}$. Pages should be numbered.

7. Article title should not include abbreviations and conventions.

8. Uniformity of terms, units of measurement, abbreviations and conventions should be strictly observed. All abbreviations should be explained with the first mentioning.

9. Formulas should be printed starting from a new text line. Formulas should be numbered sequentially, made in round brackets, centered to the right. Simple formulas are executed with command «Insert Symbol». Complex formulas are executed in the editor of MS Word. Formulas made as images are forbidden. Transcription of alphabetical marks in formulas in text should be made in text editor. Transcription made in editor for formulas is forbidden. Letters of Roman alphabet denoting the physical quantities should be made in italics, and numbers - with standard font. Letters of Greek and Russian alphabet should be in direct inscription font. Font of the Latin alphabet in direct Inscription is used for: similarity numbers, all mathematic functions, thermal values, conditional mathematic reductions, chemical elements and compounds.

10. All illustrations (figures, schemes, graphs, etc.) should be placed within the text as MS Word objects and be attached in separate files, made in image editor programs Adobe Illustrator, Adobe Photoshop, Corel Draw, Microsoft Project, Origen Pro, MS Office. Photographs should be made in tiff format with resolution of 300 dpi (color code CMYK). Illustrations should be made in a way that all points and curves are visible and not merging together in a case of decreasing picture size. Number of illustrations should be minimal and in proportion with the volume of an article. All clarifications in illustrations should be made in Russian.

11. Numeric data should be presented in tables. Each table should have serial number and name. Abbreviations in tables are forbidden with the exception of units of measurement.

12. All references in text should be in squared brackets, with bibliographic list at the end of the article. List should be made in Russian (Литература) in accordance with the requirements of GOST 7.0.5-2008 «Bibliography reference. General requirements and rules» and in English (References) in accordance with international DB (database).

13. In addition to the text author should provide in digital form in a separate file on Russian and English the following: UDC index, article title, short (not more than 500 characters) abstract; key words and word combinations (up to 5-7); information concerning authors (full names of all authors; scientific degree, title, full name of institution in nominative and its address, e-mail address of all authors and contact phone).

14. Editorial board is making a decision on accepting, sending to revision or rejecting the article for publication, which is then reported to the author.

15. No fee for publication of manuscripts is charged. 


\section{ИЗДАТЕЛЬ АО «НПП «ПУЛЬСАР»}

Журнал издаётся с 1958 года, заслужил статус профессионального отраслевого издания, широко популярен среди учёных и специалистов. На страницах издания публикуются статьи по разработке и производству полупроводниковых приборов СВЧ диапазона, интегральных схем, приборов силовой и фотоэлектроники; физическому и технологическому моделированию, топологическому и схемотехническому проектированию; технологии изготовления, измерениям и испытаниям; разработке и производству СВЧ твердотельных сложных функциональных блоков и модулей РЭА.

Журнал включён в Перечень ведущих рецензируемых научных журналов и изданий, в которых в соответствии с решением ВАК могут публиковаться основные научные результаты диссертаций на соискание учёной степени доктора и кандидата наук.

Журнал включён в информационную систему «Российский индекс научного цитирования (РИНЦ)». Подписной индекс 59890 в каталоге АО Агентство «Роспечать» - «Издания органов научно-технической инфрормации».

Очередной выпуск [2 (257) 2020 г. ] журнала подготовлен в соответствии с принятыми по решению Президиума ВАК Минобрнауки РФ критериями к научным периодическим журналам и изданиям для включения в Перечень, а также техническими требованиями РИНЦ.

На официальном сайте журнала (j.pulsarnpp.ru) в свободном доступе размещена информация об опубликованных статьях (авторы, название статьи, аннотация, ключевые слова, сведения об авторах на русском и английском языках, а также библиографические ссылки).

Приглашаем Вас к сотрудничеству, просим высылать статьи, а также рекламный материал и сообщения для публикации по тематике журнала.

Научно-технический журнал «Электронная техника. Серия 2. Полупроводниковые приборы» распространяется только по подписке.

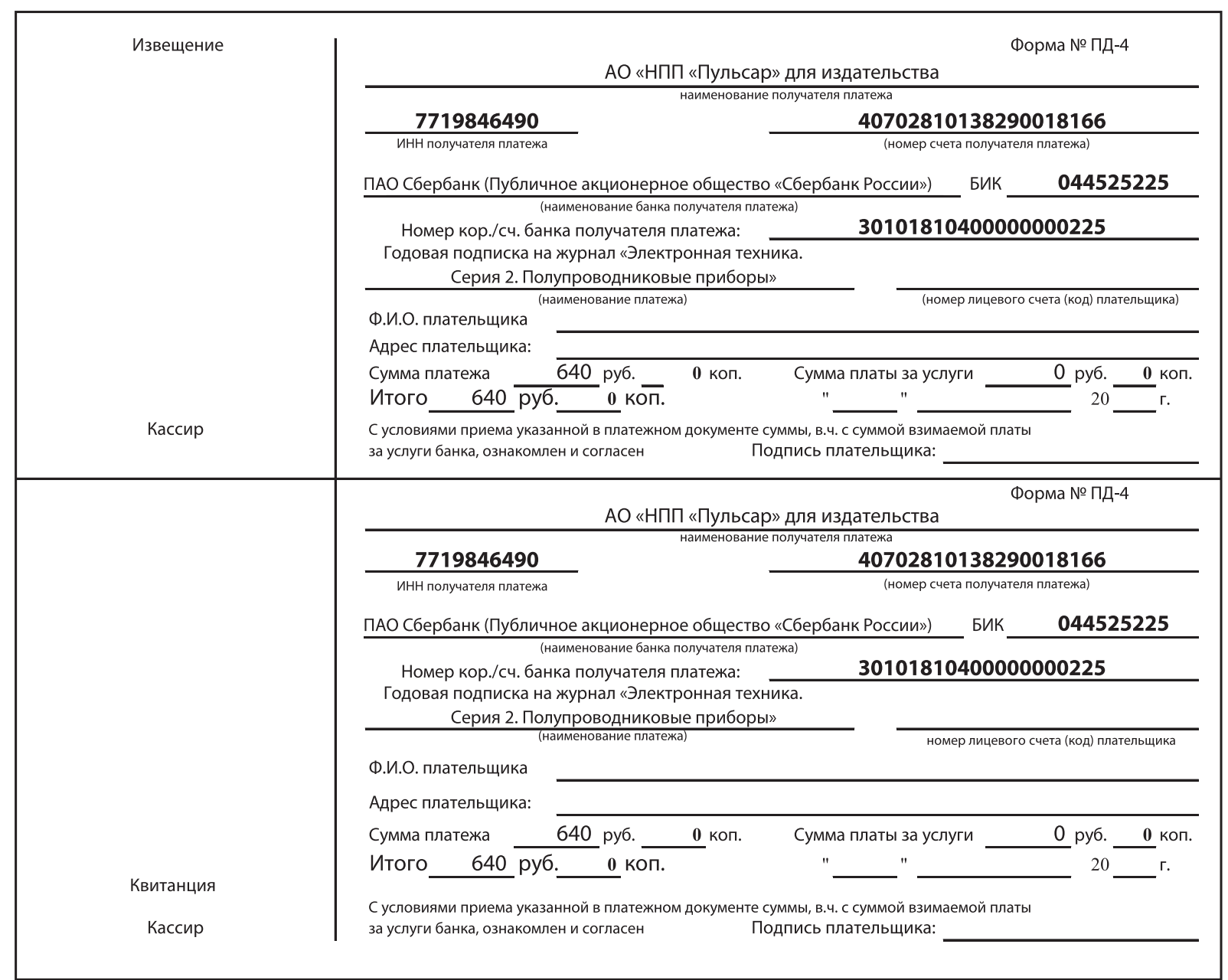

